\title{
A Contemporary Tale of Two Countries - State of Children in India and Pakistan
}

\author{
Arijit Ray \\ West Virginia University, array@mix.wvu.edu
}

Follow this and additional works at: https://researchrepository.wvu.edu/etd

Part of the Growth and Development Commons, and the Health Economics Commons

\section{Recommended Citation}

Ray, Arijit, "A Contemporary Tale of Two Countries - State of Children in India and Pakistan" (2020). Graduate Theses, Dissertations, and Problem Reports. 7513.

https://researchrepository.wvu.edu/etd/7513

This Dissertation is protected by copyright and/or related rights. It has been brought to you by the The Research Repository @ WVU with permission from the rights-holder(s). You are free to use this Dissertation in any way that is permitted by the copyright and related rights legislation that applies to your use. For other uses you must obtain permission from the rights-holder(s) directly, unless additional rights are indicated by a Creative Commons license in the record and/ or on the work itself. This Dissertation has been accepted for inclusion in WVU Graduate Theses, Dissertations, and Problem Reports collection by an authorized administrator of The Research Repository @ WVU.

For more information, please contact researchrepository@mail.wvu.edu. 


\title{
A Contemporary Tale of Two Countries - State of Children in India and Pakistan
}

\author{
Arijit Ray \\ Dissertation submitted \\ to the John Chambers College of Business and Economics \\ at West Virginia University \\ in partial fulfillment of the requirements for the degree of \\ Doctor of Philosophy in \\ Economics \\ Jane Ruseski, Ph.D.,Chair \\ Brad Humphreys, Ph.D. \\ Daniel Grossman, Ph.D. \\ Heather Stephens, Ph.D. \\ Department of Economics
}

Morgantown, West Virginia

2020

Keywords: Developing countries, India, Pakistan, sex ratio, Total Sanitation Campaign, terrorism, conditional cash transfer, female restroom, health, education

Copyright 2020 Arijit Ray 


\section{Abstract \\ A Contemporary Tale of Two Countries - State of Children in India and Pakistan \\ Arijit Ray}

Some common economic problems of the Indian subcontinent are its low per-capita income, major dependence on agriculture, heavy population pressure, chronic unemployment, slow capital formation, limited opportunity for human capital development, rising pollution, and heavy inequality in the wealth distribution. Each of these problems affects its children in its unique way, both directly and indirectly. However, some problems are human-made which directly affect its own existence. I focus on two countries in the Indian subcontinent: India and Pakistan, where such problems exist. In both societies, female children are valued less than male children, a theme which is common across many other countries in South-East Asia. Also, in both these countries, the rural-urban education gap is large, due to a lack of economic progress in rural areas. The Government of India has come forward to change the various existing cultural bias against female children in society and improve the lives of children, in general. Pakistan, on top of sharing these common issues, has been recently affected by the intentional mass destruction of public properties and human lives by terrorist entities that aim to overthrow public peace. My objective is to understand how these contemporary events have changed the picture of the two countries that we are familiar with.

Chapter 1 focuses on the cultural bias against female children that has led to an increasingly skewed female to male sex ratio in India. To counter this trend, several Indian states have adopted policies that offer future large cash incentives toward female children, subject to fulfilling certain conditions such as keeping female children unmarried until 18 and restricting the number of births. I examine whether these policies are successful in increasing female to male sex-ratio at birth. Using detailed survey data from India and a difference-in-difference strategy, I find female births increase by 0.9 - 1.7 percentage points at birth order one or two. However, I do not find any effect of these policies on overall female to male birth ratio. Surprisingly, I find the death rates for female children have increased at early birth orders and have decreased for their male counterparts, which is a spillover on the male children. Vaccination rates have fallen for both sexes post-policy period, indicating a possible shift of state attention from essential healthcare. However, effects are more pronounced for female children more than male children, indicating more postnatal sex-selection. A possible explanation is that under limited resources, large cash incentives paid in the future do not help supporting current expenditure on a larger family where female and male children both live and under 'son-preference', female children continue to bear a disproportion burden of the constraint. 
Chapter 2 looks at the inadequate school infrastructure in rural India. An important cause of the rural-urban educational gap is the lack of basic school infrastructure in the rural areas, such as availability of restrooms for children in schools, possibly causing children to fall sick and miss schools. Adolescent female children may drop out at a disproportionate rate due to a lack of privacy. In an effort to improve the health of children in rural areas, the government of India took a countrywide initiative to build restrooms in schools, known as the School Sanitation and Hygiene Education program. Using a combination of district-level school characteristics and individual-level data from various nationally representative sources, I examine the impact of this initiative on the educational gap between rural and urban areas, particularly for female children. I find completion rates and years of education have increased in rural areas, reducing the rural-urban literacy gap. Elder female children who completed secondary education experience improvement in higher secondary school completion while male children do not, indicating the importance of separate female restrooms in schools. Furthermore, female children in low-income states completed secondary education more than before, an effect which is absent for the rest of the country.

Chapter 3 is joint work with Dr. Umair Khalil and Dr. Daniel Grossman. Our objective is to study how the recent rise in terrorist activity affects the health of children exposed to violence. Using spatial and temporal variation in terrorist attacks in Pakistan, combined with a fixed effect strategy at various levels, we identify the causal effect of terrorist activity on height, weight, and health behaviors of children. We find that a one-standard deviation increased intensity of attack, defined as number of fatalities per attack, leads to approximately 5 more children per 1000 being stunted if attacks occur during gestation and between 12 and 19 more children per 1000 being stunted if attacks occur post birth. For low weight, a measure of short-term malnutrition, we find a onestandard deviation increased intensity of terrorist attack leads to between 8 and 12 more children per 1000 being low weight if attacks occur post birth. For both severely stunted and very low weight, we find statistically significant effects only for attacks during gestation. We also document a reduction of between 2 and 8 per 1000 children in vaccination take-up, in response to terrorism immediately before birth. Conclusions: Overall, we conclude that violent events experienced in utero or in early childhood can have long lasting impacts on health and human capital development. Reduced interaction with healthcare infrastructure is a possible mechanism at work. 


\section{Acknowledgments}

I express my deepest gratitude to Jane Ruseski for her constant guidance and encouragement throughout the journey. I also thank Daniel Grossman, who was always willing to spend some time discussing my progress, even on his busiest days, for his constant support, guidance, and encouragement. I am grateful to Brad Humphreys and Heather Stephens, for their guidance and valuable feedback - their doors were always open whenever I needed any help. I have learned something unique from each of you in the past five years. No amount of thanks will be enough for Umair Khalil and Arabinda Basistha, without whom the journey would not have been possible. I deeply admire your knowledge and elegance of expression.

Finally, I would like to thank my brother, Parthanil Roy, who always stood by my side, after he recognized my hidden talent, which always remained hidden from others in our family. Cheers! 
The two persons whom I wish were here -

my parents 


\section{Contents}

\section{Are Conditional Cash Transfer Schemes for Female Children Effective} in Increasing Sex Ratio at Birth? Evidence From India 1

1.1 Introduction . . . . . . . . . . . . . . . . . . . . . . . . . 1

1.2 Background and Related Literature . . . . . . . . . . . . . . . . . . . . 5

1.3 Girl Children Protection Schemes in India . . . . . . . . . . . . . . . . . . . . . . 9

1.4 Model .................................. 14

1.5 Data and Descriptive Statistics . . . . . . . . . . . . . . . . . . 15

1.6 Effect on Female Birth . . . . . . . . . . . . . . . . . . . . . . . . . 19

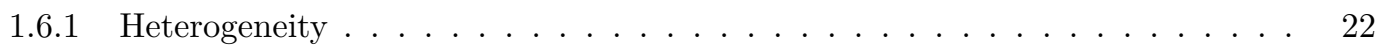

1.7 Post Natal Outcomes \& Prevalence of Son-Preference . . . . . . . . . . . . . . . . . 24

1.7.1 Mortality Rates of Children . . . . . . . . . . . . . . . . . 24

1.7.2 Effect of Policies on Child Care . . . . . . . . . . . . . . . . 27

1.7.3 Spillover Effect on Male Children . . . . . . . . . . . . . . . . . . 29

1.8 Endogeneity Concern . . . . . . . . . . . . . . . . . . . . . . . . . . 31

1.9 Summary .............................. 35

2 Reducing The Rural-Urban Educational Gap in India through Rural School Investment $\quad 56$

2.1 Introduction . . . . . . . . . . . . . . . . . . . . . . . 56

2.2 Policy Background ${ }^{1}$. . . . . . . . . . . . . . . . . . . . . . . 60

2.3 Data ............................... . . . . . . . . . . . .

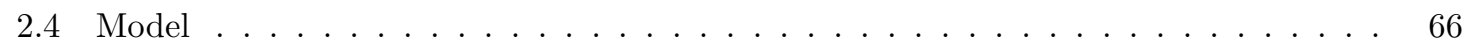

\footnotetext{
${ }^{1}$ This section is based heavily on policy information obtained from Department of Drinking Water Ministry (2005)
} and Adukia (2017). 


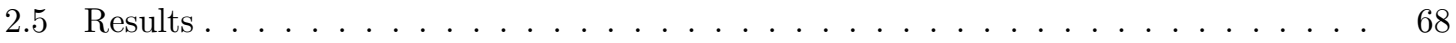

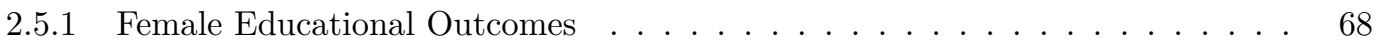

2.5 .2 Additional Results . . . . . . . . . . . . . . . . . . . . . 73

2.5.2.1 Effect on Male Children . . . . . . . . . . . . . . . . . . . 73

2.5.2.2 Effect in Low Income States _ . . . . . . . . . . . . . . . . 74

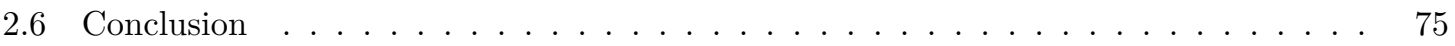

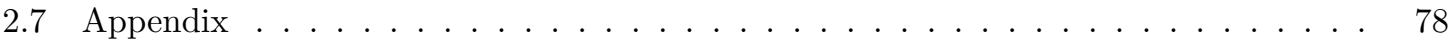

3 Terrorism and Early Childhood Health Outcomes: Evidence from Pakistan (Co-authored with Umair Khalil \& Daniel $\begin{array}{ll}\text { Grossman) } & 93\end{array}$

3.1 Introduction . . . . . . . . . . . . . . . . . . . . . . . 93

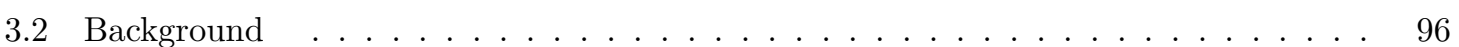

3.2 .1 Terrorism in Pakistan . . . . . . . . . . . . . . . . . . . . . . 96

3.2 .2 Mechanisms . . . . . . . . . . . . . . . . . . . . . . 99

3.3 Data and Methods . . . . . . . . . . . . . . . . . . . . 101

3.3.1 Descriptive Statistics . . . . . . . . . . . . . . . . . . . . . . . . . 101

3.3 .2 Methodology . . . . . . . . . . . . . . . . . . . . . . . 103

3.4 Results . . . . . . . . . . . . . . . . . . . . . . . . . . . . 106

3.4 .1 Height and Weight . . . . . . . . . . . . . . . . 106

3.4 .2 Vaccination Take-up . . . . . . . . . . . . . . . . . . . . . . 108

3.4.3 Limitations and Robustness Checks _. . . . . . . . . . . . . . . . 110

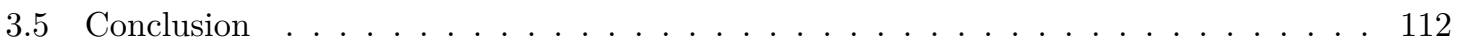

A.1 Further Robustness Check . . . . . . . . . . . . . . . . . . . . . . . . . . . . 113

A.1.1 Alternative Specifications . . . . . . . . . . . . . . . . . . . . 113

A.1.1.1 Attacks By Trimesters . . . . . . . . . . . . . . . . . . . . 113

A.1.1.2 Attacks Immediately Prior to Child's Conception . . . . . . . . . . 114

A.1.1.3 Spillovers from Neighboring Tehsils . . . . . . . . . . . . . . . . 115

$\begin{array}{ll}\text { Bibliography } & 131\end{array}$ 


\section{Chapter 1}

\section{Are Conditional Cash Transfer Schemes for Female Children Effective in Increasing Sex Ratio at Birth? Evidence From India}

\section{$1.1 \quad$ Introduction}

One form of discrimination in almost every society is based on the sex of a person. In the Indian context, the disadvantaged sex is the female and such prejudice arises from the son-preference which is deep-rooted in the cultural practices and kinship structure of the society (Das Gupta et al., 2003). Female children face discrimination much before they are born. Parents take advantage of the latest healthcare technologies, e.g. ultrasound, to know the sex of the fetus and abort them if it is a female. In case they are born, they suffer from deliberate negligence and die or in many instances, are killed intentionally. This practice of sex-selection against female children has resulted in a falling ratio of female to male children over time ${ }^{1}$.

To revert this downward trend, the Indian government has taken two types of measures. One of them is to ban the use of ultrasound to reveal the sex of the fetus while the other strand of measures targets the underlying son-preference of parents in society. A legal restriction on determination of sex of fetus to curb sexselection is likely to be ineffective as ultrasound use for maternal care is not illegal

\footnotetext{
${ }^{1}$ Biological sex ratio at birth is considered to vary between 950 - 960 females for every 1000 male birth. According to the census of India, in 1981, there were 962 female children for every 1000 male children between 0-6 years of age. It was the last time female to male child sex ratio was found to be above the benchmark. With the advent of affordable prenatal determination of sex technique in India around mid '80s, a lower child sex ratio followed in the subsequent censuses. In 1991, there were 945 females per 1000 male birth and in 2001, there were 927 females for every 1000 male birth.
} 
in India, and in the absence of strict regulation, a health care worker ${ }^{2}$, who performs an ultrasound scan during an ante-natal-care visit, may disclose the sex to an eager mother informally ${ }^{3}$ Even if the law were successful, parents could still substitute to post-natal sex-selection (Goodkind, 1996), where they invest less in their daughters compared to their male counterparts. Reasons for post-natal sex selection vis-a-vis son preference are that, first, the kinship structure in India dictates that sons continue to stay with their parents and only sons have the right to complete their funeral services after death and second, sons add to the wealth of the family continuously, whereas cultural system demands that daughters have to be married off after certain age, which involves large economic cost. Further, after marriage, she becomes a member of her husband's family, thereby no longer adding value to her own family. Basic economic theory predicts the pursuit of an action that entails the most benefit and reduction of activities that involve cost. Therefore, parents make a differential investment in their sons over daughters (Jayachandran and Kuziemko, 2011; Jayachandran and Pande, 2015). Any policy that seeks to stop sex-selection by targeting underlying son-preference will have to counteract the cost of raising a female child. Following this idea, Indian states have enacted several policies around 2005, which offer large cash transfers only to female children when their parents fulfill certain conditions such as restrict the number of children and keep daughters unmarried until they reach eighteen years of age, which is the legal age of marriage for girls. Despite the availability of these policies, the number of female children (per 1000 boys) has plummeted further to 919 in the 2011 census from 927 in the 2001 census. A natural question that follows is whether these policies were effective in influencing the female to male sex ratio at birth and I explore precisely this question in the paper.

A reason to expect that such policies may raise the female to male birth ratio is that

\footnotetext{
${ }^{2}$ Health care workers in India are the doctors, nurses, ancillary health professionals, midwives, pharmacists, traditional practitioners. Ultrasounds are usually are performed by a compounder who works for a doctor and often do not have medical certifications ( Fan and Anand, 2016). They perform the scan mechanically and over time and may learn to interpret scan reports.

${ }^{3}$ Although Nandi and Deolalikar, 2013 estimate that the national Pre-Conception and Pre-Natal Diagnostics Techniques (PNDT) Act of 1994 was associated with 106,000 female children being saved
} 
parents could use the lump sum terminal cash transfer to cover a portion of the future marriage expense of their daughters, a large part of which accrues due to a dowry. Social norms for female children in India considers marriage to be more important than any form human capital development (McCleary-Sills et al., 2015) and therefore, incentivizing parents not to abort female children through monetary reward to cover marriage expense may work ${ }^{4}$. Accordingly, I focus on 17 states with such conditional cash transfer schemes only for female children with terminal benefits obtained at the end of 18 years. A list of those policies along with the rewards is reported in Table 1 while the associated conditions for each of these policies are listed in Table 2. Some of these policies require the parents to take them for immunization while others require either of the parents to undergo sterilization. There is considerable variation in the timing of the introduction of these policies which I exploit to see whether they played a role in affecting the sex ratio at birth.

Conditional cash transfer policies have been effective as a measure against poverty. A Mexican cash transfer program, Progresa, has positive effects on education (Parker and Todd, 2017; Fiszbein and Schady, 2009), heatlh (Gertler, 2004), and on labor market outcome (Parker and Vogl, 2018). In the context of India, such policies had taken to improve education, health, age at marriage, and finally to improve female to male sex-ratio at birth - the focus of this study (Prabhu et al., 2009). The effectiveness of conditional cash schemes on female to male sex ratio has been inconclusive (Sinha and Yoong, 2009; Srinivasan and Bedi, 2011; Anukriti, 2018). This paper contributes to the literature by studying those conditional cash transfer policies to increase female to male sex ratio, which condition on both fertility and age of marriage. Previous studies have looked at sex-ratio and fertility trade-off (Anukriti, 2018) or simply sexratio (Srinivasan and Bedi, 2011) for a single state. In this paper, I identify policies targeting sex ratio-fertility-age of marriage available across many states in India and examine their effect on sex-ratio. Additionally, I explore whether these policies

\footnotetext{
${ }^{4}$ It is more likely that parents will associate a large cash transfer to marriage expense when the priority is to get daughters married off.
} 
were effective in decreasing the death rate of females compared to male children and whether they influence health care take-up of female children.

To examine the effect of these policies, I rely on a difference-in-difference method, exploiting the state and time variation in their introduction. In particular, I look at the effect of these policies on the sex-ratio at the first two birth orders. The motivation behind using such a method is a combination of two conditions of these policies. First, the transfers are only for female children and second, the number of children has to be restricted to two or three in most cases. If these policies are effective, then the effect should, on average, be highest at the first two birth orders. The literature on sex ratio has focused on birth orders (Bhalotra and Cochrane, 2010; Kalsi, 2017) assuming no sex-selection at first birth. However, given a restriction on the number of children, parents could sex select even at the first birth (Anukriti, 2018). Indeed, I find that there are about 17 more female children born per 1000 birth in order 1 and about 11 more female children born at birth order 2. An increase in the birth ratio may testify for the reduction in prenatal sex-selection.

To understand the effect on post-natal sex selection, I look at the death rate of children using a triple-difference method, using birth order, time and state of birth of the children, and sex of the children. Surprisingly, I find female children are more likely to die compared to male children. Abandonment of female children after birth, infanticide, and Lack of care are the most common (Das Gupta et al., 2003; Caldwell, 2006; Kumar and Sinha, 2018; Sudha and Rajan, 1999). With available data, I look at immunization take-up and breastfeeding of these children and I find weak evidence of differential treatment of female children in case of certain vaccines. The mechanism through which such post-natal death occurs differentially for female children could be explored more precisely if we had data on their quality and quantity of food consumption or if we had historical data on health care take-up due to common illnesses such as fever. Literature (Pokhrel et al., 2005; Hazarika, 2000) shows that parents are less willing to seek medical care if their daughters fall sick. I argue that 
while these policies are offering large cash transfers, parents have to wait until their daughters reach eighteen years of age and in the meantime, have to make continuous investments raising daughters while trying for a "son" instead of aborting them earlier and try for a "son". Wealth constrained parents cannot continue to invest in their daughters and over time, these female children die because of negligence or lack of care or both.

Further, I find that death rates of male children have fallen post policy, implying a spillover effect of these policies to a non-target group. Possibly, parents tend to take more care of the male children as they expect to have only a certain number of children, which, in turn, implies that the extent of son-preference has only gone up. Spillover effect in case of sex-ratio had not been studied (Alfano et al. (2014)) in the context of cash transfer programs targeting to improve female to male sex ratio and this paper contributes to the literature by showing such evidence ${ }^{5}$. The death rates for the two sexes together imply that the mortality gap between male and female children is now wider than before.

Section 2 describes the girl child protection schemes in India, section 3 reviews the existing literature, section 4 discusses the econometric models used, section 5 describes the data, and section 6 discusses the result.

\subsection{Background and Related Literature}

Son preference in India has been a widely studied topic in the literature. The most common cause of the existence of son-preference is identified as the patrilineal structure of the society where the descents occur through the male line from father to his son(s). Such patrilineal system dictates that the sons will continue to bear the status of the family and will inherit land, property, and wealth from his parents. Such patrilineality plays an even larger role as local political power is transferred from father

\footnotetext{
${ }^{5}$ Spillover effects from conditional cash transfer programs have been found in the context of health and education (Calderone, 2017; Guerrero et al., 2018)
} 
to their son and is important for the family to continue to rule in that area. Political power, therefore, can be directly linked to sex ratio (Das Gupta et al., 2003) in an area and female to male sex ratio will improve if parents could transfer their power to their daughters. In an effort to increase women's status in the society, Indian government has reserved political seats for women at the regional level. Kalsi, 2017 studies political reservation in India and has found such reservation has increased female to male sex ratio at birth. Such empowerment has been found to have positive secondary effect on child marriage (Castilla, 2018) - a key driver of patrilineal structure. Female children are married off earlier so they learn to be submissive to the members of her husband's family. With prevalence of patriarchal family system in Northern India, incidence of child marriage is also higher in Norther states . Child marriage varies between 6 - 27.5\% among Northern states whereas among Southern states it varies between 0 - 16.1\%. Moreover, North Indian women lack any autonomy in choosing their husbands (Vanneman et al., 2012), which reflects low value of women in the society. Women's autonomy have been found to affect fertility behavior (Abadian, 1996; Balk, 1994), maternal health care utilization (Thapa and Niehof, 2013; Singh et al., 2013; Sado et al., 2014). Women, after marriage, particularly in Northern India, gains some status if she is able to give birth of a son (Das Gupta et al., 2003). As a consequence, women prefer having a son rather than having a daughter who will be marginalized in the future, which in turn, reinforces the patriarchy in the family.

Inheritance of property rights has been one reason parents preferred having a son than daughters. Therefore, equalization of property rights is likely to reduce the persisting gender inequality in India, empower women in the society and therefore, it may work as a plausible channel that leads to improvement in female to male sex ratio. In the year 2005, Indian government has passed a law on equal inheritance rights for daughters and son of the deceased ${ }^{6}$ and it has increased female education (Roy, 2015;

\footnotetext{
${ }^{6}$ Although Maharashtra, Kerala, Andhra Pradesh, Tamil Nadu, Karnataka had modified the Hindu Succession Act of 1956 to extend inheritance right to daughters. Hindu Succession Act (1956) established full property right of women who owned a land, eliminating "limited right" of women. However, it was not until 2005, when an amendment to the law allowed equal inheritance right to daughters as sons.
} 
Deininger et al., 2013). However, a recent notable study by Bhalotra et al., 2018 shows that such empowerment has led to a fall in proportion of female children born. The argument is that ,due to patrilocality, the social custom of daughters staying with her husband's family while sons staying with his own family, parents may be reluctant to accept the daughter's right over properties out of the fear that her in-laws will exercise their control over family property . Moreover, they fear that daughters may lawsuit parents over right if they exclude their daughters from property. Although such possibility is rare, parents fear the worst and under risk-aversion, they eliminate their daughters. It is not, therefore, certain whether female empowerment will lead to an elimination of son-bias ${ }^{7}$. Arguably, such empowerment may reduce dowry payment during the time of marriage, but such channels are overpowered by parent's concern about involuntary transfer of property rights to outside of the family.

Parents have exercised elimination of daughters before birth with the advent of heath technology, referred to as ultrasound, which was intended to dictate defects in the development of fetus. Abortion is legal in India and allows parents to eliminate fetus before they reach 20 weeks, whereas the ultrasound can detect the sex of fetus as early as 12 weeks of gestation (Anukriti, S and Bhalotra, Sonia R and Tam, Eddy Hiu Fung, 2016). Bhalotra and Cochrane, 2010 estimates that such use of ultrasound for sex-selection has accounted for about 6 percent of the potential female childbirth ${ }^{8}$. On the other hand, parents may deliberately reduce investment in children when they learn the sex of the child, resulting higher pre-natal mortality or early death (Gupta, 1987; Jayachandran and Kuziemko, 2011; Pitt and Rosenzweig, 1990)9 . Moreover, since availing ultrasound and abortion are costly, such pre-natal sex-selection occur more among the wealthier and more educated women (Bhalotra and Cochrane, 2010).

\footnotetext{
${ }^{7}$ Duflo, 2012 reviews the women's empowerment literature in developing countries and discusses how it can affect the gender gap between men and women.

${ }^{8}$ Abortion may occur even if there is no son-preference Anukriti, S and Bhalotra, Sonia R and Tam, Eddy Hiu Fung, 2016 . 18\% of pregnancies in United States 2017 ended in abortion ( Induced Abortion in the United StatesGuttmacher Institute- September 2019)

${ }^{9}$ Legalization of abortion is also a source of empowerment for women as they could remove unwanted birth. Since women carry a disproportionate burden of pregnancy, such technology freed them from unwanted responsibilities. Such empowerment has been beneficial for the next generations as parents keep only those children they want. For example, see (Grossman and Joyce, 1990; Gruber et al., 1999; Kalsi, 2015).
} 
Poorer parents, however, resort to postnatal sex-selection either by continuing to bear children until they achieve a boy (Bhalotra and Van Soest, 2008) as an alternative to deliberate negligence of female children. Goodkind, 1996 argues that pre-natal and post-natal sex selection are substitutes and therefore, female children who are born in a family which can afford to terminate pregnancy based on the sex of the child are likely to be taken care of as much as a male child.

The selection against female children is worsened by the current practice of dowry which is closely related to the patrilineal tradition of society. As women were considered a part of her husband's family after she is married and traditionally land and other properties were considered to be inherited by sons, parents sometimes used to gift precious jewelry, even a part of land as a means of her independent use. Especially, she would use it to support her children and herself, in case her husband dies and had not left any means of livelihood for them (Chatterjee, 2008). This was the traditional form of dowry, which did not carry its present day connotation. However, feudal system in India had completely restricted women from being a landowner.(Sreenivas, 2008). Thereafter, any gift from parents were kept with their husband, which had turned into a custom that required bride's parents to gift a sum of money that filled the gap in their economic status ${ }^{10}$. Such custom is the form of dowry in the present day, the failure of which are often associated to domestic violence against the bride and their death (Dang et al., 2018). Associated with such risk, parents avert raising a female child, which has contributed to the low female to male child sex ratio. Recent literature has focused on this channel of sex selection. The data on dowry is limited which restricts the scope of empirical studies on dowry ${ }^{11}$. A recent comprehensive study by Anukriti et al., 2018 uses data from Rural Economic and Demographic Sur-

\footnotetext{
${ }^{10}$ Traditionally, women were assumed to be dependent on their husband and were "married-up" in the social scale. This meant either they married into higher social caste or husband had a secure source of income. This gave the groom's side the power to negotiate sum of money that bride's family has to gift to them so she is accepted into the family. Although Inter-caste marriage is still not completely acceptable to the families who belong to the upper class.

${ }^{11}$ Rural Economic and Demographic Survey (2006) in India reports actual payment by bride and grooms in a marriage. Also, it collects information on savings of both sides in financial institution, in jewelry etc. Indian Human Development Survey (IHDS) only reports total marriage expenditure. International Crops Research Institute for the Semi-Arid Tropics (ICRISAT) survey reports retrospect marriage data from only six southern states in India in 1983. Status of women and fertility ( conducted in India, Pakistan, Bangladesh, Thailand, Phillipines during 1993-94) is another data source for dowry payment but data is only categorical.
} 
vey (2006) to contribute to the empirical literature on dowry payment and finds that per-capita household savings increase and fathers work more after having a female child on the first birth. In an indirect effort to support parents to pay part of the dowry and to keep the female children alive, states in India have taken female children protection schemes, which pay a large cash transfer if parents fulfill certain conditions. These are discussed in the next section.

\subsection{Girl Children Protection Schemes in India}

Over the past few decades, the government of India has been looking at the issue of low female to male child sex ratio carefully. The discrimination against female children takes place both in the form of pre-birth and post-birth. In an attempt to address this issue, both the central (Federal) government and the state governments have started several schemes which are aimed to increase the sex ratio at birth and promote the survival of girl children. There are 17 schemes currently in 17 states which are stated to primarily target the sex ratio by offering cash incentive against keeping the girl unmarried till 18 years and other conditions. The cash incentive is offered to increase the value of the girl children. As described in Table 1.1, they were initiated in different years. The schemes have multiple objectives such as to reduce sex selection, stop infanticide, improve access to education and healthcare, eliminate child marriage, and reduce teenage pregnancy. The cash incentive paid is often restricted to two girl children with a cap on the total number of children. For some schemes, parents are required to accept sterilization after births of two children. Furthermore, final cash transfer is made to the girl children only after they have reached 18 years of age and remain unmarried (Sekhar, 2010). Parents have to enroll their girl children with necessary supporting documents within a certain period after they are born and a fixed deposit account is opened in the name of the girl children that matures when these children reach 18 years of age.

These schemes provide cash incentives to offset the cost of raising a girl. In par- 
ticular, most of these schemes offer a large sum of money (about $\$ 1500-\$ 2000$, equivalent of Rs.1Lakh) after they turn 18, the legal age of marriage in India. Given the monthly per capita consumer expenditure being Rs. 1430 (Approx \$22) in the rural areas and Rs. 2630 (Approx \$40) (NSSO 68th round) in the urban areas, the offered amount can at least offset the actual expenditure made on the children until they turn 18. A common misconception in society is that since females are to be married off, they are a burden to the family and do not add to the wealth of the family. Given this attitude, they are often withdrawn from school early in their life as it is believed that it is difficult to find a suitor for marriage for the girl if they are more learned. When they stay home instead, they can contribute to household chores, which is also considered as her training to keep her 'own' house in order after they leave parents' home to stay with her in-laws. Many of these schemes also offer financial incentives to the parents on a monthly or yearly basis for enrolling them in school,however, those financial incentives are smaller compared to the final sum. The other condition that needs to be fulfilled in most of these schemes is to restrict the number of children to three or less with no more than two girls. Parents of the children enrolled in some schemes are required to undergo sterilization after they have reached the limit stipulated by a scheme, or in some cases, before they register for the schemes. For example, Bhagyalakshmi Scheme in Karnataka allows an enrolled couple to have 3 children and the benefits are offered to at most two girls out of the three children. On the birth of the third child, either of the parents has to go through sterilization. Among some other basic conditions, almost all the schemes require parents to register the birth of the children and some require them to complete immunization. Tables 1.2 list these additional conditions for each scheme.

Tamil Nadu, a southern state in India, introduced such a girl child protection scheme in the year 1992, which was the oldest CCT girl child protection scheme running in India. It was introduced in response to the falling sex ratio that was noticed in the 1991 census. Rajasthan, another northern state suffering from a similar issue, 
had introduced a policy back in 1992 which was discontinued in the year 2005. Another northern state, Haryana, had a similar policy running from 1994 to 1998 and then again from 2004 till now. Between the years 1997- 2005, Indian government ran a centrally sponsored scheme, Balika Samriddhi Yojana, which provided similar incentives to the parents to support girl children. However, the scheme was discontinued by the central (federal) government following a massive lack of promotion and enrollment in the scheme and state governments were directed to have their schemes. The beneficiaries of the schemes were continued to be given the promised sum regularly, however, no new application was accepted. Around 2005, several states started their schemes with far more attractive incentives compared to the one offered by the central government. The introduction of these policies over time had some state and time variation which provided a basis for a difference in difference framework. Figure 1 shows the introduction and availability of schemes over the states and years.

The issue of son-bias is an old one in India and is a prominent phenomenon in Northern India. The earliest state-sponsored cash transfer policy addressing this issue was laid out by Tamil Nadu in 1992. Starting in 2005, CCT schemes became widespread as a number of states undertook similar CCTs in different years. However, there was only one centrally (Federally) sponsored scheme which was implemented in 11 blocks of 7 states on a pilot basis. These 7 states were considered to be lagging behind the rest of the country and were identified as 'Backward' in terms of human development outcomes (Bank, 2018). While a few studies (Sinha and Yoong, 2009; Srinivasan and Bedi, 2011; Anukriti, 2018) examine individual state-sponsored schemes to see if they have improved the sex ratio, there is no study looking at whether the sex ratio at birth has improved due to these state-sponsored programs on a national scale and the latest census figures attesting to declining child sex ratio despite the availability of these schemes enforces the research question whether these schemes are effective in improving female to male child sex ratio.

A recent study byAnukriti (2018), which looks at a policy in Haryana in contrast to 
a synthetic control group, finds that the program reduced the overall fertility rate, but was unable to improve the birth ratio, possibly because the enrolled parents wanted a son within the limited number of children they can have. Moreover, it indicated that such a policy has unintended consequence of decreasing sex ratio for the first birth, which was previously shown to be random (Bhalotra and Cochrane, 2010; Pörtner, 2015). Adding to the literature, using the variation in the timing of the introduction of these policies, we get a natural control group- the states without such policies.

The consequences of skewed sex ratio have also been studied in the context of the marriage market (Angrist, 2002) which indicates men find it difficult to find a prospective wife. While a surplus of men is shown to be positively correlated to crime (Edlund, Lena and Li, Hongbin and Yi, Junjian and Zhang, Junsen, 2013, 2007), the findings have been mixed (Kaur, 2013). Srinivasan and Bedi (2011) uses data from Vital Events Survey to estimate a reduction in pre-birth daughter elimination and post-birth mortality in girl children in Tamil Nadu between the years 19961999 and 2003. While the study does not focus on the causal impact of a scheme, it reports a causal effect of having a number of similar schemes compared to a few within districts in Tamil Nadu and they find that districts with multiple schemes were successful in improving sex-ratio at birth. The cash transfer scheme Tamil Nadu had been strengthened in terms of cash payment which may have played a partial role in the birth ratio improvement. In another study, Sinha and Yoong (2009) look at the impact of another state-sponsored program in Haryana on the child-sex ratio of each mother in the state and desired fertility. While improvement in sex ratio testifies to the success of the program, it does not reveal whether sex-selection occur at earlier births or report whether number of girls that a mother had given birth has improved for each age. Another stream of literature looks at the availability of technology that reveals the sex of the fetus. The widespread availability of sex-determination technique of the fetus and ubiquity of illegal abortion affects the survival of girl-fetus negatively. Perhaps the most widely cited study Bhalotra and Cochrane (2010) show 
that after the arrival of the Pre-Natal Diagnostic Technique (PNDT), chances of a girl being born after first birth falls compared to the pre-PNDT period. The study takes into account the sex of previously born children and therefore, clearly shows evidence of sex-selection at each birth order. Nandi and Deolalikar (2013) show that a legal ban on PNDT could prevent the child sex-ratio to go down any further.

As shown in Table 1.1, there are about twenty CCT programs in India (Sekhar, 2010) which aim to provide long term support to the girl children starting from the birth of the girl till she gets married. My objective in this paper is to see if these policies, taken by different states at various time points, are successful in improving the birth sex ratio in India. Since most of these policies are taken recently, their long-run effects on marriage and health are not possible to evaluate.

In the foreign context, China's one-child policy stands closest to India's statesponsored policies. China's one child policy, although was initiated by its national government during the 70's, there were variations in the number of children one can have and the penalties associated in exceeding them depending on regions, provinces, and ethnicity (Li and Zhang, 2017, 2007). Ebenstein (2010) exploited the regional variation in the penalties to identify the effect of the policy and found that regions with higher penalties had a lower level of fertility. However, these regions also showed a fall in the sex ratio, testifying fertility-sex ratio trade off. In our context, most policies place a restriction on the number of children and the combination of sex allowed and hence, it is critical that we examine both the questions carefully. In the context of Pakistan, Nepal, Bangladesh, and Mexico, Conditional Cash Transfer policies aimed at improving educational attainment(Alam et al., 2011; Chaudhury and Parajuli, 2007; Acharya and Luitel, 2006 Khandker et al., 2003; Schultz, 2004). Conditional Cash Transfer policies are also found to be effective in improving the health of children in a randomized control trial in Mexico (Gertler, 2004). In India, Conditional Cash Transfer programs for mothers was introduced in 2005 which was conditioned on mother delivering their babies in a health facility, which was found 
to be successful but the success varied across states (Lim et al., 2010). Cash transfer policies are also found to be effective in reducing inequality in Brazil, Chile, and Mexico (Soares et al., 2009).

This paper aims to make the following contribution. It evaluates the effect of introduction of state-sponsored conditional cash transfer policies aimed at partially subsidizing the cost of girl children in various points of time in India on the birth ratio and their combined effect on overall fertility rate. While it does not aim for evaluation of any particular state policy, it looks into whether, on an average, they could influence the chances of survival of girl children at birth and solve the puzzle of declining sex-ratio at birth.

The following sections explain the empirical model, the data used, and some preliminary results.

\subsection{Model}

The empirical specification for estimating the effect of adopting girl children protection scheme is given by

$$
\begin{gathered}
\text { female }_{i j t}=\alpha+\beta_{1} I(\text { Birth Order } 1)_{i} \times I(\text { Policy })_{j t}+\beta_{2} I(\text { Birth Order } 2)_{i} \times I(\text { Policy })_{j t}+ \\
\beta_{3} I(\text { Birth Order } 1)_{i}+\beta_{4} I(\text { Policy })_{j t}+\beta_{5} I(\text { Birth Order } 2)_{i}+\gamma X_{i j t}+\mu_{t}+\lambda_{j}+\varepsilon_{i j t} \ldots \ldots \ldots \ldots . .(1),
\end{gathered}
$$

where female $_{i j t}$ denotes the $i-t$ th child born in state $j$ in year $t . I(\text { Birth Order } 1)_{i}$ is an indicator for the child being of birth order of 1. Similarly, I(Birth Order 2) $i$ is an indicator for birth order 2 and $I$ (Policy $)_{j t}$ is an indicator for the $j$-th state having a policy at time $t . X_{i j t}$ is a set of control variables such as age of mother, age of the child,age of mother at child birth, indicator for the religion of the child, and an indicator for mother having at least secondary education. Neither DHS or DLHS ask for the income of the household but provide a wealth index which capture 
the condition of living. Since I combine different surveys, it will be incorrect to use the wealth index as they are not comparable. Instead, I put an indicator for the household having a car, an indicator for the household head being a female, if the location of the household is in the urban area, whether the household has a toilet, and an indicator for the household having electricity. $\beta_{1}$ and $\beta_{2}$ are our coefficients of primary interest which are identified using difference-in-difference method. The control groups are birth order of three and above and state without a girl child protection scheme in year t. They show whether states which have adopted girl child protection schemes have female birth at order one and two respectively, compared to the third and above birth order children and those states which have not adopted any girl child protection schemes. Furthermore, $\beta_{4}$ shows whether the policy had been helpful in influencing the overall female birth in the treated states compared to the control states. Additionally, the specification includes, $\mu_{t}$, time fixed effects, and $\lambda_{j}$ which are state fixed effects. Finally, $\varepsilon_{i j t}$ denotes an error term.

\subsection{Data and Descriptive Statistics}

I use phases IV (1998-99), V (2005- 06), and VII (2015-16) of Demographic and Health Survey (DHS) and round 3 (2008) of District Level Household Survey (DLHS) data. DHS is a cross-sectional household level survey conducted by the International Institute for Population Sciences (IIPS) in India and is more popularly known as National Family Health Surveys (NFHS). They are targeted towards covering detailed information on health, fertility history, and nutrition for women aged 15-49 and on vaccinations and illness of their children. They also collect basic characteristics of households. They surveyed 92,486 households in 26 states in 1998, 109,041 households from 29 states in 2004-05, and in 2016, they interviewed 601,509 households covering 29 states and 7 union territories. For each household, it collects demographic information including age, sex, education, and religion of each member along with 
characteristics of the household such as - source of drinking water, type of house, type of toilet, source of light. For ever-married women between age 15-49, the survey ask for information about each birth along with the birth year, the order of birth, and sex of the child and if the child is alive. For each phase, I focus on births that occurred in the last five years prior to the interview date so as to rule out women who had completed their birth history long ago. Since there was no NFHS survey between 2005 and 2015, I use DLHS round III for births between 2005-09. DLHS data is akin to NFHS data except unlike NFHS, it identifies the district in which each household belongs. It surveys 1000 households from each district in all the states. Round III of DLHS, completed during 2007-09 reports that occurred in the last five years. DLHS round IV was carried out during 2012-13, however, it did not survey seven states as they were already included in a contemporary longitudinal health survey known as Annual Health Survey (AHS). The questionnaire of AHS did not ask for the information required to combine them with earlier rounds of NFHS or DLHS. Therefore, using data from NFHS and DLHS, I created state-year panel data which I subsequently merged with the household and mother characteristics of the children. I restrict the data to 1996, as this is the year when a law against determination of sex of fetus was passed and therefore births before 1996 are more likely to have a larger reporting bias against girl children.

It is important to mention that none of the surveys report an annual income of households. Both NFHS and DLHS surveys create a wealth index instead, using an array of household characteristics. However, the wealth indices reported across surveys may not be directly comparable. As an alternative, I use basic characteristics of households such as the location of house, having electricity, and having a car to indicate their wealth level. Both NFHS and DLHS collect information on these indicators.

I use a range of useful outcome variables. For sex-ratio, I use an indicator for a female child. For the analysis of the prevalence of mortality among children, I cre- 
ated an indicator each for death before one month, one year, and five years using the month and year of death of a child. For childcare, I use indicators for receipt of various vaccines and whether they had been breastfed, respectively. While several interesting outcomes for breastfeeding are used with NFHS data (Jayachandran and Kuziemko, 2011), the lack of uniformity between NFHS and DLHS data does not allow me to create such variables. For vaccinations, however, a number of variables could be collated from NFHS and DLHS. In particular, I use indicators for receiving vaccinations against Tuberculosis, Measles, and Diphtheria. NFHS asks if the recent two births were vaccinated against several diseases while DLHS collects such information for most recent birth only. The importance of receiving these vaccines in India is described in the corresponding results section. Finally, I analyze the receipt of vitamin A tablets.

Tables 1.3 and 1.4 show the descriptive statistics of the data. In Table (3), I divide the sample of mothers into two groups- one for those who gave at least one birth after a policy was introduced in her state of residence and another is a group in which mothers have not given any birth after introduction of policy. There are 265,449 mothers who did not give birth after a state had a policy and 142,377 mothers who had at least one birth post policy period. Since parents are unable to alter their decision for having children that they took before the introduction of these policies, this is one way to see if the distributions of boys and girls born in the pre and postpolicy periods, respectively, were different. Column (3) shows the difference between columns (1) and (2). Among mother, who gave births only in the pre-policy period, 72.17 percent had a female child about 71.31 percent of mothers who had at least one child had at least one female child. Looking at similar percentages of mothers who carried a male child, the numbers were 76.09 and 74.61, respectively, implying a significant fall by 1.48 percentage points. The fall in the percentage of mothers having a male child is larger than the percentage of mothers who had a female child, which may indicate there was a change in the trend of having a female child. Seen another 
way, the total number of children born falls from 2.41 per mother to 2.25 per mother, out of which there were 1.2 and 1.14 girls, respectively. Clearly, the fall in average number of male children was larger than the fall in the number of female children, implying the ratio of female to male children has improved in post-policy era. A fall in the total number of children can be attributed to these policies placing an upper limit on the number of children the parents can have or because mothers who had given birth only in the pre-policy era had already completed their childbearing history. Both birth and death for boys and girls fell significantly in the post policy years. The average age of mothers in post-policy years is higher, they are more likely to have electricity in their household, however, are less likely to be educated.

Table (4) summarizes the data in a different way. In column (1), I have mothers who had their first child in the pre-policy period and in column (2), The idea is to compare the distribution of girls and boys born mothers who knew about the existence of such policies before their first pregnancy to those who did not. I have mothers who had their first child in the post-policy period. There was a fall the proportion of mothers who have a male child and a female child, respectively and average number of children born to each mother falls by around 50 percent. Also, it shows the average number of female children born to a mother falls proportionately more than the average number of male children born. While this way of summarizing indicates female to male sex ratio has fallen, it should be noted that the sample of mothers in column (2) is substantially smaller than column (1). Comparing figures from Tables (4) and (5), it is difficult to have a clear direction of movement of female to male child sex ratio. Therefore, I turn to econometric analysis for models described in section 4.

The data for policies came from various sources. Sekhar (2010) reports conditional cash transfer policies up to 2010. For such policies introduced after 2010, I rely on reports from each state's directorate of women and child development or similar departments. These administrative units are responsible for formulating rules and 
regulations for welfare of women and children in the society ("Ministry of Women and Child Development") and they work with local government bodies and nongovernment organizations to ensure implementation of these rules. Since documentation of these policies is often not well maintained, I also make use of various other sources (vikaspedia.in) to gather the data on the year of initiation, conditions of these policies, and values of transfer amount. The availability and year of initiation of these policies are shown in Figure 1. Table (1) describes the period during which a policy was active in its state(s), restrictions on the date of birth of a child to be considered for the policies, and restriction on the number of children and the allowed composition of their sexes. Table (2) further describes the conditions to be fulfilled to obtain the terminal amount.

\subsection{Effect on Female Birth}

In this section, I present the main result for the paper- effect of the cash incentives on the female birth.I estimate equation (1) and the results are presented in Table 5.

The validity of a difference-in-differences model depends on a well-defined control group, which I examine in Figure 2. Parallel trend assumption, in this case will be satisfied if, in absence of policies, the female to male sex ratio at birth in the treated states remains parallel to the sex ratio at birth in the control states. Children are categorized according to their order of birth with third and above birth is consolidated into a single group and is a control group. Figure (2) shows the average proportion of female children born at birth order one, two, and higher, respectively, over states. In the horizontal axis shows the number of years elapsed from the introduction of the policy. The average proportion of girl children born in the year of introduction of policy is shown at zero. I plot the average proportion of female children at birth during a window of 10 years, 5 years before policy initiation to 5 years after. For birth order three and above, the proportion of girl children has remained roughly constant 
both before and after the year of policy initiation which ascertains that third and higher birth order is a valid control group for equation (1).

In the 'before' periods, proportion of female children at birth orders one, two, and above move very closely, between 0.47 and 0.48 , while in the 'after' periods, average female births show a sharp increase at birth order one. Starting from just below $48 \%$, female births stay close to $48.5 \%$ on an average, reaching a maximum of $49.2 \%$ approximately after 3 years of passage of policies. For birth order two, there are some improvements, but in relatively later years. The average female birth fluctuates from year to year considerably. This is likely due to the fact that survey data are not representative of the births every year. To compare the periods before and after policy take up in states that have adopted the policies, I plot a similar graph for states adopting policies in Figure 3. Trend of female birth at different orders is very close to each other to the left of zero. To the right of zero, they show the same pattern as in Figure 2. Taken together, these plots may indicate that the observed rise in female births follows from states with policies and the effects of these policies are more pronounced after a few years of initiation. In the Indian context, the flow of information from administrative level to the general population, the incentive of local political parties in power, and the level of complexity in enrolling in the policyall play a role in determining the success of these policies. Gupta (2017) finds that the treated group in a randomized control trial, who were offered aid to fill up the application forms, had higher percentage of enrollment into a policy. These state level policies are often promoted by the ruling party in their respective states. However, if oppositions are ruling at the local level of government, such promotions may not reach people in those areas.

To see whether the observed increase in the proportion of female births was significant, I estimate equation (1) and report the results in Table 5.

Column (1) estimates equation (1) with only time-invariant state fixed effects and state-invariant time fixed effects. The estimate shows that there are about 15 more 
girl children born, per 1000 boys at birth order 1, on average, in states with policies, compared to states without policies and at birth order 3 or above. The estimate is significant at 1\%. At birth order 2, 10 more girl children are born for every 1000 boys, an estimate which is also significant at $1 \%$ level. However, the estimates of female births at order one and two, without interacting with the post variable, show that, at both birth orders, the proportion of girls is not significantly different from the proportion of girls born at order 3 and above. While this is a little counter-intuitive given evidence of higher sex selection at higher birth order, the column does not yet control for any time and state varying characteristics, which may be correlated to births at order 1 or 2 . For example, if women belonging to families where female children are valued less than male children have their first child at an older age are more likely to sex select on early births compared to younger mothers coming from similar families.

In column (2) , I control for a number of mother and household characteristics, which are likely to be correlated with sex-selection at different birth orders. The interaction terms show there are 17 more girl children born per 1000 birth at order 1 and about 11 more girl children born at birth order 2 . These are really large impacts on female births. The smaller coefficient for interaction with birth order 2 may indicate that larger sex selection at higher birth order still prevails. The indicators for birth order 1 and 2 are larger compared to column (1) and (2), yet insignificant. The post variable is negative and significant as in column (1) and neither the coefficient nor its standard error are different, which may imply the absence of correlation between female birth at higher order at post policy period and variation among various household and mother characteristics. The coefficient implies there is one percentage point fall in the proportion of female children at higher birth order after the policies were introduced in states, after controlling for changes at birth order one and two. The effect may be due to those mothers who already had more than 3 children as stipulated by the policies when the policies were introduced and showed 
no change in the attitude towards female births. Further, in column (3), I put a statespecific linear trend to rule out any state-specific movements not already captured by the state fixed effects. This is the most saturated form of equation (1) in which estimate and the coefficients are virtually unchanged. Finally, I restrict the sample to 17 states where policies were ever introduced. The coefficients are slightly smaller and interestingly, pre- policy average effects for female births are positive, significant, and show an increasing trend at order 1 and 2, respectively. Finally, I focus on the total effect of a policy on female birth. I fail to reject the hypothesis that there is no change in the sex ratio at birth as shown by the last two rows in the table. The total effect is negligible and statistically insignificant. This indicates that, even after ten years of the policies, the sex ratio at birth has not improved.

\subsubsection{Heterogeneity}

I explore heterogeneity in the female birth in Table 1.6 and Table 1.7. I start by dividing the sample between those children who had electricity and those who did not. Electricity has been widely used as a measure of income growth (Henderson et al. (2012)). It appears that proportion of birth increase at order 1 is 2 percentage points and at birth order 2 , the increase is about 1 percentage point. In contrast, there is no increase in the proportion of births at either of these birth orders, when families do not have electricity. Other indicators of income such as toilet availability, having a car, and living in an urban area show some significant increase in female birth when the sample is dichotomized in a similar manner. However, sub-samples that have these characteristics show stronger effect of policies. It appears that positive effect of policies were stronger for families that have higher socioeconomic status. When the sample were divided by the religion of the household head, results appear to be stronger for being a Hindu household and not being a Muslim or Christian household. These results raises the questions whether policies were systematically allocated to 
higher income areas or areas that are resided by Hindus and thereby, whether policy take up was related to unobservable characteristics of an area. I address this concern in section 8. After controlling for certain covariates, treated children do not appear to be significantly belonging to household with electricity or to those household, whose head is a Hindu. Finally, female births appear have increased significantly more in male-headed household.

Sex-selection against female children is associated to income of the families and religion. As the literature indicates (Bhalotra and Cochrane, 2010; Edlund, Lena and Li, Hongbin and Yi, Junjian and Zhang, Junsen, 2007), families belonging to higher income categories are more likely to have induced abortion, possibly because of their financial ability to know the sex of the fetus. Similarly, there is a religiongradient toward son-preference. According to 2011 census of India, 79.8\% population were Hindus, $14.23 \%$ were Muslims, and 2.30\% were Christians - these three religion together make up about $96 \%$ of the population. According to Islamic law, fetal sexselection is not considered unlawful as long as they are done through medical means (Schenker (2002)) ${ }^{12}$ In contrast to Islamic doctrine, Hinduism is build on multitude of beliefs so it is difficult to conclude that Hindu beliefs support or oppose sex-selection. However, regardless of its strand of beliefs, males were considered more important than females as evidenced in the Veda, the oldest text on Hinduism. In one of its hymns, it is stated that women experience happiness from her sons and post- wedding rituals are performed so she that is blessed with a son (Sineath, 2004). Backed by these religious underpinning, son-preference is therefore more likely to prevail among Hindus.

\footnotetext{
${ }^{12}$ Such techniques are known as Preimplantation Diagnosis (PGD) or Sperm Separation by Flow Cytometry (Schenker, 2002).
} 


\subsection{Post Natal Outcomes \& Prevalence of Son-Preference}

\subsubsection{Mortality Rates of Children}

For poorer part of the society, discrimination between sexes is common after birth of a child. Parents may focus on the male children and invest in their human capital while female children contribute to the household work and farming. Moreover, families tend to allocate more nutrition and healthcare to male children (Pande and Yazbeck (2003)). In effect, female children are less likely to survive compared to male children. Reducing child mortality rate is one of the Millennium Development Goals and has been a long concern for policymakers in developing countries. India has shown moderate improvement in reducing child death over the past decades (United Nations, 2010). However, under-five mortality rate has historically remained higher for female children in India. Female death in India was 108 per 1000 live births in the 1990s whereas male death rate was 97 per 1000 live births. The figures reduced to 82 deaths per 1000 live births for females and 74 deaths per 1000 live births for males in 2000 (Sawyer, 2012) ${ }^{13}$. The substantial difference in death rate for both sexes is contributed to the high mortality of children under 1 year ${ }^{14}$.

Therefore, it is natural to ask whether cash incentives were effective in reducing the difference in mortality rates of the two sexes or, in other words, were effective in decreasing the death rates for female children for whom the cash transfers were offered. I use the following difference-in-difference-in-differences specification to estimate the effect of policy on female children at birth order one and two on death rates before one month, one year, and five years.

\footnotetext{
$Y_{i j t}=\alpha+\beta_{1} I(\text { Order } 1)_{i}$ Post $_{j t} I\left(\right.$ female $_{i}+\beta_{2} I(\text { Order } 2)_{i}$ Post $_{j t} I\left(\right.$ female $_{i}+\beta_{3} I(\text { Order } 1)_{i} I(\text { female })_{i}+$ $\beta_{4}$ Post $_{j t} I\left(\right.$ female $_{i}+\beta_{5} I(\text { Order } 2)_{i} I(\text { female })_{i}+\beta_{6}$ Post $_{j t}+\beta_{7} I(\text { Order } 1)_{i}$ Post $_{j t}+\beta_{8} I(\text { Order } 2)_{i}$ Post $_{j t}+$ $\beta_{9} I(\text { Order } 1)_{i}+\beta_{10} I(\text { Order } 2)_{i}+\beta_{11} I(\text { female })_{i} \gamma+X_{i j t}+\mu_{t}+\lambda_{j}+\varepsilon_{i j t} \ldots$

$Y_{i j t}$ is an outcome variable for child $i$, born in state $j$, in the year t, which in

${ }^{13}$ The mortality rates were estimated for 131 countries in Sawyer (2012) using UN population prospects (2010 revisions). The figures here are obtained from their estimates for India.

${ }^{14}$ For infant mortality rate between 1-4 years, female deaths were 38 and 26 (per 1000 live births) in 1990 and 2010, respectively, compared to male death of 27 and 19 (per 1000 live births) in 1990 and 2000, respectively.
} 
this context is an indicator if the child is dead before a certain age. Each of the two triple difference terms is an interaction among birth order of the $i$-th child, the Post $_{j t}$ variable which indicates whether there was a policy in state $j$ in year $t$, and I (female), an indicator for a female child. The omitted categories are birth order 3 or higher and the male children. Control variables used are the same as in equation 1.

I start by looking at death before one month in Table 1.8. In column (1), I only have state and time fixed along with the twice-difference and level terms. The death rate for female children goes up by 0.03 percentage points at birth order 1 . In column (2), I add several household and mother level characteristics. The results indicate that postpolicy, death before one month has increased for female children by 0.3 percentage points, about ten-fold increase compared to column (1). I find similar estimate when I add a state-specific linear trade, in column (3). There is no significant change in the death of female children at birth order 2. The interaction terms of birth order and post-policy show the change in death rate for the male children at early births compared to male children at higher birth order. At birth order 1, male children are 0.63 percentage points less likely to be reported dead compared to male children at order 3 and above. Adding a linear trend indicates a fall by 0.69 percentage points after policies were taken. The differential that existed between higher-order male children and male children at order 1 in terms of neonatal death, is now smaller. However, the same is not true for girl children. Female children are 0.25 percentage points more likely to be reported dead at birth order 1 compared to male children at order 1 and on an average, after policies were taken, higher order female children are 0.24 percentage points more likely to be reported dead compared to higher order male children, implying that the neonatal death rate differential between female and male children has increased. If there were a general improvement in neonatal care, death rate of both female and male children should have fallen post policy. When I restrict the sample to policy enacting states, the direction of the estimates do not 
change while the absolute values are larger.

As neonatal deaths are noisy due to several reasons including mother's prenatal health condition and possible adverse conditions during birth of the child, I further look at the death before one year in Table 1.9. I restrict the data to those children who survived at least one month. There is no significant change in the death of female children at birth order 2 but there is 0.28 percentage points increase in the death rate of female children at birth order 1. Male children are less likely to die compared to their higher order counterpart. When restricted to only policy states, coefficients are larger in absolute terms.

Finally, in Table 1.10, I have a similar analysis for death within 5 years of birth. I restrict attention to those children who had survived at least one year, thereby considering death between one and five years of age. For a fully specified model, I report the estimate in column (3), I observe a significant 0.18 percentage points increase in the death of female children at birth order 1 and birth order 2. Estimates are larger at both birth orders when the sample is restricted to policy states in column (4). However, in contrast to one-month and one-year death rates for male children at order 1 , I observe a small yet significant increase in the death rates for male children at that birth order by 0.05 percentage points. However, when restricted to only policy states, the coefficient is not different from zero. However, even in this case, increase in male deaths do not rule out preferential care of parents towards the male children as the coefficient is approximately one-fourth of the increase in death rates for female children. It could be that the death of male children could not be avoided by the parents, despite their best efforts.

The results for death rates consistently suggest that male children at early birth orders benefited rather than the female children, for whom the policies were directed. Female death rates unambiguously goes up for children of all ages. What remains a concern is an increase in the death rates for male children within one to five years. I turn the attention to vaccination outcomes for children to find a possible expla- 
nation for such increase in death rates for both sexes that may indicate a possible deterioration of the healthcare system.

\subsubsection{Effect of Policies on Child Care}

Immunization schedules require children to be vaccinated before 1 year in India (Ministry of Health and Family Welfare, 2017), which is often neglected ${ }^{15}$. Laxminarayan and Ganguly (2011) estimate there are fewer than 44\% of India's young children who receive the full schedule of immunization. NHFS and DLHS both collect information about immunization of children. Except for NFHS-2, all rounds of NFHS collected vaccination history of all births in the last five years from the date of interview. In NFHS-2 ( 1998-99) and DLHS-3, vaccination history of only the last two births was collected. Both the surveys ask first for a vaccination card or a health card, which is issued when the child receives a vaccine or obtains health care service in a health facility. If the respondent can present a vaccination card for the child, the surveyors note the relevant dates for vaccinations received by the child. If not, then surveyors ask the respondents if they can recall the child having received different vaccines. A typical round of these surveys asks whether vaccinations against Tuberculosis, Polio, Diphtheria, and Measles are received. I use equation 2 to examine if female children were left out disproportionately from receiving necessary healthcare. Here, $Y_{i j t}$ is an outcome variable for child $i$, born in state $j$, in the year $t$, which in this context is an indicator if the child had received a certain vaccine. The outcome variables are binary ( 1 if yes and 0 if no). Additionally, I also look at whether a child has received vitamin A tablets and whether they had been breastfed. I report the estimation results in Table 1.11. Each column in Table 1.11 has two sub-columns. Sub-column (1) is for all states in the sample and sub-column (2) is only for the policy enacting states.

Column (1) shows results for receiving BCG, a vaccination against Tuberculosis (TB). I do not find any significant effect for the triple difference term for birth -order

\footnotetext{
${ }^{15}$ It is difficult to estimate what percent of children were vaccinated timely as our data is very limited due to largely absent vaccination history of children. Surveys resorted to asking yes/no for each type of vaccination.
} 
1 using the full sample. However, at birth order 2, there is evidence of a fall in vaccination of female children born post-policy era compared to boys. The margin is 1.6 percentage points smaller compared to male children even though both children of both sexes suffer from a lower rate of vaccination. As indicated in Table 1.10, this could be one channel which increased the death rate of children between 1 to 5 years, regardless of their sexes. However, female children at early birth orders are more likely to miss vaccination than male children at these birth orders. For policy abiding states, vaccination after policy introduction for female children at birth order one and two are smaller compared to male children at post-policy period. For measles and diphtheria, coefficients remain largely significant for the interaction between birth order and post variable and have the same negative sign. Looking at results vitamin A intake, I find similar declines for male children post-policy period. However, female children do not appear to have experienced any larger decline in receiving vaccinations against measles and diphtheria or in receiving vitamin $\mathrm{A}^{16}{ }^{17}$. A possible cause for the fall in vaccination is that state financing of these policies is taking away the focus from immunization related programs.

The final column in this table shows results about breastfeeding. Breastfeeding is considered to be one of the most important sources of nutrients for the newborns. However, parents may choose to breastfeed children differentially based on its sex if son -preference is strong (Jayachandran and Kuziemko, 2011). I do not find female children were breastfed less than their male counterparts, even if they are born in the post-policy era. Birth order fixed effects are positive and significant for both first and second-order male children which mean that at first two order, male children are breastfed more than the male children at higher birth orders. This behavior is also

From a policy perspective, this is important as India already carries the burden of one-fourth of the total TB cases around the world while Measles and Diphtheria are equally widespread (Murhekar, 2017,Vaidya, 2015). During the sample period in this paper, there were seven outbreaks of Diphtheria and most reported cases were found to be unvaccinated against the disease. Median age for these cases were five years or older suggesting lack of immunization affected older children more, possibly due to lack of Diphtheria booster dose, which is expected to be very low.

${ }^{17}$ Furthermore, until 2008, India implemented only one dose of the measles vaccine and was the only country among 193 countries under World Health Organization. All other nations implemented two doses of measles. A recent case study in Pune, a city in Maharashtra, found that $40 \%$ of the infected measles patients were only had one dose.
} 
supported by the literature. Jayachandran and Pande (2015) show that eldest sons are allocated more resources than their younger siblings. I find breastfeeding for male children at order one and two both decrease in the post-policy era, as shown by the interaction terms between the birth orders and the post variable but I do not observe any differential treatment for female children. Overall, the results suggest that there could be a shift of state attention from essential healthcare, possibly contributing to the increase in death before five years for female and male children alike, and added with 'son-preference' of parents, female children fall behind in the race of survival.

\subsubsection{Spillover Effect on Male Children}

Although these cash transfer policies are only for the female children, I find male children are 0.7 - 0.9 percentage points less likely to die at birth order one and about $0.2-0.26$ percentage points less likely to die at the birth order 2 . Since these policies were only directed towards the female children and not the male children, this may imply that the existing son-preference has led to spillover of the benefits to the male children. One possible argument for such result is that in presence of monetary incentive, parents are now keeping their female children alive and have a larger family, possibly with male children. However, the policies are only paying after the female children have reached 18 years of age. In the meantime, everything else constant, the wealth level of the families remain the same, while there are more children to take care of. Faced with the budget constraint, parents allocate more resources to the male children as the marginal return of such investment is larger and let female children die. The effects are very prominent for death before one month and death before one -year. Although the five-year mortality rate for male children also increases, increase in death rate for female children is about four-times the increase in death rate of male children. Looking at different child vaccination outcomes in Table 1.11, there is a mild evidence for a larger decline for female children as shown by Tuberculosis vaccination 
(BCG). After controlling for state-year fixed effects for vaccination outcomes and death rates in Table 1.15 \& Table 1.14, respectively, the estimates continue to remain significant and validate a larger disparity in child-care and mortality between two sexes. Therefore, it is possible that states failed to continue maintaining same level of healthcare before these policies were taken and under a stringent healthcare system, combined with wealth constraint, families prioritize care for male children, leaving female children behind.

To support the argument for such spillover effects on male children under wealth constraint, I divide the sample into a sub-sample of eight states that imposed a maximum of two children (except three in one state) through sterilization and in another sub-sample for rest of the nine states which did not impose any restriction on the number of children. If the above reasoning is true, then it should only hold or at least the effect should be stronger in those states where sterilization had not been imposed as a policy condition, allowing the families to have male children further down the birth order and therefore, have a larger family. I test this argument by looking at the death rates for children in the states with sterilization (imposing states) and without sterilization (non-imposing states) separately. The results are reported in Table 1.12. Death rates before one month, one year, and five years - all show a positive effects, significant at $5 \%$ for female children at birth order one, for states which did not impose sterilization. For death before one-year and five-years, such effects are present at birth-order two as well. For states which imposed sterilization, such effects are largely absent, except for one-month mortality rate. Further, these increments in death rates for female children in non-imposing state are accompanied by a fall in male child death rate as evidenced by a 1.3 percentage point fall in onemonth mortality and 0.3 percentage points fall in one-year mortality rate at first birth. While one-month mortality also goes down at birth-order one for imposing states, such effects are more than double in non-imposing states. For imposing states, such effects are completely absent for one-year and five-years mortality rates. This 
may suggest under wealth constraint, families in non-imposing states did not take care of the female children as much as the male children due to their son-preference, and hence there is an unintended spillover on the male children.

Spillover effects in cash transfer policies are not uncommon. Calderone, 2017 discussed the spillover effect of an youth employment program In Nigeria, which paid cash to young males and female in a group for creation of start-up businesses without any conditions. It is found that the money paid to males in the group is effective in increasing educational expenditure of male while for females, such effects were absent. The study argues that possibly female members of the group had to pay male members a part of the allocated money due to re-distributive pressure such as financial borrowings by others in the group. Csapo, 2017 studies the effect of the spillover effects of a conditional cash transfer program in Brazil and finds that Municipalities substitute away healthcare spending from primary care clinics, thereby negatively affecting the children of the poor in that area. Guerrero et al., 2018 studies Peruvian conditional cash transfer policy targeted to reduce the use of low quality informal health care services and finds that the the policy affected the non-eligible member of the treated households in the program. The effect of cash transfer policy found in the context of sex-selection against female children is new and adds to the literature on spillover effect of cash transfer policies.

\subsection{Endogeneity Concern}

Since the policies in different states were taken at different years, endogeneity issues may arise due to contemporary policies taken. In fact, in 2005, The Hindu Succession (Amendment) Act was passed, which gave women equal right to property after their parents die. This established daughter's equal right on parent's property as their sons. This law was an amendment to the earlier Hindu Succession Act, 1956, which had excluded daughter's property rights. A number of studies have looked at the effect on this law on socioeconomic outcomes. In our context, Bhalotra (2017) show that 
such property right equalization have led to increased foeticide in India, indicating escalation of son-preference in the country. Any confounding factor that is already not captured by the covariates and fixed effects used in the baseline specification will have to be systematically associated with the variation in our double-difference terms. As the law had affected control and treated states equally, the passage of this law should not affect estimates, however, I extend my analysis to include a set of stateyear fixed effects so that I can eliminate endogeneity issues due to factors in a state in a year but were invariant to birth-orders. The results are reported in Tables 13, 14, and 15. Table 11 shows the results for female birth including state-year fixed effects. The effect of the policies on the first and the second birth orders are approximately the same, varying between 0.8 to 1.6 percentage points. The coefficient of post is now significant and shows different signs in two columns. The interpretation of the coefficient should be carefully considered as we have several state-birth year fixed effects which are likely to be highly correlated to the post variable since both of them vary at the state-year level.

Death rates of female children before one month, one year, and five years show consistently negative effect of these policies at birth order one, which are reported in Table 11. The first column for each mortality rate shows the estimates for the complete sample while the second column restricts the sample to the states which took the policy. At birth order 2, the coefficients are not significant for one month and one year mortality rates but are significant for the 5 year mortality rates. Comparing the size of the coefficients of the triple-difference interaction terms in Tables 6,7 , and 8 with the the ones in Table 11, I find they are not much different and are consistent whether I use a linear time trend or state-year time fixed effects. Further, I continue to see a fall in the male death rates for one-month mortality rates and one-year mortality rates, indicating a spillover effect of these policies.

In a similar manner, I estimate of the effects of these policies on the child care variables as in Table 9. The results are reported in Table 12. The direction and size 
of the coefficients are similar. The effects on Tuberculosis vaccination continues to show that female children were vaccinated less that the male children, after these policies were taken. Moreover, after I control for state-birth year fixed effects, I find vaccination against measles have fallen at birth order one. All other effects are similar compared to Table 9.

A further concern is whether the policy take-up were related to states characteristics which motivated the state governments to introduce them. Among the sample states with policies, Haryana, Punjab, Delhi have shown worse sex ratio compared to others. ${ }^{18}$ Northern states, as discussed in section 2, have shown stronger son preference. However, such unobservable concerns should be taken care by state-fixed effects. Among other factors, education and income have strong correlation with low female to male child sex ratio. In fact, the difference in son-preference among the northern and southern states have been explained by the education, income, and religion. Bhalotra (2010) found wealthier families and more educated mothers were more likely to sex-select against female children and further, conditional on these factors, Hindus were more likely to sex-select compared to Muslims. Edlund (1999) discusses possible reasons behind the hypothesized positive correlation between higher socioeconomic status and favoritism for male children. The religious difference is more likely due to explicit ban on abortion or infanticide among Muslims (Almond 09). To check whether these policies were more likely to be taken up by wealthier families, more educated families, or more Hindu families, I run a balance test using the covariates used in equation (1). The results are reported in Table 16. Treated are those at birth order one or two born in a state implementing a policy. In panel A, I use the full sample and compare the means of mother-specific or household specific characteristics. The difference between treated and control groups appears to be significant, which may indicate that even though we controlled for these covariates in our preferred specification, treatments were correlated to some unobservable characteristics. How-

\footnotetext{
${ }^{18}$ Number of female children (per 1000 male children) in Haryana, Punjab, and Delhi in 2011 census were 834, 846, and 871 respectively.
} 
ever, many of the observed difference such as age of mother and total children born may arise because mothers who are in the control group were perhaps already beyond the first two births at the time introduction of these policies, in which case they are likely to be older than those who are in the treatment group and therefore,are likely to have more children, and undergo more USG tests. To circumvent this problem, I compare the characteristics for the first two births only. The results are reported in Panel B of Table 16, where most of the differences have disappeared. However, the difference between the groups persist for having electricity in the household and for religion. This indicates the treated children belong to wealthier household and Hindu families. If these characteristics were time invariant, then our estimates still hold as our preferred specification controls for state fixed effects or if other controls together have adequately captured variation in income or religion, then after controlling for those covariates, indicators for having electricity and Hindus should not affect our treatment. To confirm this, I take two strategies. First, I re-estimate equation (1) excluding electricity and Hindu, respectively, and compare the estimates with our main estimates in Table 5. For ease of comparison, I consolidate the results in Table 17. The results are virtually unchanged. In an alternative strategy, I regress the indicator for having electricity and indicator for Hindu household head on an indicator for those who were treated and all other covariates including the fixed effects. The results are reported in Table 18. In column 1, I regress indicator for household head being Hindu on treated and all the covariates except electricity included in main regression, along with state fixed effects, time fixed effects, and a state-specific linear trend. In column 2, I use indicator for having electricity as the outcome variable and exclude Hindu from the regression. I do not find any association between treatment and either of these outcome variables. This imply that after controlling for a subset of variables, observable characteristics are not associated and therefore, it is unlikely that any un-observable will be associated. 


\subsection{Summary}

There has been an ongoing effort to reduce the prevailing sex selection against girl children in India in the form of cash incentives on the birth of a female child for more than than a decade now. These cash transfer policies have multiple objectives such as improving female survival, reducing fertility, and improving the age of marriage. I identify such policies taken between until 2016 in different states in India and use three rounds of NFHS and one round of DLHS data to see if they were effective in improving the sex ratio more favorably towards female children. Previous studies focused on evaluating a single policy in a single state. I focus on such policies in 17 states in India and find evidence that the policies were effective in improving sex ratio at early birth orders. More female children are reported at birth on order one and two. This means that there was a redistribution of sex over birth orders. Pörtner (2015) found that due to a falling trend in fertility, there was sex selection at early birth orders but had not yet reached order one. I find specifically that at birth-order one and after the policies come into effect, more female children are reported at birth. However, I also find that death rates before age of one month and one year go up for female children and go down for male children and death rate before five years of age go up only for female children. This represents two puzzles. First, why more female children are reported to be dead and second, why is there an effect on the male children, given these policies are not targeted toward them. One possible explanation is that future cash transfers motivates parents to keep their female children alive but do not add to the current wealth of families. Under limited resources, families take more care of male children compared to female children. While looking at immunization of children against several diseases, I find evidence that female children are missing out on vaccination against tuberculosis more than male children. It is also possible that the focus of the states is moving away from healthcare service to the children which, combined with the limited family resources and son-preference, continue to affect female children more than male children. It appears that while implemented 
with best intentions, these policies are failing to affect the age- old bias against female children in the society. 
Tables and Figures 
Figure 1.1: Availability of Policy over States

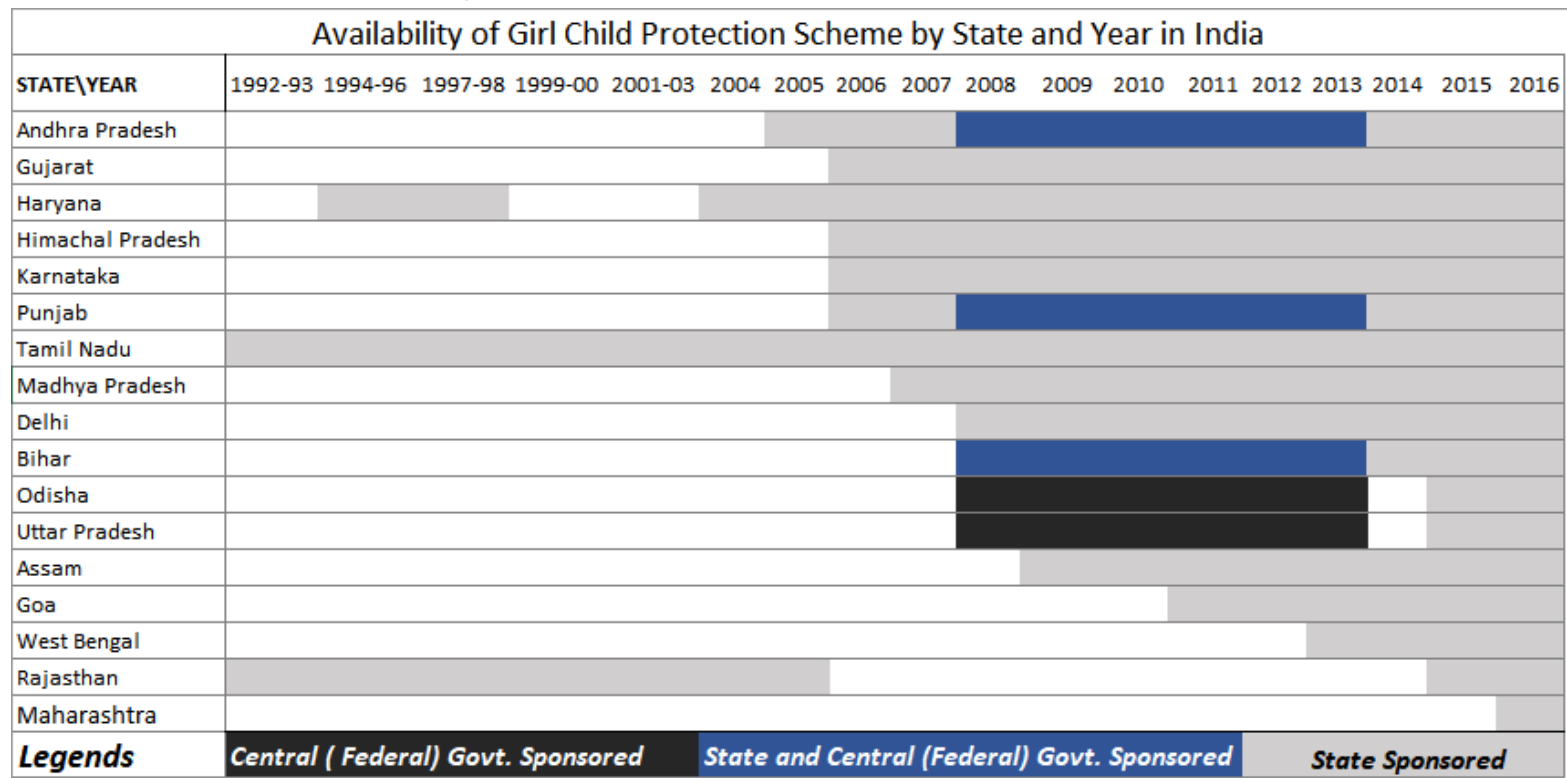




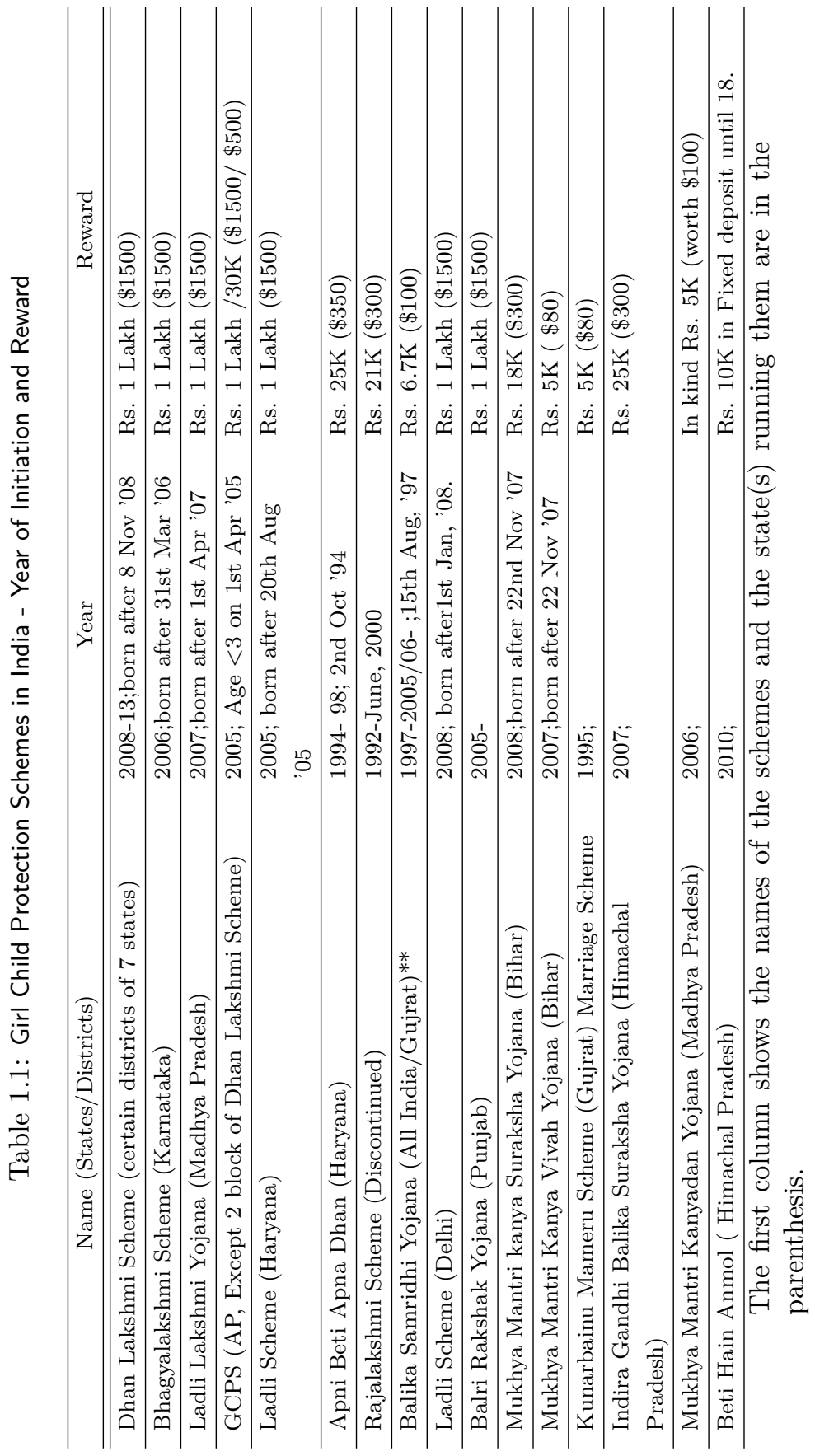




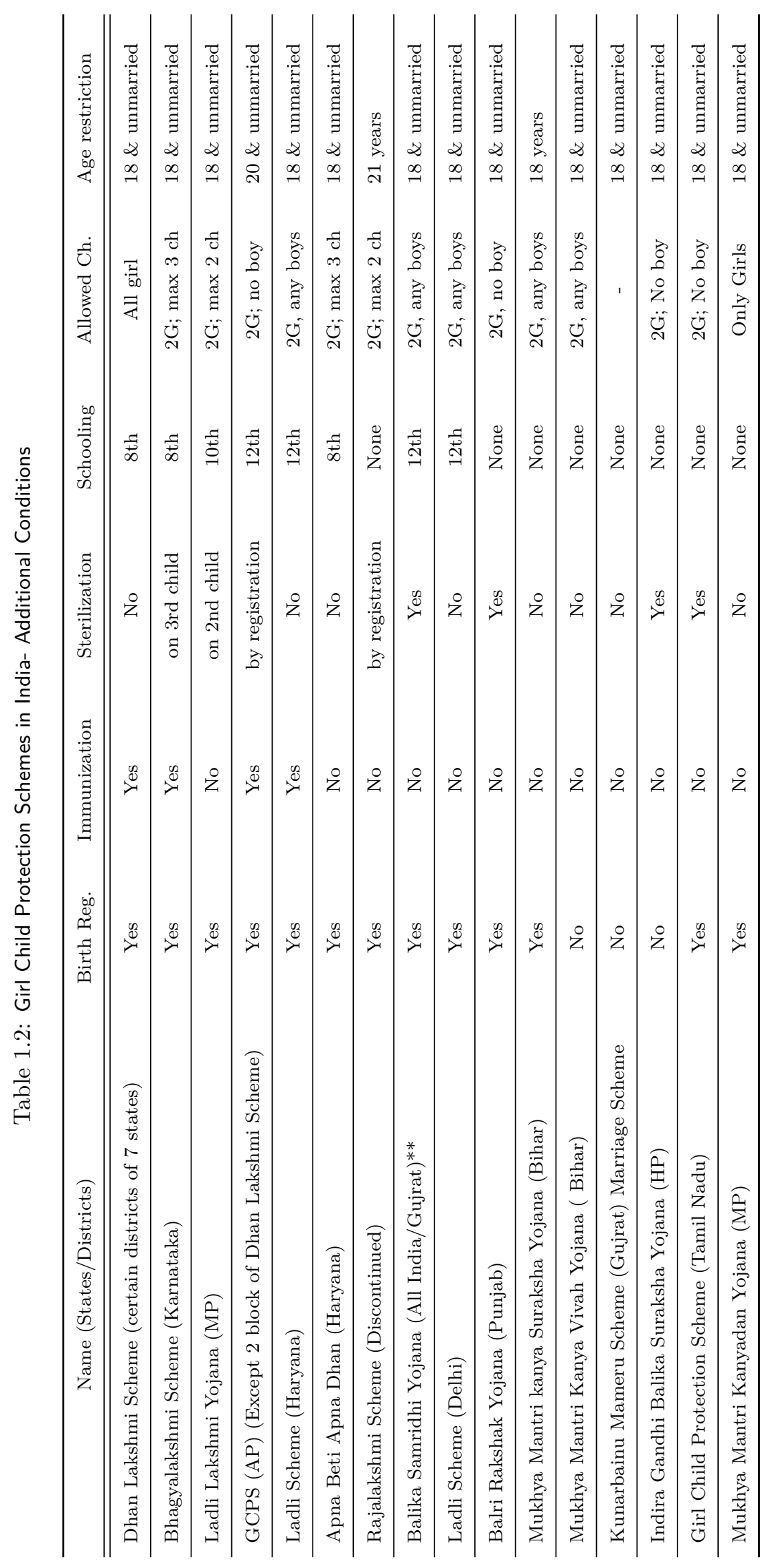


Table 1.3: Descriptive Statistics of Mothers in Sample

\begin{tabular}{cccc}
\hline & $\begin{array}{c}\text { Had no child in } \\
\text { post policy period } \\
(1)\end{array}$ & $\begin{array}{c}\text { Had at least one } \\
\text { child in } \\
\text { post-policy } \\
\text { period } \\
\text { Has a female child }\end{array}$ & $\begin{array}{c}\text { Difference } \\
(2)\end{array}$ \\
Has a male child & 0.7217 & 0.7131 & $0.0087^{* * *}$ \\
Total children born & 0.7609 & 0.7461 & $0.0148^{* * *}$ \\
Total girls & 2.4128 & 2.2464 & $0.1664^{* * *}$ \\
Total boys & 1.2012 & 1.1410 & $0.0601^{* * *}$ \\
Boys died & 1.2116 & 1.1055 & $0.1061^{* * *}$ \\
Girls died & 0.1002 & 0.0808 & $0.0194^{* * *}$ \\
Age of mother at birth & 0.0863 & 0.0681 & $0.0182^{* * *}$ \\
Has electricity & 24.2020 & 24.3164 & $-0.1143^{* * *}$ \\
Lives in an urban area & 0.6625 & 0.8002 & $-0.1378^{* * *}$ \\
Has at least secondary education & 0.2475 & 0.2496 & -0.0021 \\
$\mathrm{~N}$ & 0.7079 & 0.6148 & $0.0931^{* * *}$ \\
\hline Note: $* * *, * *$, and ${ }^{*}$ indicate significance at the $1 \%, 5 \%$, and $10 \%$ level, respectively.
\end{tabular}

Table 1.4: Descriptive Statistics of Mothers in Sample

\begin{tabular}{cccc}
\hline & $\begin{array}{c}\text { Had first child in } \\
\text { pre-policy period }\end{array}$ & $\begin{array}{c}\text { Had first child in } \\
\text { post-policy } \\
\text { period }\end{array}$ & $\begin{array}{c}\text { Difference } \\
(3)\end{array}$ \\
Has a female child & $(1)$ & $(2)$ & 0.5328 \\
Has a male child & 0.7492 & 0.5925 & $0.2164^{* * *}$ \\
Total children born & 0.7825 & 1.2667 & $1.2667^{* * * *}$ \\
Total girls & 2.5334 & 0.6325 & $0.6718^{* * *}$ \\
Total boys & 1.2749 & 0.6636 & $0.5949^{* * *}$ \\
Boys died & 1.2585 & 0.0293 & $0.0747^{* * *}$ \\
Girls died & 0.1040 & 0.0226 & $0.0667^{* * *}$ \\
Age of mother at birth & 0.0894 & 22.2787 & $2.2824^{* * *}$ \\
Has electricity & 24.5611 & 0.8290 & $-0.1379^{* * *}$ \\
Lives in an urban area & 0.6911 & 0.2761 & $-0.0324^{* * *}$ \\
Has at least secondary education & 0.2437 & 0.7307 & $-0.0644^{* * *}$ \\
\hline $\mathrm{N}$ & 0.6663 & 57,550 & 407,826 \\
\hline
\end{tabular}

Note: $* * *,{ }^{* *}$, and $*$ indicate significance at the $1 \%, 5 \%$, and $10 \%$ level, respectively. 
Figure 1.2: Ratio of Female Children Born at Different Birth Orders over All States

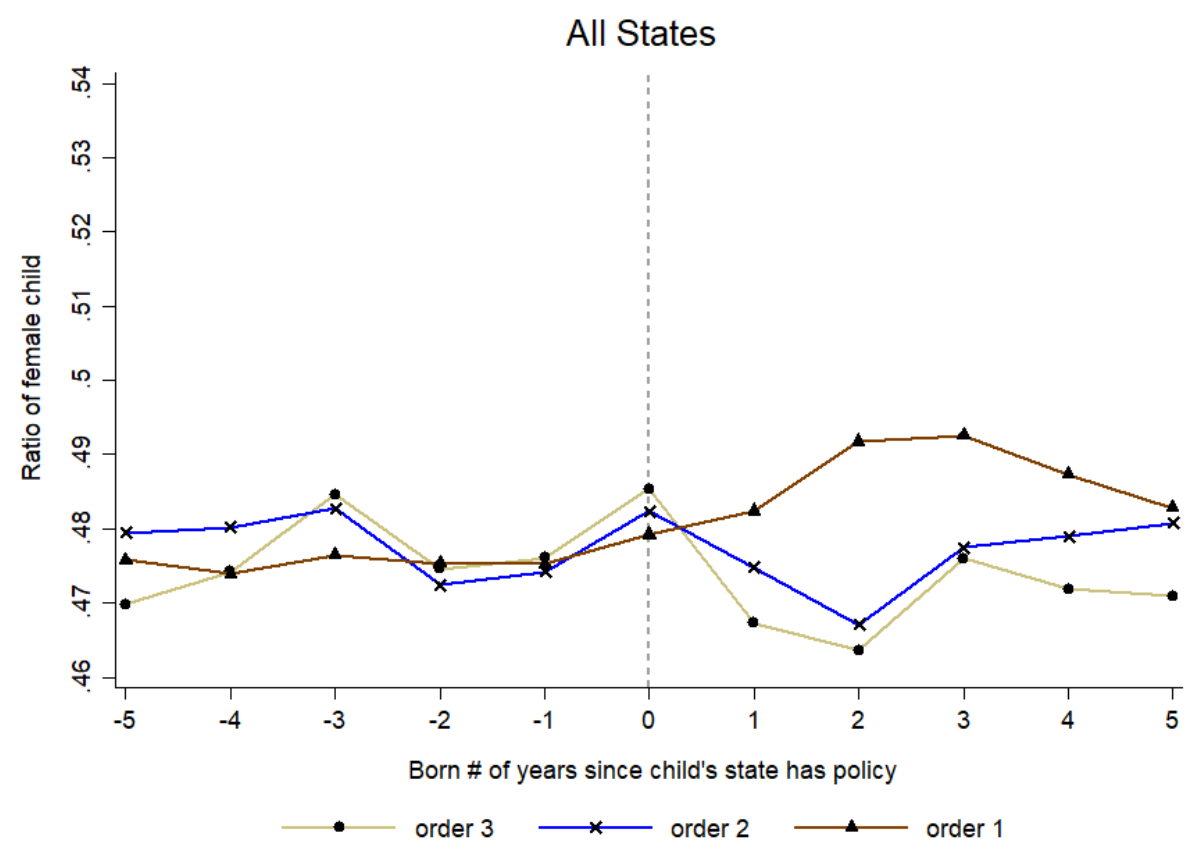

Figure 1.3: Ratio of Female Children Born at Different Birth Orders over All States

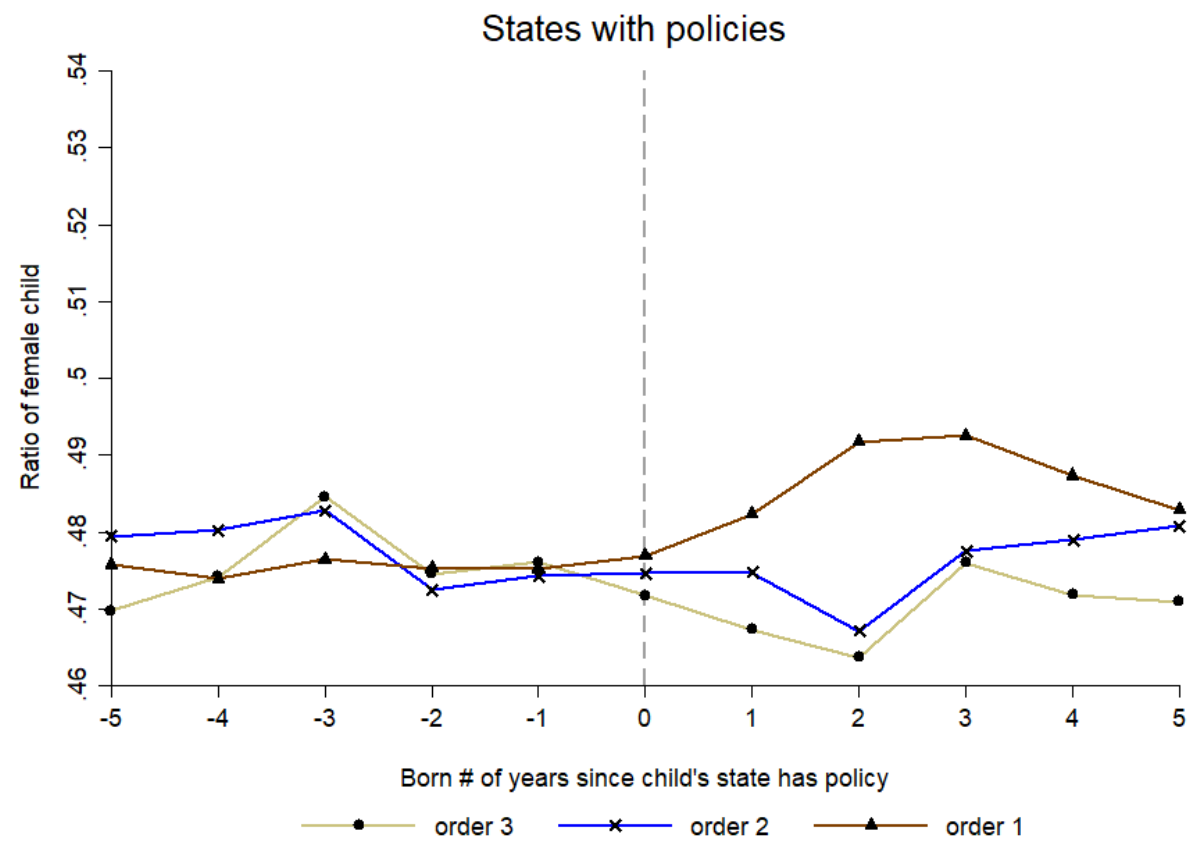




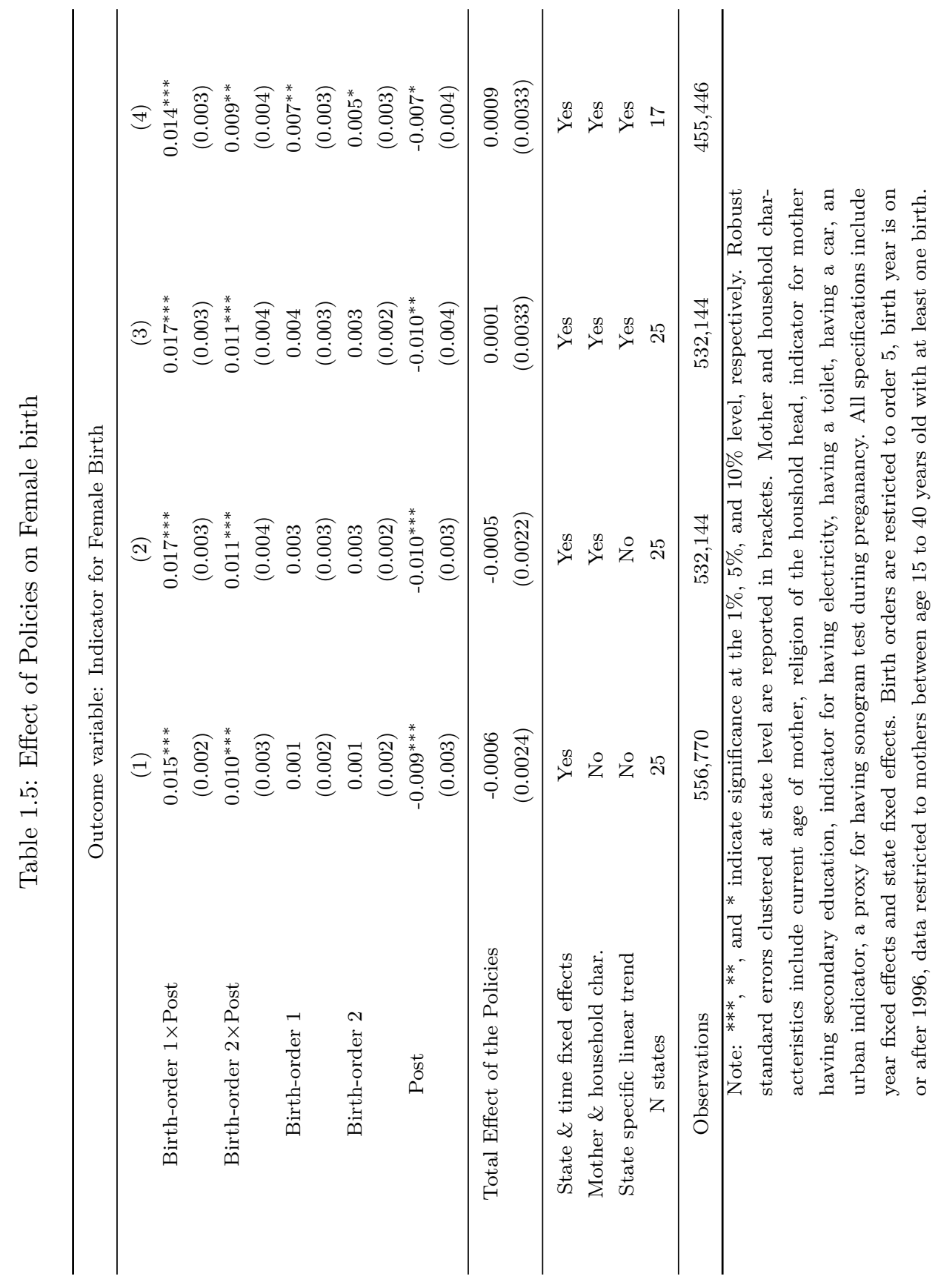




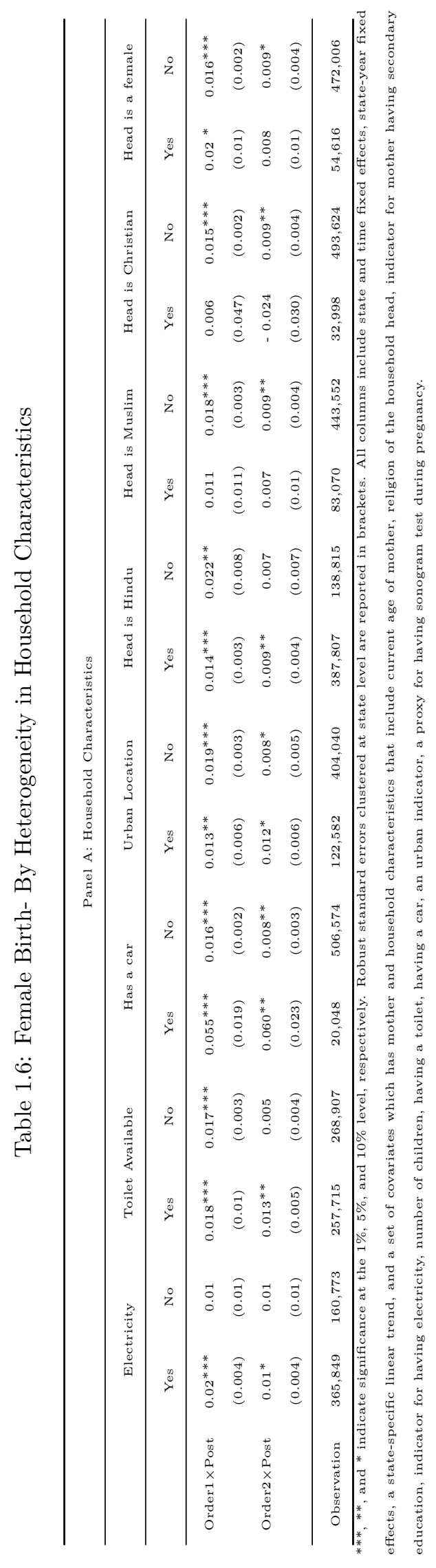




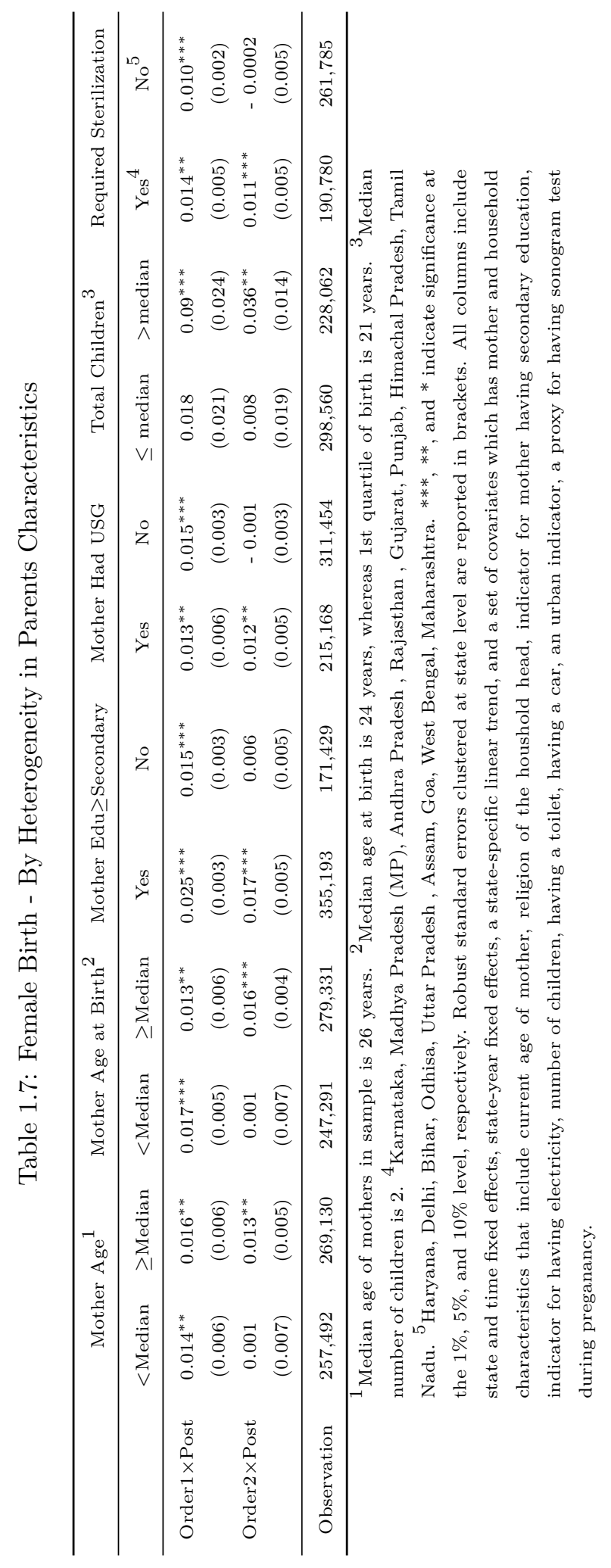


Table 1.9: Effect of Policies on Death within 1 year

\begin{tabular}{|c|c|c|c|c|}
\hline \multicolumn{5}{|c|}{ Outcome variable: Indicator for Death within 1 year } \\
\hline & (1) & (2) & (3) & $(4)$ \\
\hline \multirow[t]{2}{*}{ Birth-order $1 \times$ Post $\times$ Female } & $0.0025^{*}$ & $0.0028^{* *}$ & $0.0028^{* *}$ & $0.0033^{* *}$ \\
\hline & $(0.0012)$ & $(0.0012)$ & $(0.0011)$ & $(0.0013)$ \\
\hline \multirow[t]{2}{*}{ Birth-order $2 \times$ Post $\times$ Female } & 0.0013 & 0.0014 & 0.0014 & 0.0017 \\
\hline & $(0.0013)$ & $(0.0013)$ & $(0.0012)$ & $(0.0014)$ \\
\hline \multirow[t]{2}{*}{ Birth-order $1 \times$ Post } & -0.0013 & $-0.0016^{* *}$ & $-0.0019^{* * *}$ & $-0.0025^{* * *}$ \\
\hline & $(0.0007)$ & $(0.0007)$ & $(0.0007)$ & $(0.0006)$ \\
\hline \multirow[t]{2}{*}{ Birth-order $2 \times$ Post } & 0.0002 & -0.0002 & -0.0004 & -0.0004 \\
\hline & $(0.0006)$ & $(0.0006)$ & $(0.0006)$ & $(0.0007)$ \\
\hline \multirow[t]{2}{*}{ Birth-order $1 \times$ Female } & $-0.0027^{* *}$ & $-0.0025^{* *}$ & $-0.0026^{* *}$ & $-0.0031^{* * *}$ \\
\hline & $(0.0009)$ & $(0.0009)$ & $(0.0009)$ & $(0.0010)$ \\
\hline \multirow[t]{2}{*}{ Birth-order $2 \times$ Female } & $-0.0021^{*}$ & $-0.0020^{*}$ & $-0.0020^{*}$ & $-0.0024^{*}$ \\
\hline & $(0.0010)$ & $(0.0009)$ & $(0.0011)$ & $(0.0012)$ \\
\hline \multirow[t]{2}{*}{ Post $\times$ Female } & $-0.002^{*}$ & $-0.0020^{*}$ & $-0.0020^{*}$ & $-0.0025^{* *}$ \\
\hline & $(0.0009)$ & $(0.0009)$ & $(0.0009)$ & $(0.0009)$ \\
\hline \multirow[t]{2}{*}{ Female } & $0.0022^{* *}$ & $0.002^{* *}$ & $0.0020^{* *}$ & $0.0026^{* * *}$ \\
\hline & $(0.0008)$ & $(0.001)$ & $(0.0008)$ & $(0.0007)$ \\
\hline \multirow[t]{2}{*}{ Birth-order 1} & $0.0011^{*}$ & $0.003^{*}$ & $0.003^{*}$ & $0.004^{* *}$ \\
\hline & $(0.001)$ & $(0.0006)$ & $(0.0016)$ & $(0.001)$ \\
\hline \multirow[t]{2}{*}{ Birth-order 2} & -0.0001 & 0.001 & 0.0016 & 0.0014 \\
\hline & $(0.0004)$ & $(0.001)$ & $(0.001)$ & $(0.0013)$ \\
\hline \multirow[t]{2}{*}{ Post } & -0.0004 & -0.0001 & -0.0001 & 0.0005 \\
\hline & $(0.0008)$ & $(0.0008)$ & $(0.0008)$ & $(0.0008)$ \\
\hline State \& time fixed effects & Yes & Yes & Yes & Yes \\
\hline Mother \& household char. & No & Yes & Yes & Yes \\
\hline State specific linear trend & No & No & Yes & Yes \\
\hline $\mathrm{N}$ states & 25 & 25 & 25 & 17 \\
\hline Observations & 520,319 & 520,319 & 520,319 & 446,586 \\
\hline \multicolumn{5}{|c|}{$\begin{array}{l}\text { Note: } * * *, * * \text { and } * \text { indicate significance at the } 1 \%, 5 \% \text {, and } 10 \% \text { level, respectively. Robust standard } \\
\text { errors clustered at state level are reported in brackets. Coulmn (1) includes state and time fixed effects, } \\
\text { Column (2) add mother and household characteristics that include current age of mother, religion of } \\
\text { the houshold head, indicator for mother having secondary education, indicator for having electricity, } \\
\text { having a toilet, having a car, an urban indicator, a proxy for having sonogram test during preganancy. } \\
\text { Column (3) inlcudes a state specific linear term. Column (4) restricts the data to } 17 \text { states which had } \\
\text { a policy. All specifications include year fixed effects and state fixed effects. Birth orders are restricted } \\
\text { to order } 5 \text {, birth year is on or after } 1996 \text {, data restricted to mothers between age } 15 \text { to } 40 \text { years old } \\
\text { with at least one birth. Sample of children restricted to those who survived at least one month. }\end{array}$} \\
\hline
\end{tabular}


Table 1.10: Effect of policies on death within 5 years

\begin{tabular}{|c|c|c|c|c|}
\hline \multicolumn{5}{|c|}{ Outcome variable: Indicator for Death within 5 years } \\
\hline & $(1)$ & (2) & $(3)$ & $(4)$ \\
\hline \multirow[t]{2}{*}{ Birth-order $1 \times$ Post $\times$ Female } & $0.0018^{*}$ & $0.0018^{*}$ & $0.0018^{*}$ & $0.0024^{* *}$ \\
\hline & $(0.001)$ & $(0.0009)$ & $(0.0009)$ & $(0.0010)$ \\
\hline \multirow[t]{2}{*}{ Birth-order $2 \times$ Post $\times$ Female } & $0.0018^{* * *}$ & $0.0018^{* * *}$ & $0.0018^{* * *}$ & $0.0021^{* * *}$ \\
\hline & $(0.0006)$ & $(0.0006)$ & $(0.0006)$ & $(0.0006)$ \\
\hline \multirow[t]{2}{*}{ Birth-order $1 \times$ Post } & $0.0011^{* * *}$ & $0.0007^{* *}$ & $0.0005^{*}$ & 0.0004 \\
\hline & $(0.0003)$ & $(0.0003)$ & $(0.0002)$ & $(0.0003)$ \\
\hline \multirow[t]{2}{*}{ Birth-order $2 \times$ Post } & $0.0009^{* * *}$ & 0.0005 & 0.0003 & 0.0004 \\
\hline & $(0.0003)$ & $(0.0003)$ & $(0.0003)$ & $(0.0003)$ \\
\hline \multirow[t]{2}{*}{ Birth-order $1 \times$ Female } & $-0.0018^{*}$ & $-0.0016^{*}$ & $-0.0016^{*}$ & $-0.0020^{* *}$ \\
\hline & $(0.0010)$ & $(0.0009)$ & $(0.0009)$ & $(0.0009)$ \\
\hline \multirow[t]{2}{*}{ Birth-order $2 \times$ Female } & $-0.0017^{* *}$ & $-0.0016^{* *}$ & $-0.0017^{* *}$ & $-0.0019^{* *}$ \\
\hline & $(0.0009)$ & $(0.0006)$ & $(0.0009)$ & $(0.0003)$ \\
\hline \multirow[t]{2}{*}{ Post $\times$ Female } & -0.0022 & $-0.0022^{* *}$ & $-0.0022^{* *}$ & $-0.0027^{* *}$ \\
\hline & $(0.0009)$ & $(0.0009)$ & $(0.0009)$ & $(0.0009)$ \\
\hline \multirow[t]{2}{*}{ Female } & $0.0022^{* *}$ & $0.002^{* *}$ & $0.0021^{* *}$ & $0.0027^{* *}$ \\
\hline & $(0.0008)$ & $(0.0009)$ & $(0.0008)$ & $(0.0009)$ \\
\hline \multirow[t]{2}{*}{ Birth-order 1} & $-0.0011^{* * *}$ & 0.0002 & 0.0003 & 0.0003 \\
\hline & $(0.0002)$ & $(0.0008)$ & $(0.0007)$ & $(0.0008)$ \\
\hline \multirow[t]{2}{*}{ Birth-order 2} & $-0.0009^{* * *}$ & 0.0002 & 0.0003 & 0.0001 \\
\hline & $(0.0002)$ & $(0.0006)$ & $(0.0006)$ & $(0.0006)$ \\
\hline \multirow[t]{2}{*}{ Post } & -0.0006 & -0.0000 & 0.0003 & 0.0005 \\
\hline & $(0.0005)$ & $(0.0005)$ & $(0.0005)$ & $(0.0006)$ \\
\hline State \& time fixed effects & Yes & Yes & Yes & Yes \\
\hline Mother \& household char. & No & Yes & Yes & Yes \\
\hline State specific linear trend & No & No & Yes & Yes \\
\hline $\mathrm{N}$ states & 25 & 25 & 25 & 17 \\
\hline Observations & 517,501 & 517,501 & 517,501 & 444,013 \\
\hline \multicolumn{5}{|c|}{$\begin{array}{l}\text { Note: } * * * * *, \text { and } * \text { indicate significance at the } 1 \%, 5 \% \text {, and } 10 \% \text { level, respectively. Robust standard } \\
\text { errors clustered at state level are reported in brackets. Coulmn }(1) \text { includes state and time fixed effects, } \\
\text { Column }(2) \text { add mother and household characteristics that include current age of mother, religion of } \\
\text { the houshold head, indicator for mother having secondary education, indicator for having electricity, } \\
\text { having a toilet, having a car, an urban indicator, a proxy for having sonogram test during preganancy. } \\
\text { Column (3) inlcudes a state specific linear term. Column (4) restricts the data to } 17 \text { states which had } \\
\text { a policy. All specifications include year fixed effects and state fixed effects. Birth orders are restricted } \\
\text { to order } 5 \text {, birth year is on or after } 1996 \text {, data restricted to mothers between age } 15 \text { to } 40 \text { years old } \\
\text { with at least one birth. Sample of children restricted to those who survived at least one year. }\end{array}$} \\
\hline
\end{tabular}




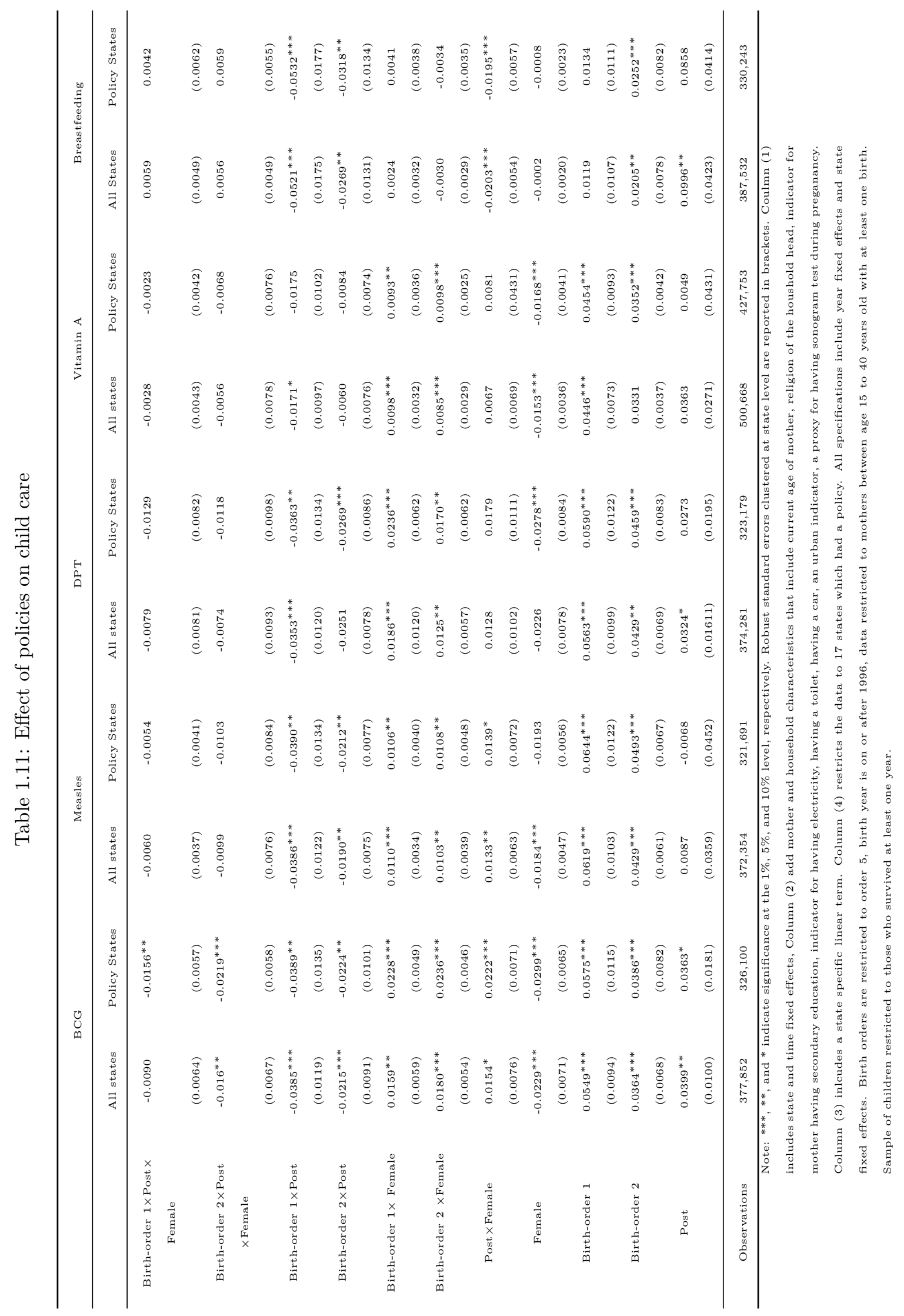




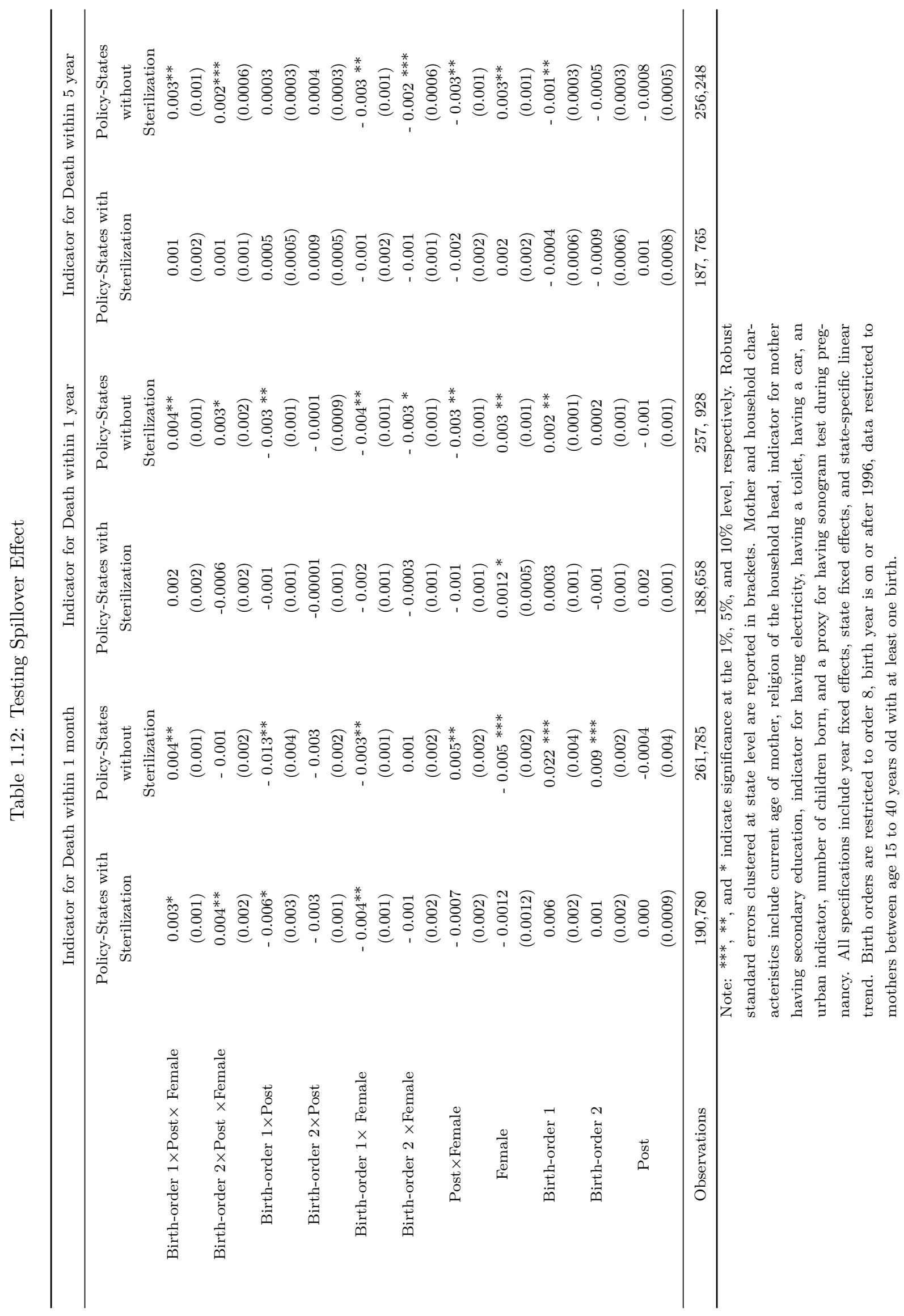


Table 1.13: Effect of Policies on Female Birth - Including state-year fixed effect

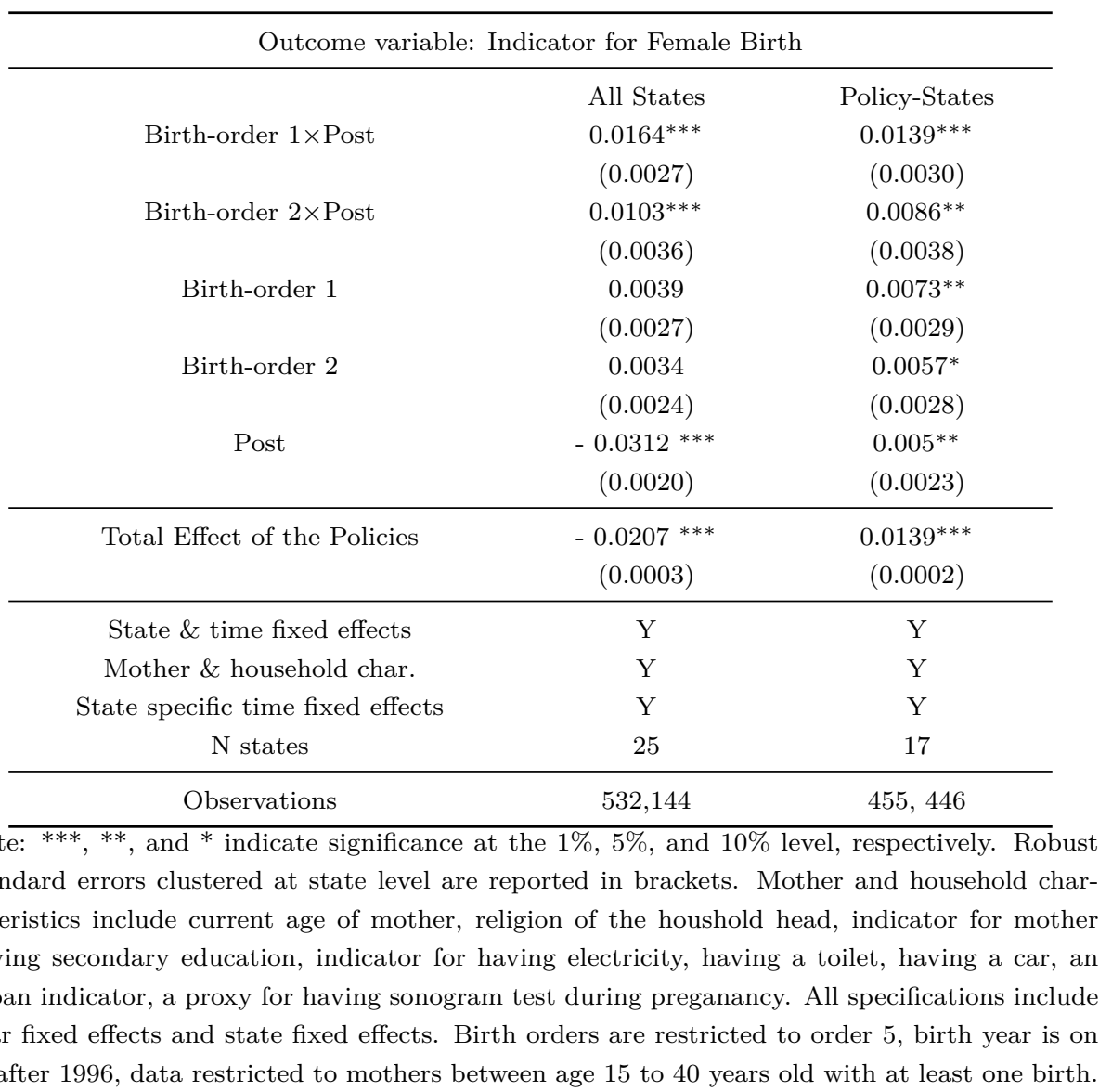




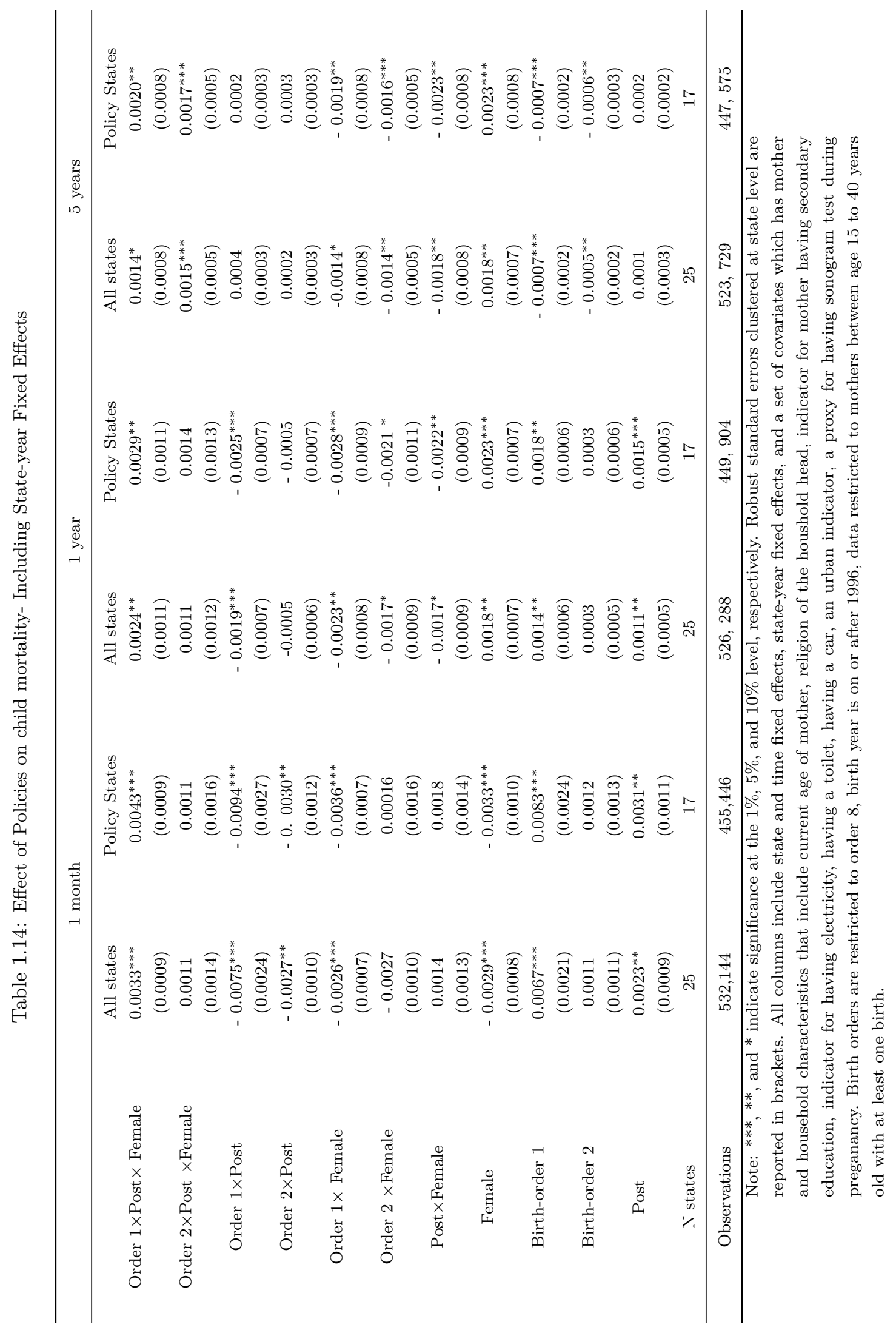




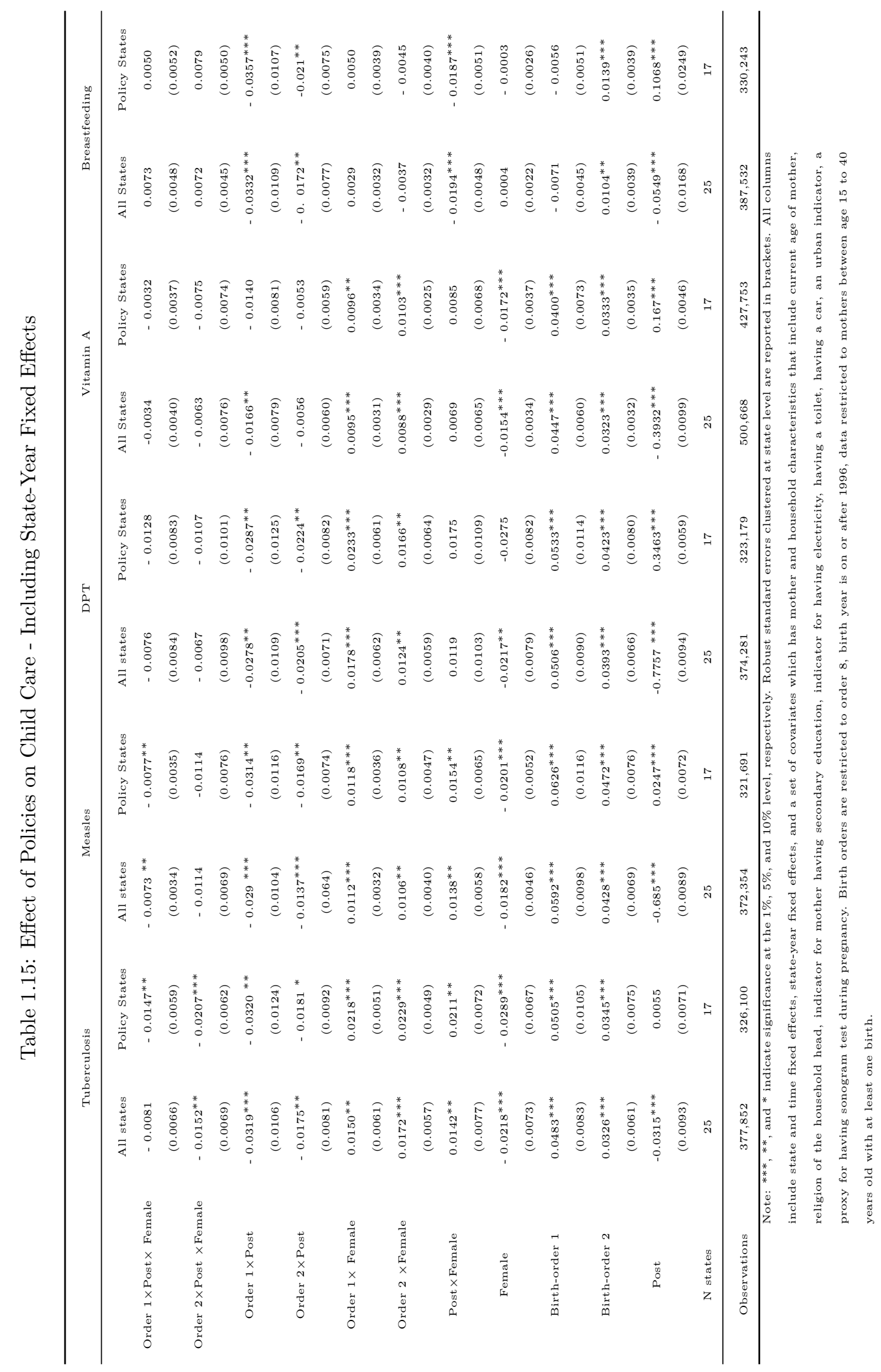


Table 1.16: Balance Test

\begin{tabular}{|c|c|c|c|c|c|c|}
\hline & \multicolumn{3}{|c|}{ Panel A: All births } & \multicolumn{3}{|c|}{ Panel B: Upto first two births } \\
\hline & Treated & Control & Diff & Treated & Control & Diff \\
\hline Age of mother & $\begin{array}{l}25.03 \\
(0.21)\end{array}$ & $\begin{array}{l}26.75 \\
(0.19)\end{array}$ & $\begin{array}{c}-1.72^{* * *} \\
(0.24)\end{array}$ & $\begin{array}{l}25.03 \\
(0.21)\end{array}$ & $\begin{array}{l}24.60 \\
(0.33)\end{array}$ & $\begin{array}{c}0.43 \\
(0.40)\end{array}$ \\
\hline Age of mother at birth & $\begin{array}{l}23.14 \\
(0.18)\end{array}$ & $\begin{array}{l}24.93 \\
(0.20)\end{array}$ & $\begin{array}{c}-1.78^{* * *} \\
(0.25)\end{array}$ & $\begin{array}{l}23.14 \\
(0.18)\end{array}$ & $\begin{array}{l}22.80 \\
(0.29)\end{array}$ & $\begin{array}{c}0.34 \\
(0.29)\end{array}$ \\
\hline Has Secondary education & $\begin{array}{c}0.68 \\
(0.05)\end{array}$ & $\begin{array}{c}0.67 \\
(0.02)\end{array}$ & $\begin{array}{c}0.01 \\
(0.04)\end{array}$ & $\begin{array}{l}0.68 \\
0.05\end{array}$ & $\begin{array}{c}0.76 \\
(0.02)\end{array}$ & $\begin{array}{l}-0.08 \\
(0.05)\end{array}$ \\
\hline HH has no toilet facility & $\begin{array}{c}0.45 \\
(0.04)\end{array}$ & $\begin{array}{c}0.53 \\
(0.06)\end{array}$ & $\begin{array}{r}-0.08^{*} \\
(0.05)\end{array}$ & $\begin{array}{c}0.45 \\
(0.04)\end{array}$ & $\begin{array}{c}0.45 \\
(0.05)\end{array}$ & $\begin{array}{r}-0.006 \\
(0.05)\end{array}$ \\
\hline HH has electricity & $\begin{array}{c}0.82 \\
(0.04)\end{array}$ & $\begin{array}{c}0.66 \\
(0.07)\end{array}$ & $\begin{array}{c}0.17^{* * *} \\
(0.04)\end{array}$ & $\begin{array}{c}0.82 \\
(0.04)\end{array}$ & $\begin{array}{c}0.71 \\
(0.06)\end{array}$ & $\begin{array}{c}0.11^{* * *} \\
(0.04)\end{array}$ \\
\hline HH owns a car & $\begin{array}{c}0.05 \\
(0.01)\end{array}$ & $\begin{array}{c}0.03 \\
(0.01)\end{array}$ & $\begin{array}{l}0.02^{*} \\
(0.01)\end{array}$ & $\begin{array}{c}0.05 \\
(0.01)\end{array}$ & $\begin{array}{c}0.05 \\
(0.01)\end{array}$ & $\begin{array}{l}0.006 \\
(0.63)\end{array}$ \\
\hline HH head is Hindu & $\begin{array}{c}0.83 \\
(0.03)\end{array}$ & $\begin{array}{c}0.71 \\
(0.05)\end{array}$ & $\begin{array}{c}0.12^{* *} \\
(0.05)\end{array}$ & $\begin{array}{c}0.83 \\
(0.03)\end{array}$ & $\begin{array}{c}0.71 \\
(0.05)\end{array}$ & $\begin{array}{c}0.12^{* *} \\
(0.05)\end{array}$ \\
\hline $\mathrm{HH}$ head is Christian & $\begin{array}{c}0.02 \\
(0.01)\end{array}$ & $\begin{array}{c}0.08 \\
(0.04)\end{array}$ & $\begin{array}{r}-0.06 \\
(0.04)\end{array}$ & $\begin{array}{c}0.02 \\
(0.01)\end{array}$ & $\begin{array}{c}0.08 \\
(0.04)\end{array}$ & $\begin{array}{c}-0.06^{*} \\
(0.04)\end{array}$ \\
\hline HH head is Muslim & $\begin{array}{c}0.11 \\
(0.02)\end{array}$ & $\begin{array}{c}0.17 \\
(0.03)\end{array}$ & $\begin{array}{c}-0.06^{* *} \\
(0.03)\end{array}$ & $\begin{array}{c}0.11 \\
(0.02)\end{array}$ & $\begin{array}{c}0.15 \\
(0.04)\end{array}$ & $\begin{array}{l}-0.04 \\
(0.04)\end{array}$ \\
\hline HH head is a female & $\begin{array}{c}0.11 \\
(0.02)\end{array}$ & $\begin{array}{c}0.10 \\
(0.01)\end{array}$ & $\begin{array}{c}0.01 \\
(0.01)\end{array}$ & $\begin{array}{c}0.11 \\
(0.02)\end{array}$ & $\begin{array}{c}0.09 \\
(0.01)\end{array}$ & $\begin{array}{c}0.02 \\
(0.01)\end{array}$ \\
\hline $\mathrm{HH}$ is in urban area & $\begin{array}{c}0.26 \\
(0.03)\end{array}$ & $\begin{array}{c}0.22 \\
(0.02)\end{array}$ & $\begin{array}{c}0.04 \\
(0.03)\end{array}$ & $\begin{array}{c}0.26 \\
(0.03)\end{array}$ & $\begin{array}{c}0.26 \\
(0.02)\end{array}$ & $\begin{array}{c}0.01 \\
(0.03)\end{array}$ \\
\hline Total children born & $\begin{array}{c}1.78 \\
(0.05)\end{array}$ & $\begin{array}{c}2.95 \\
(0.13)\end{array}$ & $\begin{array}{c}-1.16^{* * *} \\
(0.1)\end{array}$ & $\begin{array}{c}1.78 \\
(0.05)\end{array}$ & $\begin{array}{c}1.85 \\
(0.03)\end{array}$ & $\begin{array}{r}-0.06 \\
(0.06)\end{array}$ \\
\hline Had USG test & $\begin{array}{c}0.65 \\
(0.05)\end{array}$ & $\begin{array}{c}0.33 \\
(0.05)\end{array}$ & $\begin{array}{c}0.31^{* * *} \\
(0.05)\end{array}$ & $\begin{array}{c}0.65 \\
(0.05)\end{array}$ & $\begin{array}{c}0.41 \\
(0.05)\end{array}$ & $\begin{array}{c}0.24^{* * *} \\
(0.06)\end{array}$ \\
\hline Observation & 122,072 & 404,550 & 526,622 & 122,072 & 221,236 & 343,308 \\
\hline
\end{tabular}

Note: ${ }^{* * *}, * *$, and $*$ indicate significance at the $1 \%, 5 \%$, and $10 \%$ level, respectively. Robust standard errors clustered at state level are reported in brackets. 
Table 1.17: Effect of Policies on Female birth -Testing for Dependence on Hindu Religion and Electricity

\begin{tabular}{|c|c|c|c|}
\hline \multicolumn{4}{|c|}{ Outcome variable: Indicator for Female Birth } \\
\hline \multirow{3}{*}{ Birth-order $1 \times$ Post } & $(3)$ & $(4)$ & $(5)$ \\
\hline & $0.019^{* * *}$ & $0.019^{* * *}$ & $0.019^{* * *}$ \\
\hline & $(0.003)$ & $(0.003)$ & $(0.003)$ \\
\hline \multirow[t]{2}{*}{ Birth-order $2 \times$ Post } & $0.011^{* * *}$ & $0.011^{* * *}$ & $0.011^{* * *}$ \\
\hline & $(0.003)$ & $(0.003)$ & $(0.003)$ \\
\hline \multirow[t]{2}{*}{ Birth-order 1} & 0.001 & 0.001 & 0.001 \\
\hline & $(0.003)$ & $(0.003)$ & $(0.003)$ \\
\hline \multirow[t]{2}{*}{ Birth-order 2} & 0.002 & 0.002 & 0.002 \\
\hline & $(0.003)$ & $(0.003)$ & $(0.003)$ \\
\hline \multirow[t]{2}{*}{ Post } & $-0.010^{* *}$ & $-0.010^{* *}$ & $-0.009^{* * *}$ \\
\hline & $(0.003)$ & $(0.003)$ & $(0.003)$ \\
\hline \multirow{3}{*}{$\begin{array}{c}\text { Control for Having Electricity } \\
\text { Control for Hindu Household Head } \\
\text { N states }\end{array}$} & Yes & Yes & No \\
\hline & Yes & No & Yes \\
\hline & 25 & 25 & 25 \\
\hline Observations & 526,622 & 526,622 & 526,622 \\
\hline \multicolumn{4}{|c|}{$\begin{array}{l}\text { Note: }{ }^{* *},{ }^{*}, \text { and }{ }^{*} \text { indicate significance at the } 1 \%, 5 \% \text {, and } 10 \% \text { level, respectively. Robust } \\
\text { standard errors clustered at state level are reported in brackets. Mother and household char- } \\
\text { acteristics include current age of mother, Household head being Muslim, Household head being } \\
\text { christian, indicator for mother having secondary education, having a toilet, having a car, an } \\
\text { urban indicator, total number of children, a proxy for having sonogram test during pregnancy. } \\
\text { All specifications include year fixed effects and state fixed effects. Birth orders are restricted to } \\
\text { order } 8 \text {, birth year is on or after } 1996 \text {, data restricted to mothers between age } 15 \text { to } 40 \text { years old } \\
\text { with at least one birth. }\end{array}$} \\
\hline
\end{tabular}

Table 1.18: Effect of Policies on Female birth - Alternative Testing for Dependence on Hindu Religion and Electricity

\begin{tabular}{ccc}
\hline & Household Head is & Household Has \\
Treated & Hindu & Electricity \\
& -0.0016 & 0.0030 \\
N states & $(0.0015)$ & $(0.0113)$ \\
Observations & 25 & 25 \\
\hline
\end{tabular}

Note: ${ }^{* * *},{ }^{* *}$, and ${ }^{*}$ indicate significance at the $1 \%, 5 \%$, and $10 \%$ level, respectively. Robust standard errors clustered at state level are reported in brackets. Mother and household characteristics include current age of mother, Household head being Muslim, Household head being christian, indicator for mother having secondary education, having a toilet, having a car, an urban indicator, total number of children, household head being a female, age of mother at birth, a proxy for having sonogram test during pregnancy. All specifications include year fixed effects, state fixed effects, and state-specific linear trend. Birth orders are restricted to order 8, birth year is on or after 1996, data restricted to mothers between age 15 to 40 years old with at least one birth. 


\section{Chapter 2}

\section{Reducing The Rural-Urban Educational Gap in India through Rural School Investment}

\section{$2.1 \quad$ Introduction}

Human capital outcomes may vary widely within a country because of existing regional difference in economic development. Rural areas, for example, in almost all low and middle income countries, face shortages in the supply of basic necessities of life such as food, healthcare, education, and sometimes, even lack habitable environment. Under these circumstances, public policies that apply across regions are likely to be more effective in urban areas compared to rural areas.

One fundamental policy focus of less developed countries for the past two decades is to empower their female citizens. Several policies exist at the state or country level to benefit its women and the female children that have been found to improve female-tomale sex ratio (Kalsi, 2017), reduce child marriage (Castilla, 2018), increase maternal healthcare utilization (Sado et al., 2014), improve educational outcomes (Kalsi, 2015), and improve overall economic development (Duflo, 2012). The underlying strategies of these policies range from providing cash transfers, legalizing abortion to providing basic means of transportation to pursue higher education ${ }^{1}$, which are expected to create economic demand for human capital.

\footnotetext{
${ }^{1}$ An example of female empowerment in politics is the reservation of seats for women in India. The $73 \mathrm{rd}$ and 74 th Amendments established villages and urban units as the smallest unit of governance. One-third of the total number of seats from each unit was reserved for women. Duflo (2012) is an excellent source for understanding how the gender gap has reduced following economic development and how economic development in turn, has affected various aspect of the gender gap.
} 
However, supply-side disparity between urban and rural areas is likely to cause rural areas to fall short of urban areas in terms of policy achievements. To reduce these regional economic differences, measures have been pursued by developing countries using tax revenues and development aid from multiple sources such as the World Bank, United Nations, and philanthropic efforts from foreign organizations. Moreover, targets set by the Millennium Development Goals to achieve its key objectives within a given period of time have made it more important than before to address these fundamental issues. Whether these efforts can successfully translate to broader economic success, remains to be seen.

In particular, this paper examines whether rural-urban difference in education among female children falls following an investment in rural school infrastructure, which heavily falls short of their urban counterpart. A basic necessity for every school is to have a proper sanitation system. While all children are equally disadvantaged when it comes to using a restroom where there is none, female children are more vulnerable to a lack of a restroom compared to their male peers because they need more privacy as they reach adolescence and go through menstruation cycles. In general, they may feel unsafe if they are forced to use open areas when they need to relieve themselves and as a result, they may discontinue attending schools. Moreover, such practices are also associated with spread of infectious diseases (Fentiman et al., 1999; Burgers, 2000; Kirk and Sommer, 2006) and clean sanitation practices are considered to be a first preventive measure to prevent human contamination. Female children born in the urban areas do not face such basic lack of infrastructure and therefore, are advantaged compared to rural children. Given this scenario, a policy that incentivizes children to attend schools may only achieve limited success in the rural areas.

Historically, female literacy rates have been low in India, particularly in rural areas. The 2001 census revealed that female literacy rates in rural and urban areas were 46.7 percent and 73.2 percent, respectively (Ministry of Statistics and Programme 
Implementation, India 2016) ${ }^{2}$. Using district level school characteristics from 175 districts $^{3}$ in India, surveyed during 2001-02 academic year, I find that on average, only $16.5 \%$ of the primary schools had a separate female restroom on average. Lack of proper sanitation is widely linked to spreading of diseases such as diarrhea (PrussUstun, Annette and World Health Organization and others, 2008), which is among the top causes of infant mortality in India (Lakshminarayanan and Jayalakshmy, 2015).

Moreover, having separate restrooms for adolescent females is important because they need more privacy as they go through menstruation, a biological function experienced by them every month. A survey done by Adukia for her seminal paper (Adukia, 2017), revealed that female children drop out as the timing of exams and menstrual cycles coincide, which cannot be retaken later. ${ }^{4}$ She established that female enrollment increased following restroom establishment. Factors other than menstruation are also important for female school attendance. Ray and Datta, 2017 finds that provision of female restrooms through SSHE reduced gender-parity index of enrollment for schedule-caste children ${ }^{5}$ although gender-parity improved for all children, which may indicate caste-related discrimination in the society. Similar provisions in schools in Kenya are associated with increased attendance rates at the primary level ( Kim, Hyoungjong and Rhee, Dong-Eun, 2019) and the effects are larger for pubescent-age female children than boys.

To the best of my knowledge, this is the first paper looking at regional gap in school completion rates. These gaps have remained wide for decades for a number of reasons that include supplying labor to household work, considering education to be unnecessary, withdrawing children out of school for marriage, not having proper fa-

\footnotetext{
${ }^{2}$ The earlier figures for female rural (urban) literacy rates in the censuses were $4.87 \%(22.33 \%)$ in $1951,10.1 \%$ $(40.5 \%)$ in $1961,15.5 \%(48.8 \%)$ in $1971,21.3 \%$ (56.3) in 1981, and $30.17 \%(64.05 \%)$ in 1991.

${ }^{3}$ Out of approximately 500 districts, approximately 175 districts were surveyed, Source: District Information System of Education, India.

${ }^{4}$ Globally, there is a stigma around menstruation (Litman, 2018) and India, given its cultural attitudes towards women, lacks no behind others (Garg and Anand, 2015). In Adukia's survey, the principles of a number of schools opined that not having a separate restroom or not having a restroom at all is not a problem for the students as they follow "regimented" hygiene practice.

${ }^{5}$ Schedule Caste and Schedule Tribes refer to communities of people of depressed classes who were considered as 'low-caste' groups historically.
} 
cilities at the school, and lack of transportation/ roads connecting to schools (NFHS2 , Young Lives Survey). Adukia, 2017 showed that enrollment rates have increased, more students appeared for exams, and passed exams.

This paper examines rural-urban educational gap for female children following rural female restroom provision in schools. The underlying assumption is that children in urban area do not move to a rural area following the provision of female restrooms in schools and vice versa. The assumption is likely to be valid as it is unlikely that parents who are able to afford living in urban areas will send their daughters to school in a rural area because of better restrooms. Moreover, rural children, especially village children, take up schooling within their village (Adukia, 2017).

In this paper, I use data from Demographic (National Family and Household Survey in India) Health Survey and District Level Household survey for individual educational achievement and match the available proportion of schools with female restroom data in their district of residence from the District Information System for Education in India. I compare the average educational achievement of a female child in rural areas within a district, at each age, and academic year to the average educational achievement of a female child in an urban area within that district, age, and academic year. The variation in the proportion of schools with a female restroom reflects the "before" and "after" period of availability of female restrooms. The underlying assumption is that, in absence of the policy, rural areas would have followed the same trend in educational achievement as prior to having schools with restroom provision.

I find that a one percentage point increase in the proportion of schools with female restrooms increases the probability of secondary school completion of rural female children by 6 percentage points. The corresponding increase in the years of education of among female children attending secondary schools in rural area is 0.63 years. For upper primary education (standard 6-8), there is 13 percentage points more completion and 0.58 more years of education. Higher secondary (standard 11-12) school 
children do not experience any significant increase in the completion rate and the benefit is limited to female children who have completed secondary education. Primary school attendees also gain significantly from the provision of restrooms.

Assuming there has been similar a increase in the proportion of restrooms for male children, as the policy targeted building restrooms separately for both sexes, I find school completion rates at every level, except higher secondary schooling, have increased for rural male children as well. In contrast to female children, positive effects are absent for male children who have completed secondary schooling, implying that female children gain marginally more due to restroom building in schools.

The rest of the paper is organized as follows. Section 2 describes policy background, section 3 describes the data, section 4 describes the econometric model used, section 5 discuss the results, and section 6 concludes.

\section{$2.2 \quad$ Policy Background ${ }^{6}$}

Building female restrooms in households and schools, particularly in the rural areas, was a part of the Government of India's policy goals from the 1980s. In an effort to achieve the goals, the Central Rural Sanitation Program (CRSP) was initiated in 1986 to provide sanitation facilities (Kumar et al., 2010). Despite subsidies, there was a shortage of the funds to push the program and therefore, rural sanitation systems remained underdeveloped for the next decade (Pruss-Ustun, Annette and World Health Organization and others, 2008). Only 22 percent rural households were found to have access to restrooms in 2001. The CRSP was restructured and renamed as the Total Sanitation Campaign (TSC) in 1999 and was implemented across 606 districts of 30 states in India (Kumar et al., 2010).

Alongside the program, the UN announced Millennium Development Goals in early 2000 which were aimed at reducing infant mortality in developing countries by 2015. However, reaching such goals alone by building school toilets was not possible,

\footnotetext{
${ }^{6}$ This section is based heavily on policy information obtained from Department of Drinking Water Ministry (2005) and Adukia (2017).
} 
given the practice of open defecation, particularly in rural areas of India with high prevalence of soil and water-borne diseases. Given the large school going population in India and its open defecation culture in the rural areas, it required a parallel program that would educate the population about the importance of safe sanitation practices. To fulfill that objective, the School Sanitation and Hygiene Education (SSHE) program was also implemented as a part of the TSC that sought to eliminate open defecation, educate people about the importance of hygiene, and promote safer environment for female children in schools by building female restrooms (Snel et al., 2002; Adukia, 2017). The program involved the local community to promote words on safe hygiene practices and monetary awards were announced for areas that reached complete sanitation coverage and elimination of open defecation. These awards were important for local leaders who boasted their achievements to neighboring villages.

The SSHE program was implemented by the National Government through State Governments which involved the democratically elected local government at the village level, known as the gram-panchayat. Each state government in India is decentralized at multiple levels. A state is divided into a few divisions and each division consists of a number of districts (or Zilla). Districts are further divided into subdivisions (also known as Tehsils ) which are divided into blocks and wards. Blocks refer to the rural parts of the subdivision and wards refer to the urban areas. A block consists of several villages whereas wards consist of city councils.

At the school level, the Parent Teacher Association, School Management Committee and at the village level, gram-panchayat were responsible for the implementation of the SSHE. The funds for building restrooms came from both the national government and state government, although national government's share were almost double that of state government's share for each academic year. During the initial years of the projects, between 1999-2002, available funds were low, but picked up substantially during school year 2002-03 (Department of Drinking Water Ministry, 
$2005)^{7}$. To ensure the functioning of the newly built restrooms, the government also allocated funds for water facilities. Each state was asked to prepare an action plan for SSHE that included the number schools that needed water sources, restrooms, repair, and maintenance. To develop coordination between the various involved departments such as education, health, and public health engineering, and women and child development, a representative body (State Water and Sanitation Mission) was formed (Department of Drinking Water Ministry, 2005).

Redistribution of funds from the district level to the local government did not follow any systematic pattern and each district differed in their respective strategy for allocation. Funds for school restrooms and water facilities (under the SSHE) remained separate from funds for restroom facilities for households in the TSC (Adukia, 2017). However, local political connections with states may have played a role in the allocation of resources, specifically if offices were held by female politicians (Lee, 2018) who may stress on developments that benefit female children. In this paper, I cover the full roll-out period of distribution of the policies, taking into consideration proportion of female leaders from each state who were holding offices at the center during that period. The next section describes the several sources of data that I use to study impact of the policy.

\subsection{Data}

The data for this paper comes from three sources. For records on educational achievements of children, I use rounds II and III of District Level Household Survey (DLHS) and National Family Health Survey (NFHS) Round 2 and Round 4. DLHS and NFHS are cross-sectional household level surveys conducted by the International Institute for Population Sciences (IIPS) and are targeted towards tracking reproductive and child health in India, and collect detailed information of currently married women aged 15-44 and unmarried women aged 15-24. Round II of DLHS survey was com-

\footnotetext{
${ }^{7}$ Adukia (2017) reports that financial allocation increased substantially from 2003-04 academic year.
} 
pleted during the year 2002-04 in 593 districts and round III was conducted during the year 2007-2009. NFHS round 2 and round 4 were carried our between 1998-00 and 2015-16.

For each household, NFHS collects demographic information including age, sex, and years of schooling of each member along with characteristics of the household such as source of drinking water, type of house, type of toilet, source of light, availability of electricity, and whether the household is located in an urban or a rural area. Other rounds of NFHS data do not identify the district in which the household is located and DLHS-III only surveys certain states of India due to its complementarity with another survey in the same year. From the date of interview, I identify the academic year in which the household was surveyed. Years of schooling implies how many standards the person completed, for example, 9 years of education means he passed standard 9. There is no information on the year in which the person attended his last year of education and the combined data does not indicate if the person is currently in school as such information is missing on the DLHS-II. I drop children whose number of years of education is more than his/her age.

The source of school data is District Information System for Education, which provides district level aggregate data on schools in India annually. The earliest year of data available is $2001-02^{8}$. For earlier years in the full sample between 2001-16, the survey only collected data from a small number of districts, however, over the years, it expanded to cover every district in India. For each district, it reports the total number of schools available in each of five discrete categories, primary only (standard 1-5); primary with upper primary (standard 1-8); primary, upper primary, with secondary and higher secondary (standard 1-12); upper primary only (standard 6-8); and upper primary with secondary and higher secondary (standard 8-12). It also reports district level information for the number of schools with no female teacher, number of public and private schools, and number of schools with female restrooms for each of the

\footnotetext{
${ }^{8}$ Although $2000-01$ is available, the information are different from later years.
} 
five categories above. Using the five categories of schools, I calculate the percentage of schools with female restrooms providing $l$-th level of education, where $l$ can be primary, upper-primary, secondary or higher secondary. In the appendix, for each level, I describe how the percentage is calculated.

Until 2013-14, the survey reported the number of schools with unisex restrooms and female restrooms, but afterwards, they report the number of schools with female restrooms and male restrooms separately. Since neither complete information on the number of schools with unisex restrooms or male restrooms are available, I restrict my main analysis to only female children.

Also, parents may prefer sending a female child to a school which has a female teacher and therefore, it is important to control for the proportion of schools with female teachers. Omitting proportion of schools with female teachers may cause omitted variable bias as female teachers may be more willing to accept a job at a school which has a female restroom. Data on the proportion of schools without a female teacher is available for years until 2013-14. I assume that during the academic years 2014-15 and 2015-16, percentage of schools with no female teachers remain the same.

I match school data using the child's district of residence and I restrict the sample to female children who are not married, because the surveys do not identify where women lived prior to marriage. In India, the patriarchal system dictates that women leave their parents' house to stay with her in-laws/husband and none of the surveys available during that period reported residence before marriage. I further assume that a child attended school in the district where the household resides. Moreover, since the earliest year of usable school data available is from the 2001-2002 academic year, I assign the children in NFHS round 2 the district level school information available in the 2001-02 academic year. This assumption is likely to be valid as there was very little effort in improving school infrastructure before 2003-04, when financial support from the government of India increased substantially. 
The main challenge in constructing the combined data is that between 1998 and 2015, new Indian states were formed from existing states and numerous districts were divided into smaller districts, revising district identifiers in each survey. To have a common identifier for each state and each district for the combined data, I manually assigned each state and district the codes used in NFHS-2. Newer districts were identified and were assigned its parent district code. The restricted sample of unmarried female children between age 6 and 18 contains 1,150,951 observations. However, due to missing values in the school data, some observations are dropped from the analysis. I restrict the analysis to children between age 6 and 18 as they are considered the typical age at which a child enters standard 1 and completes standard 12 , respectively.

Table 2.1 reports changes in the rural and urban characteristics over time, assuming SSHE took off in 2003. Both urban and rural areas have experienced significant changes in local household characteristics. In Table 2.2, I look at how the rural-urban educational gap changed in the post-2003 years from pre-2003 years and report the raw difference-in-differences figures for each level of school completion. I observe that both regions experienced an increase in completion rates, however, rural areas experienced larger increases, indicating that rural-urban educational gap has declined. It also shows the change in the available proportion of schools with female restrooms for respective levels of education. It also appears that there has been a 23-40 percentage point increase in the proportion of schools with female restrooms. It appears that for each percentage point increase in proportion of schools with female restrooms, the difference in high school completion rate between rural-urban area is reduced by 9 percentage points. Corresponding numbers for secondary, upper-primary, and primary completion rates are 13 percentage points, 23 percentage points, and 15 percentage points, respectively. It remains to see if these changes are significant after controlling for changes in regional characteristics, for which, I turn to an empirical framework described in the next section. 


\subsection{Model}

The empirical specification for estimating the effect of new toilets on schooling is given by

$$
Y_{i d t}=\alpha+\beta_{1} T_{d t}+\beta_{2} I\left(\operatorname{Rural}_{i}\right)+\beta_{3} T_{d t} \times I\left(\operatorname{Rural}_{i}\right)+\gamma X_{i t d}+\mu_{t}+\phi_{d}+\varepsilon_{i t d} \ldots \ldots \ldots \ldots . .(1),
$$

where $Y_{i d t}$ denotes educational achievement of the $i-t h$ child in district $d$ in academic year $t$. In some analyses, $Y_{i d t}$ is an indicator if child $i$ has completed primary education, upper-primary education, secondary education, or higher-secondary education and in some analyses, it is the number of years of education of child $i$ completed. $T_{d t}$ is the percentage of schools with female restrooms at different levels of education. $I\left(\right.$ Rural $\left._{i}\right)$ is an indicator for child $i$ living in a rural area. The primary interest is coefficient $\beta_{3}$, the interaction of percentage of schools with female restrooms with the rural indicator. $\beta_{3}$ is identified under two assumptions. First, rural and urban children followed similar trends in educational achievement and second, in the absence of SSHE or TSC, the trend in rural percentage of schools with female restroom follow the same trend as that before the policy introduction. I estimate $\beta_{3}$ for each level of schooling, separately, restricting the sample to appropriate age group for each set of analyses. Typically, a child enters standard 1 at age 6 and completes primary education at age 11 when she is promoted to standard 6 and thereby enters upper-primary education. Students are on average 14 years old when they complete upper primary education by passing standard 8 and start secondary schooling. If a student continues her studies without a break, she completes secondary education (standard 10) at 16 and higher secondary education (standard 12) at 18 years of age, respectively. Robust standard errors for the coefficients are calculated clustering the data at the district level.

$X_{i d t}$ is a set of control variables that includes total number of schools, percentage of school without female teachers, female literacy rate calculated using the primary 
school completion rate of women aged 15 or above, an indicator for household head being a female, household head's religion, sex of the child, dummies for age of children, number of women in the household, and an indicator for having electricity. $\mu_{t}$ are academic year fixed effect and $\phi_{d}$ are district fixed effects. Finally, $\varepsilon_{i t d}$ denotes an error term capturing other factors that may affect $i^{\prime} s$ schooling.

Among the covariates, the percentage of schools without a female teacher is important as parents may not want to send their female child to a school where no female teachers are available, for possibly security concerns. Moreover, the presence of female teachers makes it likely that the school will have separate female restrooms (Kremer et al., 2005). Female literacy rate proxies for the time varying cultural attitude towards females that is not captured by the district fixed effects. Having electricity is a proxy for development in a region (Henderson et al., 2012), as I do not observe the wealth of a family, I use having electricity as a proxy.

In separate regressions for urban and rural children on the percentage of schools with female restrooms controlling for age, district, and academic year fixed effects will allow me to interpret the estimated coefficient as the increase in the probability of school completion within every age, in a year, and within a district where the variation in the percentage of schools with female restrooms comes from SSHE initiative. Interacting percentage of schools with restrooms with a rural dummy and controlling for rural areas fixed effects merely combines two separate regressions for rural and urban areas and reflects $\beta_{3}$ in specification 1 , which shows the difference in the changes in probability of school completion due to one percentage point increase in schools with restrooms between the rural and the urban areas. 


\subsection{Results}

\subsubsection{Female Educational Outcomes}

Table 2.3 shows the higher secondary education outcome for female children. In panel A, the outcome variable is an indicator for the $i$-th child completing higher secondary education or alternatively passing standard 12 while in panel $\mathrm{B}$, it is the years of education for female children of age 16-18. Higher secondary examination is one of the two state-level/ country-level examinations that a child has to take to complete school education. It is taken at the end of standard 12 . The first and the other secondary examination is held at the end of standard 10. The certificates and scores obtained from these exams are often used later in life to qualify for taking college/university entrance examinations or to apply for jobs. Therefore, these two examinations are considered the most important examinations in school. Schools often target preparing the students for these examinations as the reputation of schools depend on the outcomes of these examinations. For female children in rural areas, this may not be an overly important factor, especially given the attitude towards these children, but they may matter on the margin for parents who want to provide quality education for their children.

The main parameter of interest is $\beta_{3}$ in equation 1 , the interaction between the percentage of higher secondary schools with female restrooms and an indicator for $i$-th child residing in a rural area. Ideally, a child finishes school at age 18 and therefore, I restrict the sample to 18 year old unmarried female children. Consequently, the age dummy is dropped from the set of control variable in equation 1. Column 1 shows the estimates without any fixed effects or additional regressors. The estimate shows that a one percentage point increase in the proportion of higher secondary schools with female restrooms increases higher secondary completion rate for rural female children by 7 percentage points. The results in column (1) are robust to adding years and district level fixed effects (column (2)). 
When regressors to control for household and local area characteristics are added to the specification (column (3)), it appears that the interaction between percent of higher secondary schools with female restrooms and rural residence of child $i$ is correlated to the area and household characteristics and omitting them causes a positive bias in estimating $\beta_{3}$. Well off families may invest more in the education of their children and relatively wealthier rural areas may have more improved higher secondary schools than poorer areas. Controlling for the local characteristics approximates standard of living of the families in that area and therefore, it reduces the magnitude and takes away the significance of $\beta_{3}$.

Higher secondary education demands significantly more efforts than an internal mid-term examination. Given this requirement, education cost is often higher as students pay tuition and buy more books. Education is free up to upper primary level in public schools, beyond which, parents need to pay school tuition. As a result, there is a significant difference in the proportion of children continuing education after they complete upper-primary education, particularly in the rural areas.

In column (4), I restrict the sample further to those 18-year old children who have completed secondary education. I find a 5 percentage points increase in higher secondary completion rate for rural female children. The restricted sample differs significantly in terms of wealth-related household characteristics, 89.6 percent of the children have electricity in their household compared to 81 percent in the full sample. 68 percent of children have toilets in their household compared to 57 percent of children in the sample used in column (3). Finally, 72 percent children have a television in their household compared to 58 percent children in the full sample. Together, these differences may indicate that the sample of 18 year old children who completed secondary education differ from the rest of the sample in terms of family income. Only these parents could harness the benefit of having female restrooms in schools by sending their female children to schools, resulting in a marginally significant increase in completion rates. 
In panel B, the sample is restricted to 16-18 years old children who would typically attend higher secondary education. I estimate equation (1) without any covariates or fixed effects in column (5) and find 1.06 years increase in the years of schooling for female children between 16 and 18. Adding district and year fixed effects in column (6) increase the coefficient to 1.27 years. In column (7), I add the remaining covariates and estimate the fully specified equation (1). The estimate indicates that a one percentage point increase in the proportion of higher secondary schools with female restroom is associated with 0.48 more years of education. However, not everyone in the sample will actually attend standard 11-12 because some children will fall behind due to grade repeat, missed years of schooling, and dropping out of school earlier. Moreover, schools with higher secondary education may have other levels of education (such as secondary education) and since a restroom use is not grade specific, the estimate likely reflects an increase in years of schooling that includes years gained in secondary education or in other levels of education- I explore this possibility later in the analysis for secondary, upper-primary, and primary education.

To see if years of education has increased among rural female children who have completed secondary education, I exclude children with years of education less than 10 in column (8) (similar to column (4)). These children do not obtain any significant increase in the years of education as a result of more female restrooms. Again, these restricted sample has children who belong to a wealthier family, therefore, they were likely to afford education nevertheless and hence, no significant increase in the number of years of education.

Taking column (3) and (7) together in Table 2.3, students between 16-18 years are getting more years of education than before the SSHE initiative but are not completing higher secondary education at higher rates than before the initiative. On the other hand, in column (4) and (8), students who have completed secondary education and are likely from better-off families, have not gained any significant years of education from restroom building but are completing higher secondary education 
than before. It is not immediately clear why there is no increase in years of education yet a significant increase in completion rate. One possible explanation is that these children were attending schools further from their residence before the SSHE initiative and such long commutes left them little time and energy to focus on their studies completely. After restrooms were built in nearby schools, they chose to enroll in a nearby school and gained time to study for final exams. Unfortunately, I cannot evaluate this hypothesis because I do not observe the distance of the school they attended.

Column (3), column (7), and column (8) together imply that students who dropped out, repeated grades or enrolled late in school are continuing their education. As seen from years gained in column (7), for full sample who do not complete higher secondary education rates than before the initiative (column (3)). The increase in the number of years of education are absent for female children who are in grade for their age (column (8)), thus the gain is likely to be coming from those who were left behind.

I follow similar exercises for secondary education. The results are shown in Table 2.4. In the interest of space, I focus the discussion of results on the preferred specification with household and local characteristics shown in columns (3), (4), (7), and (8). Between 14-16 years, children are likely to attend secondary education and at 16 years, a child is likely to have completed secondary education. For rate of completion in panel $\mathrm{A}$ in Table 2.4, therefore, I look at children within 16-18 years of age. I observe one percentage point increase in schools with female restroom is associated with 6 percentage points increase in secondary school completion for rural female children. For children who have completed upper primary education, the increase is 4 percentage points. The corresponding increase in the years of education are 0.63 and 0.02 years (column (7) and column (8)), respectively. Unlike higher secondary education, there is an increase in secondary completion rate in Column (3), perhaps because students who dropped out earlier were coming back to complete secondary education and obtain their first state level educational certificate, which is considered 
the minimum requirement in applying for jobs or for further education.

Next, I examine the effect of an increase in female restrooms on upper primary and primary education. The results for completion rates and years of education are shown in Tables 2.5 and 2.6. The main difference in the analyses of these two levels of education is that, unlike secondary and higher secondary education, primary and upper primary education is free in public schools. In case of upper primary schooling, a one percentage point increase in female restrooms is associated with a 13 percentage points increase in completion rates and 0.58 years increase in the years of upper-primary education among rural female children. The corresponding increases for primary schooling are 9 percentage points and 0.25 years, respectively. Upper primary female students are most likely to experience monthly menstruation for the first time so it is not unreasonable to observe the largest effect for these children, as they can obtain free education while having a safe and separate sanitation system in school.

Children who dropped out, repeated grades or had enrolled in grades later for their age are continuing their education and completing secondary, upper-primary, and primary education at higher rates after SSHE initiative, as seen from columns (3) and (7) of Tables (4) - (6). The coefficient in column (3) is at least as large as that in column (4) and the coefficient in column (7) is at least as large as that in column (8). Columns (4) and (8) restrict the sample to those who are in grade for their age. The presence of increase in the years of education and the absence of completion of higher secondary education of children 16-18 years old in Table (3) reinforce the result that those who fell behind are more likely to complete the lower grades of education following the increase in the percentage of schools with female restrooms. These results suggest that the SSHE policy initiative was successful in improving educational outcomes among female children. 


\subsubsection{Additional Results}

In this section, I further explore the effect of the SSHE initiative on sub-populations of interest other than female children. I examine any possible benefits for two such samples: male children 18 years or younger and children residing in low-income states in India. Studying the effect of restrooms on male children allows us to understand whether the benefits of building separate restrooms were limited to female children only and if not, it lets us compare the magnitude of the effects for the two sexes. Section 5.2.1 focuses on the effects of male children. On the other hand, the subset of low-income states in India is of special interest as they are expected to have the least proportion of schools with female restrooms. Economic theory predicts that marginal benefits are larger when inputs are low, so we can expect provision of restrooms in schools in the poorest areas will have larger benefits. Section 5.2.2 examines this possibility.

\subsubsection{Effect on Male Children}

I estimate the model of educational outcomes for male children while continuing to focus on the interaction between proportion of schools with female restrooms and rural residence. The data do not report percent of schools with boys restrooms for majority of the years. However, it can be assumed that if a school has a separate restroom for females, it also has a separate restroom for males. Also, the SSHE program had the objective of building separate school restrooms for both sexes, therefore, it can be assumed the proportion of schools with male restrooms and female restrooms grew at the same rate.

Increases in the percentage of schools with male restrooms did not have significant effect on high school completion rates (Table 2.7), even when the sample is restricted to those who have completed secondary education. In contrast, female children who completed secondary education gained from restroom building in schools. The lack of significant effects on educational outcomes for male children suggests the importance 
of a separate restrooms for female children.

For male children, however, there are significant increases in secondary (Table 2.8), upper-primary (Table 2.9), and primary completion rates (Table 2.10) associated with increases in schools with restrooms. The effects are almost always stronger for female children except for secondary schooling. A possible reason could be that, culturally, male children are assumed to earn for their families and therefore, having a certificate on a state/nationally recognized exam is important as passing secondary education is the minimum educational qualification for many public sector jobs that pay secured income with additional benefits until the age of retirement and pension afterwards. Consequently, there is a 7 percentage point increase in the secondary school completion rates associated with one percentage point increase in schools with restrooms (Table 2.8 column (3) ).

\subsubsection{Effect in Low Income States}

India's economic growth in the first decade of the millennium was around 6 percent. However, the positive effects of the growth were not spread equally among all the states and some low-income states remained the poorest in the country (The World Bank, 2018). These states were Bihar, Chhattisgarh, Jharkhand, Madhya Pradesh, Odisha, Rajasthan, and Uttar Pradesh. In the analysis that follows, I divide the sample into two groups of states- one for these states which I refer to as 'backward states' and the rest into another group that I refer to as 'forward states'.

Table 2.11 presents the estimates from model 1 for the two groups. Panel A and B show the results for female children belonging to backward and forward states, respectively. For brevity, I report only the results for estimating a fully specified model (corresponding columns (3), (4), (7), and (8) in Tables 3-10). Each panel reports the results for completing higher secondary, secondary, upper primary, and primary education. For each level of education, I also restrict the sample to those children who are at age for their grade, and estimate the same model, as to understand 
to what extent the overall estimates are influenced by children who did not fall behind in terms of completing the grades.

The effect of increased school restroom provision is almost always stronger for the backward states in Panel A compared to the forward states in Panel B. The benefit of having restrooms in schools gradually fades as we move up the levels of education from primary to higher secondary, in both backward and forward states. Female children in backward states benefits significantly from restroom provision in school as 7 percentage points more children are completing secondary education due to one percentage points more schools with restrooms. Similar benefits are absent for female children in forward states. This highlights the importance of supply side factors, such as restroom provision in human capital development. Poorer areas are not able to improve their standard of living because necessary supplies are not available, although there could be demand for them. Paxson and Schady (2002) finds similar results from Peru's school investment in the poorest areas.

As before, any positive effect at any level of education is considerably driven by those who completed all previous levels of education. For example, in backward states, at the secondary level, there is a 7 percentage points increase in the completion rates, and more than fifty-percent of this effect follows from those who completed the upper primary levels. Also, the largest benefits of these programs are observed for the upperprimary school children, most of whom are entering adolescence, in both backward and forward states. The trend of the effects are similar for years of education, as reported in Table 2.12. For males, a strong effect exist at the secondary level apart from the upper primary level (Table 2.13 and Table 2.14), possibly because of the stated importance of passing the secondary level exam.

\subsection{Conclusion}

Historically, India's rural-urban education gap has been consistently large in terms of education, specifically for female children. Rural areas fall behind urban areas as 
they lack proper infrastructure to provide life's basic necessities such as education and healthcare. I study the effect of constructing female restroom in schools in the districts of India through a national school sanitation system initiative focused on the rural areas. Using an individual data from multiple sources and aggregate school data at the district level, I examine whether female restroom provision in schools improved the educational outcomes of the rural children.

To summarize, I examine the effects of having female restrooms in schools on school completion rates of female children, using variation introduced by the School Sanitation and Hygiene Education program as a part of the Total Sanitation Campaign in India. I find that for one percentage point increase in rural school restroom provision, female education completion rates for secondary, upper-primary, and primary education have gone up, implying a reduction in the rural-urban educational gap for female children following the SSHE initiative to build restrooms in schools. However, similar benefits for high school completion are only observed for female children who completed secondary education - an effect which is absent for male children completing secondary education, implying restroom provision is more beneficial for female children. The effects are largest for female children entering adolescence. Furthermore, female children in low income states in India benefit more from having female restrooms than the middle and high-income states.

Under reasonable assumptions, I find that separate restrooms can benefit male children also. However, except for secondary school completion, estimates are larger for female children. Completion of secondary schooling is often a precondition for many public sector jobs and since men are culturally assumed to be the breadwinner for the family, male children opt for more secondary education, following school restroom building.

The estimates are consistent with Adukia, 2017, who estimates the effect of having restroom on school enrollment and drop out rates, both of which showed effects between 5- 12 percentage points. The paper also finds both male and female students 
benefited from building restrooms in schools. The effects likely reflect safety as well as health benefits for all children. Given the large population in India, schools are likely to be overpopulated and the spread of infectious diseases among school children is easier in an unhygienic environment. Having school restrooms are associated not only with privacy but also with curbing the spread of many infectious diseases.

Moreover, SSHE initiative also educated school children and their parents about the essential hygiene practices such as to wash hands properly after using restrooms. Children following these practices at school and home are more likely to stay healthier than before. Hence, the estimates generated in this paper reflect a combined effect of safety, privacy, and healthy behavior rather than simply restroom provision bringing female children back to school.

Finally, building female restroom may have an effect on the age of marriage of female children, which is another channel of discrimination towards female children. Parents may decide to allow their female children to continue their education given a safer environment which may push the age of marriage up. Thus, school infrastructure improvement may have important positive spillover effects beyond the immediate gains in human capital. 


\subsection{Appendix}

The school data from District Information System for Education reports female restroom availability for five discrete categories of schools in India. They are primary only (standard 1-5), primary with upper primary (standard 1-8), primary with secondary and higher secondary (standard 1-5 \& 9-12), upper primary only (standard 6-8), and upper primary with secondary and higher secondary (standard 8-12). Using these variable, I create the following measures used in the paper for percentage of schools with female restrooms for primary, upper primary, secondary, and higher secondary level of education, respectively.

1. Percentage of schools with female restrooms providing primary education $=($ Primary only schools with female restrooms + Primary with upper primary schools with female restroom + primary with secondary and higher secondary with female restroom)/ (Total primary only schools + primary with upper primary only schools + primary with secondary and higher secondary only schools)

2. Percentage of schools with female restrooms providing upper primary education $=($ Primary with upper primary schools with female restroom + upper primary only schools with female restroom + upper primary with secondary and higher secondary schools with female restrooms)/ (Primary with upper primary schools + upper primary only schools + upper primary with secondary and higher secondary schools)

3. Percentage of schools with female restrooms providing secondary/higher secondary education $=($ primary with secondary and higher secondary schools with female restroom + upper primary with secondary and higher secondary schools with female restrooms)/ (primary with secondary and higher secondary schools + upper primary with secondary and higher secondary schools)

4. Percentage of schools providing primary education without female teachers $=$ (Primary only schools without female teachers + Primary with upper primary 
schools without female teachers + primary with secondary and higher secondary without female teachers)/ (Total primary only schools + primary with upper primary only schools + primary with secondary and higher secondary only schools)

5. Percentage of schools providing upper primary education without female teachers $=($ Primary with upper primary schools without female teachers + upper primary only schools without female teachers + upper primary with secondary and higher secondary schools without female teachers)/ (Primary with upper primary schools + upper primary only schools + upper primary with secondary and higher secondary schools)

6. Percentage of schools providing secondary/higher secondary education without female teachers $=($ primary with secondary and higher secondary schools without female teachers + upper primary with secondary and higher secondary schools without female teachers)/ (primary with secondary and higher secondary schools + upper primary with secondary and higher secondary schools) 
Tables 
Table 2.1: Urban - Rural change over time descriptive

\begin{tabular}{|c|c|c|c|c|c|c|}
\hline & \multicolumn{3}{|c|}{ Rural } & \multicolumn{3}{|c|}{ Urban } \\
\hline & Post-2003 & Pre-2003 & Diff & Post-2003 & Pre-2003 & Diff \\
\hline \multirow{3}{*}{$\begin{array}{l}\% \text { Adult with Primary } \\
\text { Edu }\end{array}$} & $0.79^{* * *}$ & $0.71^{* * *}$ & $0.08^{* * *}$ & $0.83^{* * *}$ & $0.79^{* * *}$ & $0.04^{* * *}$ \\
\hline & & & & & & \\
\hline & $(0.005)$ & $0.01)$ & $(0.01)$ & $(0.005)$ & $(0.008)$ & $(0.009)$ \\
\hline \multirow[t]{2}{*}{ Head of HH Female } & $0.10^{* * *}$ & $0.07^{* * *}$ & $0.03^{* * *}$ & $0.11^{* * *}$ & $0.08^{* * *}$ & $0.03^{* * *}$ \\
\hline & $(0.004)$ & $(0.003)$ & $(0.004)$ & $(0.004)$ & $(0.003)$ & $(0.003)$ \\
\hline \multirow[t]{2}{*}{ Religion is Hindu } & $0.75^{* * *}$ & $0.81^{* * *}$ & $-0.07^{* * *}$ & $0.66^{* * *}$ & $0.73^{* * *}$ & $-0.06^{* * *}$ \\
\hline & $(0.016)$ & $(0.015)$ & $(0.014)$ & $(0.017)$ & $(0.014)$ & $(0.014)$ \\
\hline \multirow[t]{2}{*}{ Females in $\mathrm{HH}$} & $3.05^{* * *}$ & $2.91^{* * *}$ & $0.13^{* * *}$ & $2.94^{* * *}$ & $2.96^{* * *}$ & $-0.02^{* * *}$ \\
\hline & $(0.020)$ & $(0.06)$ & $(0.07)$ & $(0.027)$ & $(0.10)$ & $(0.11)$ \\
\hline \multirow[t]{2}{*}{ Has Electricity } & $0.67^{* * *}$ & $0.55^{* * *}$ & $0.12^{* * *}$ & $0.93^{* * *}$ & $0.90^{* * *}$ & $0.03^{* * *}$ \\
\hline & $(0.013)$ & $(0.017)$ & $(0.014)$ & $(0.005)$ & $(0.008)$ & $(0.008)$ \\
\hline \multirow{2}{*}{ Has Water Supply } & $0.78^{* * *}$ & $0.57^{* * *}$ & $0.22^{* * *}$ & $0.78^{* * *}$ & $0.71^{* * *}$ & $0.07^{* * *}$ \\
\hline & $(0.012)$ & $(0.014)$ & $(0.015)$ & $(0.009)$ & $(0.01)$ & $(0.01)$ \\
\hline \multirow[t]{2}{*}{ Has Toilet } & $0.37^{* * *}$ & $0.23^{* * *}$ & $0.14^{* * *}$ & $0.80^{* * *}$ & $0.67^{* * *}$ & $0.13^{* * *}$ \\
\hline & $(0.015)$ & $(0.013)$ & $(0.013)$ & $(0.009)$ & $(0.015)$ & $(0.016)$ \\
\hline \multirow[t]{2}{*}{ Has Radio } & $0.21^{* * *}$ & $0.33^{* * *}$ & $-0.13^{* * *}$ & $0.24^{* * *}$ & $0.47^{* * *}$ & $-0.23^{* * *}$ \\
\hline & $(0.006)$ & $(0.007)$ & $(0.009)$ & $(0.007)$ & $(0.010)$ & $(0.012)$ \\
\hline \multirow[t]{2}{*}{ Has TV } & $0.38^{* * *}$ & $0.28^{* * *}$ & $0.10^{* * *}$ & $0.78^{* * *}$ & $0.72^{* * *}$ & $0.06^{* * *}$ \\
\hline & $(0.010)$ & $(0.009)$ & $(0.009)$ & $(0.008)$ & $(0.010)$ & $(0.009)$ \\
\hline \multirow[t]{2}{*}{ Has Bicycle } & $0.52^{* * *}$ & $0.49^{* * *}$ & $0.04^{* * *}$ & $0.52^{* * *}$ & $0.57^{* * *}$ & $-0.05^{* * *}$ \\
\hline & $(0.013)$ & $(0.014)$ & $(0.013)$ & $(0.014)$ & $(0.016)$ & $(0.014)$ \\
\hline Female Political & 0.09 & $0.08^{* * *}$ & 0.002 & $0.09^{* * *}$ & $0.09^{* * *}$ & -0.003 \\
\hline \multicolumn{7}{|l|}{ Candidate } \\
\hline \multirow{3}{*}{ Age } & $(0.002)$ & $(0.003)$ & $(0.003)$ & $(0.003)$ & $(0.005)$ & $(0.006)$ \\
\hline & $11.73^{* * *}$ & $11.76^{* * *}$ & $-0.03^{* * *}$ & $12.21^{* * *}$ & $12.37^{* * *}$ & $-0.16^{* * *}$ \\
\hline & $(0.025)$ & $(0.033)$ & $(0.03)$ & $(0.014)$ & $(0.030)$ & $(0.03)$ \\
\hline $\mathrm{N}$ & 664,466 & 111,358 & 775,824 & 212,325 & 52,962 & 265,287 \\
\hline
\end{tabular}

Sample is for female children between $6-18$ years. ${ }^{* * *},{ }^{* *}$, and ${ }^{*}$ indicate significance at the $1 \%, 5 \%$, and $10 \%$ level, respectively. Robust standard errors clustered at district are reported in brackets. 


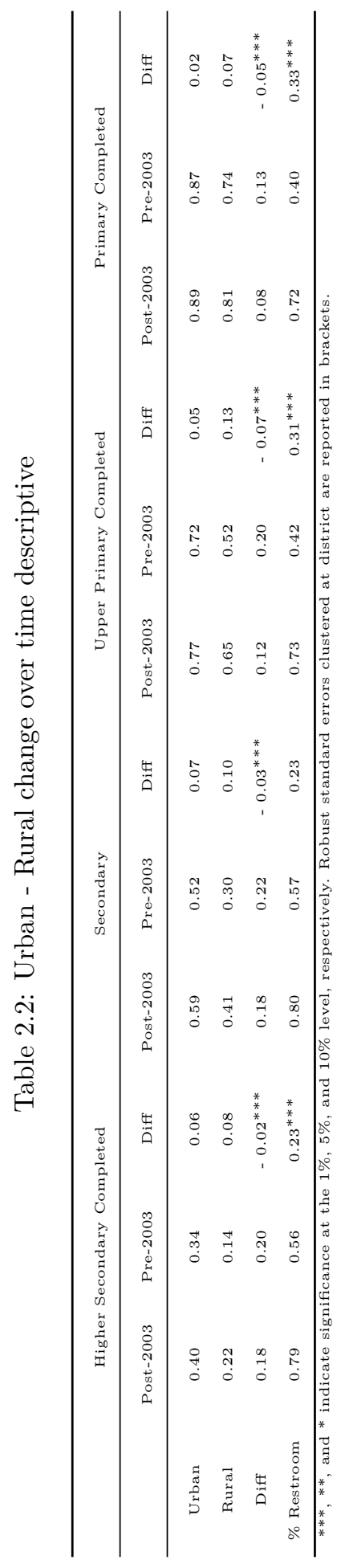


Table 2.4: Effect of Percent of Schools with Female Restrooms on Secondary Schooling

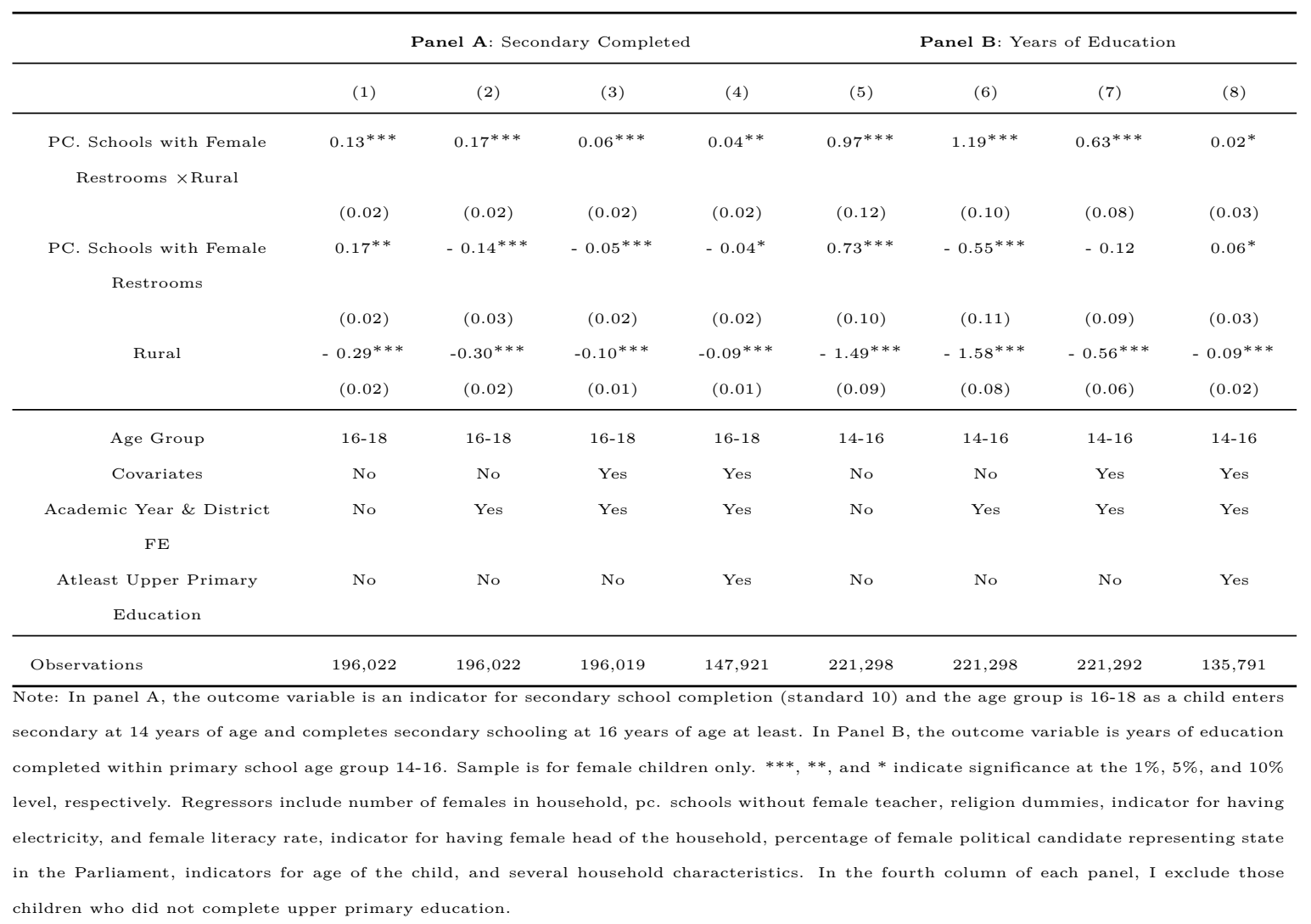


Table 2.6: Effect of Percent of Schools with Female Restrooms on Primary schooling

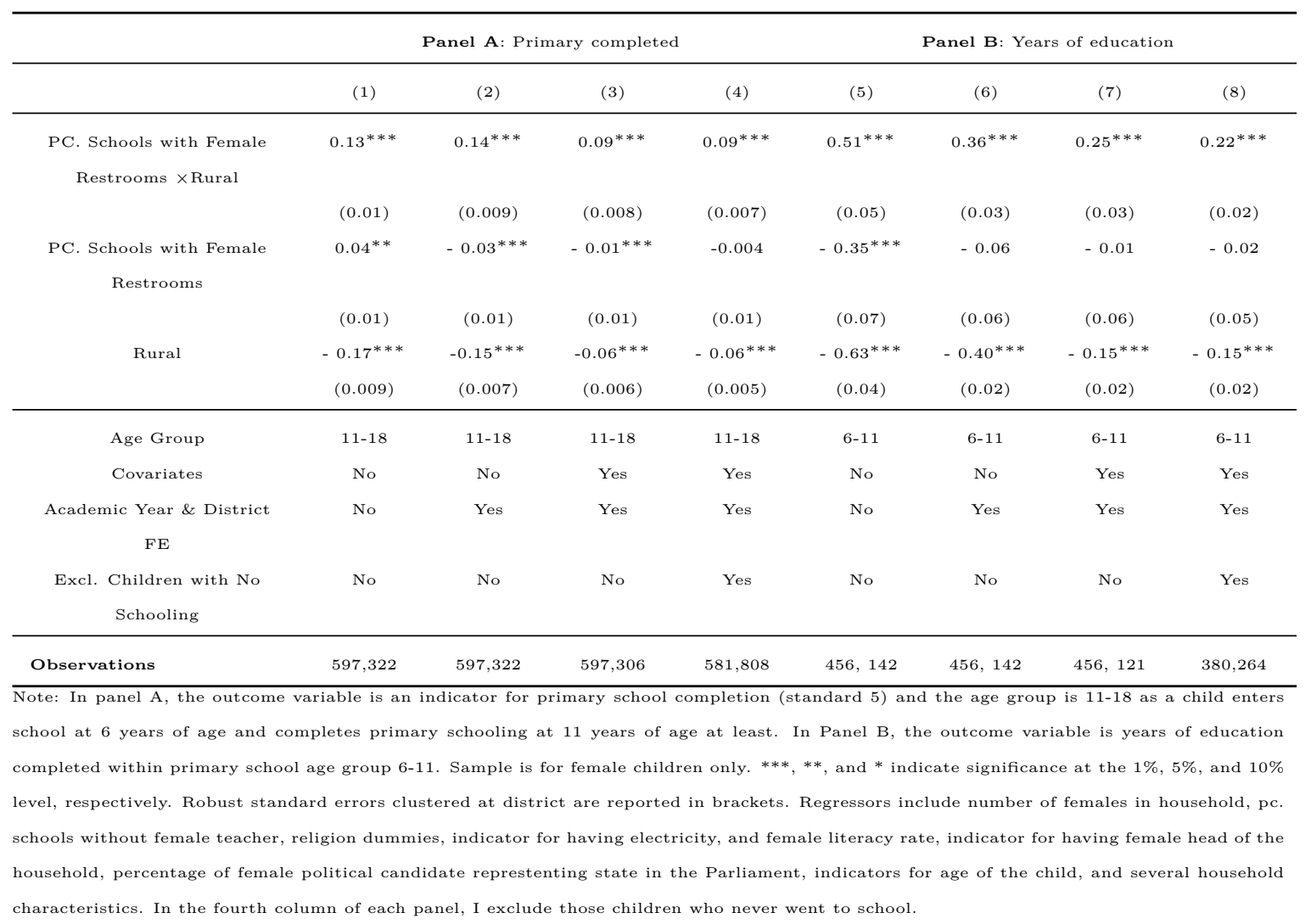


Table 2.8: Effect of Percent of Schools with Restrooms on Secondary Schooling for male children

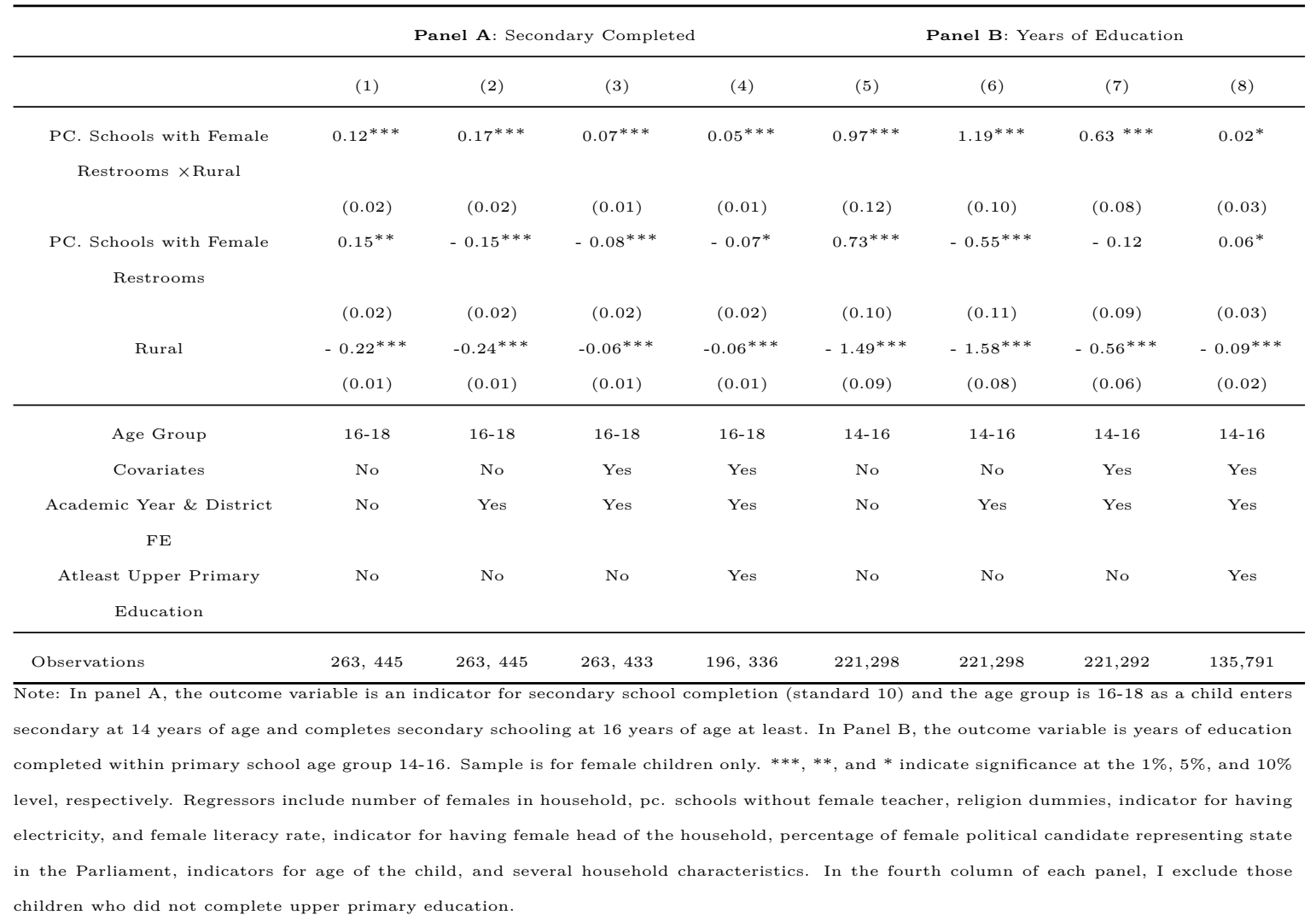


Table 2.10: Effect of Percent of Schools with Restrooms on Primary Schooling for Male Children

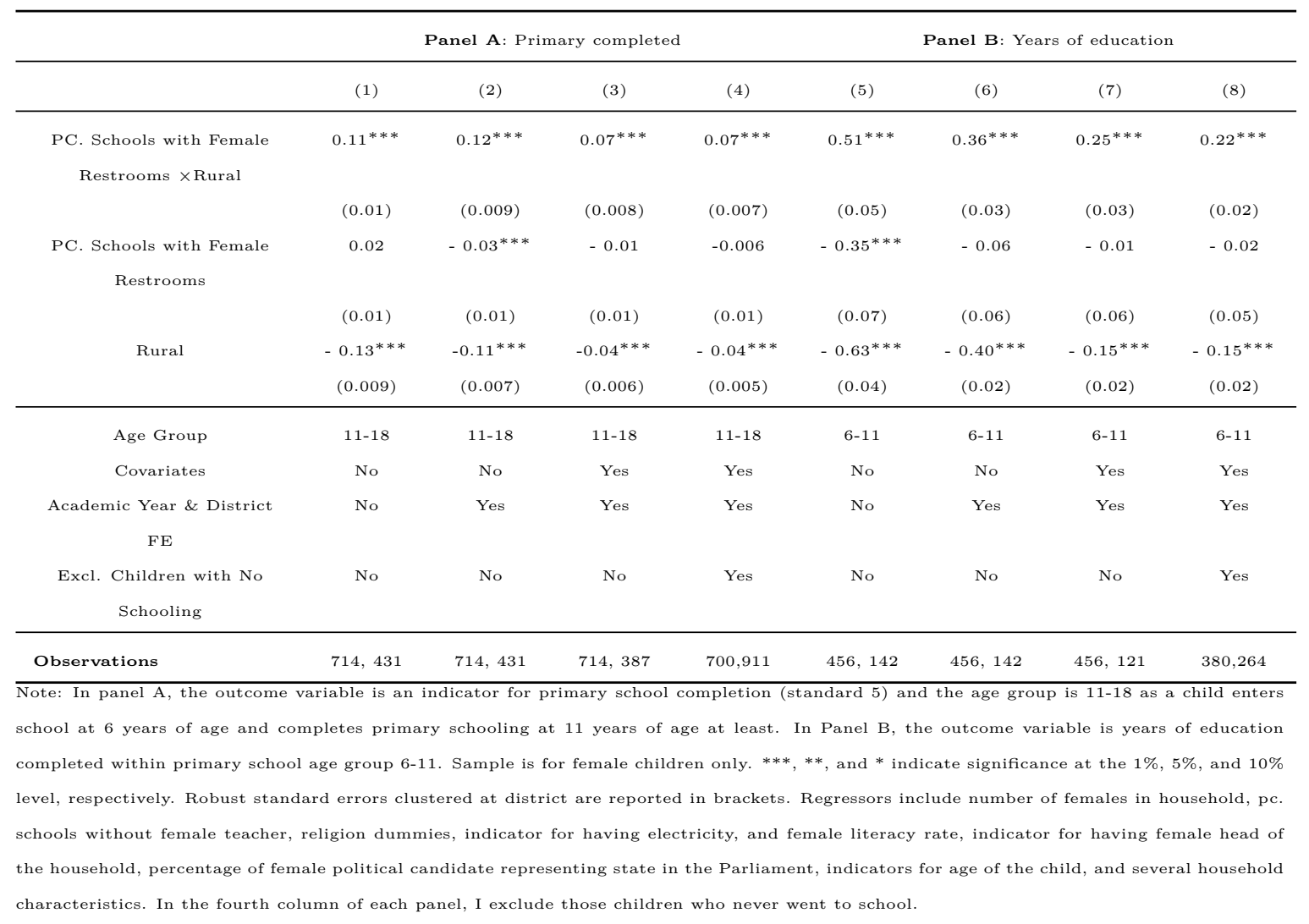

Table 2.11: Effect of Percent of Schools with Female Restrooms on School Completion Rates

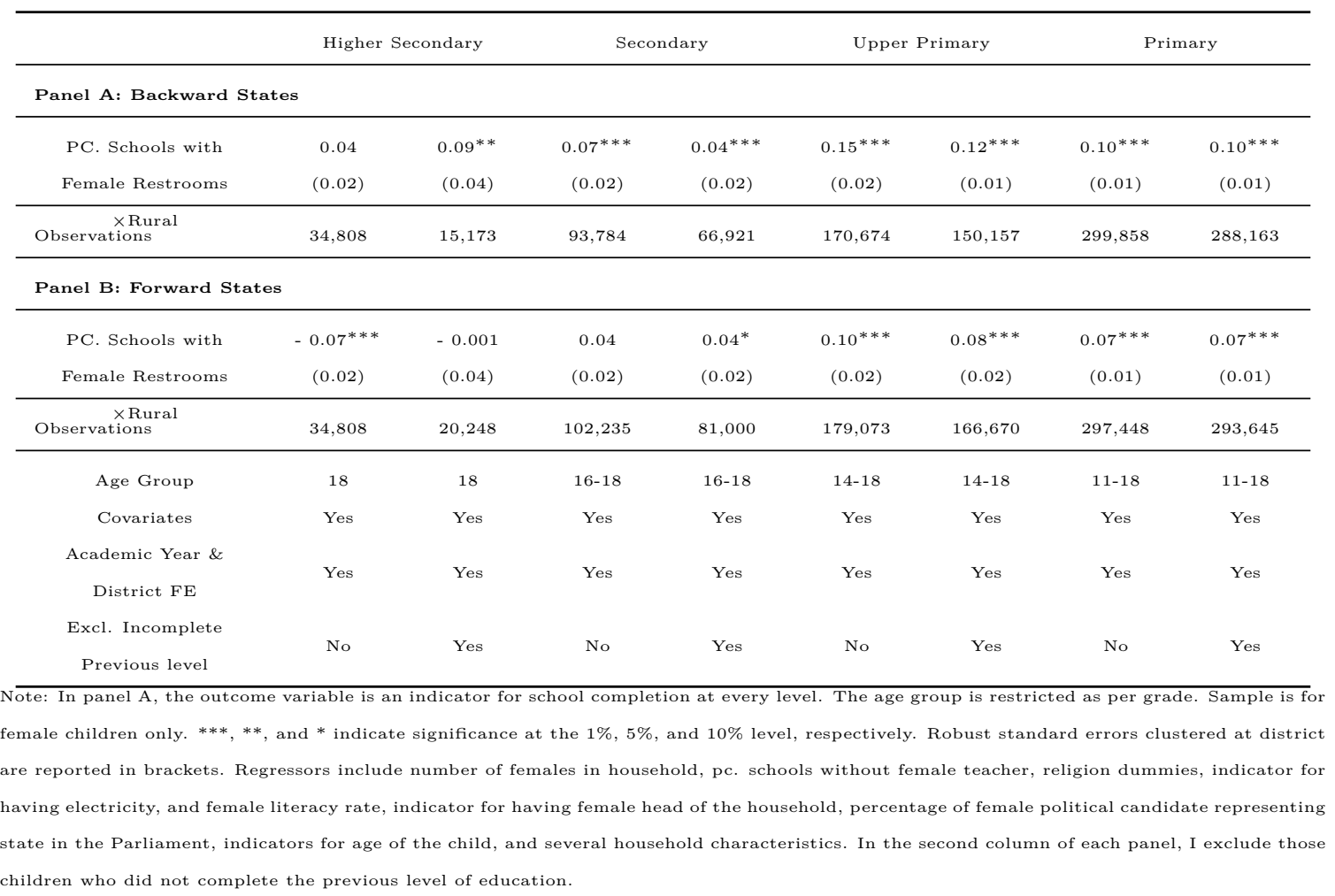


Table 2.12: Effect of Percent of Schools with Female Restrooms on Years of Education

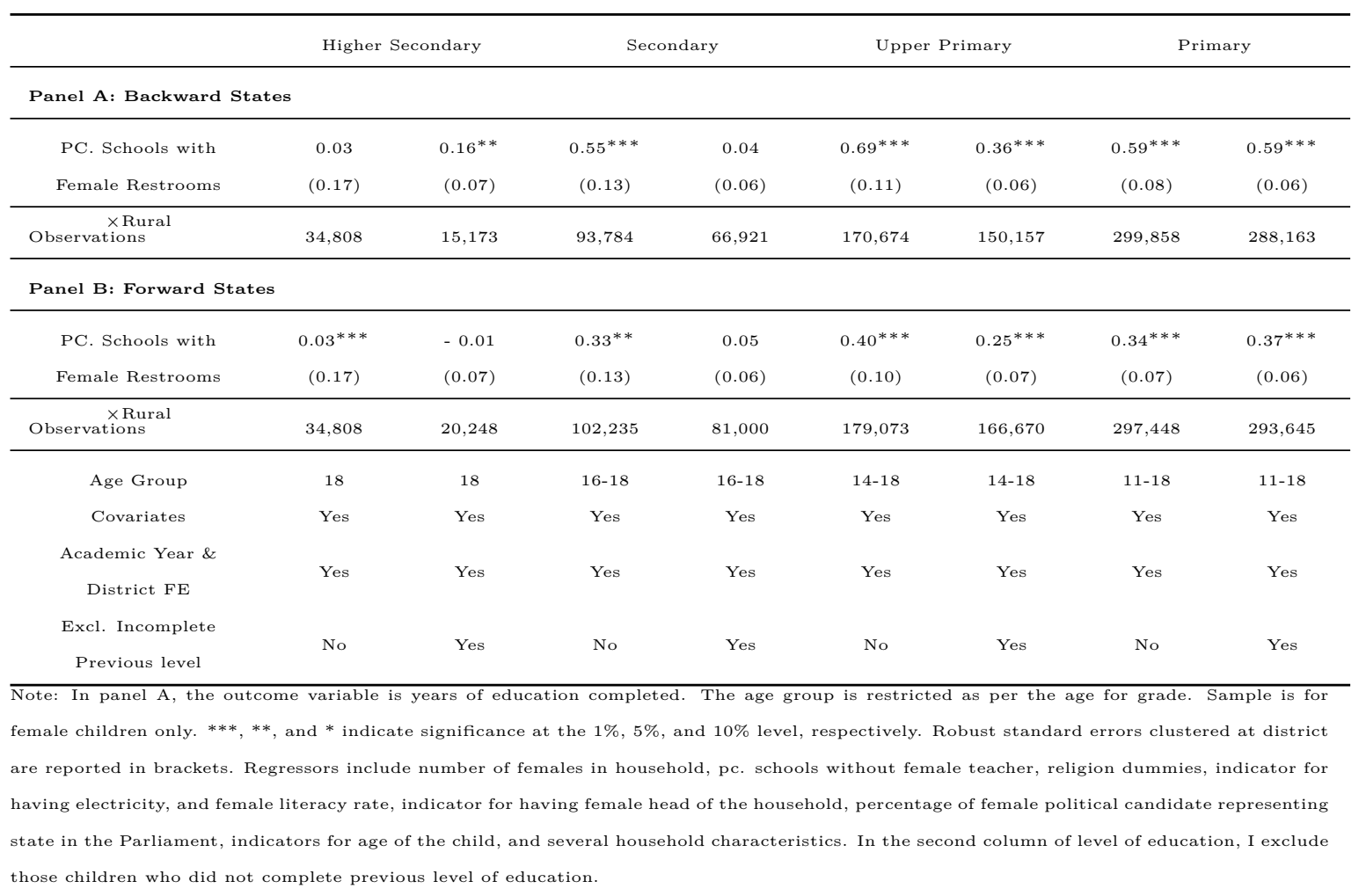

Table 2.13: Effect of Percent of Schools with Restrooms on School Completion Rates

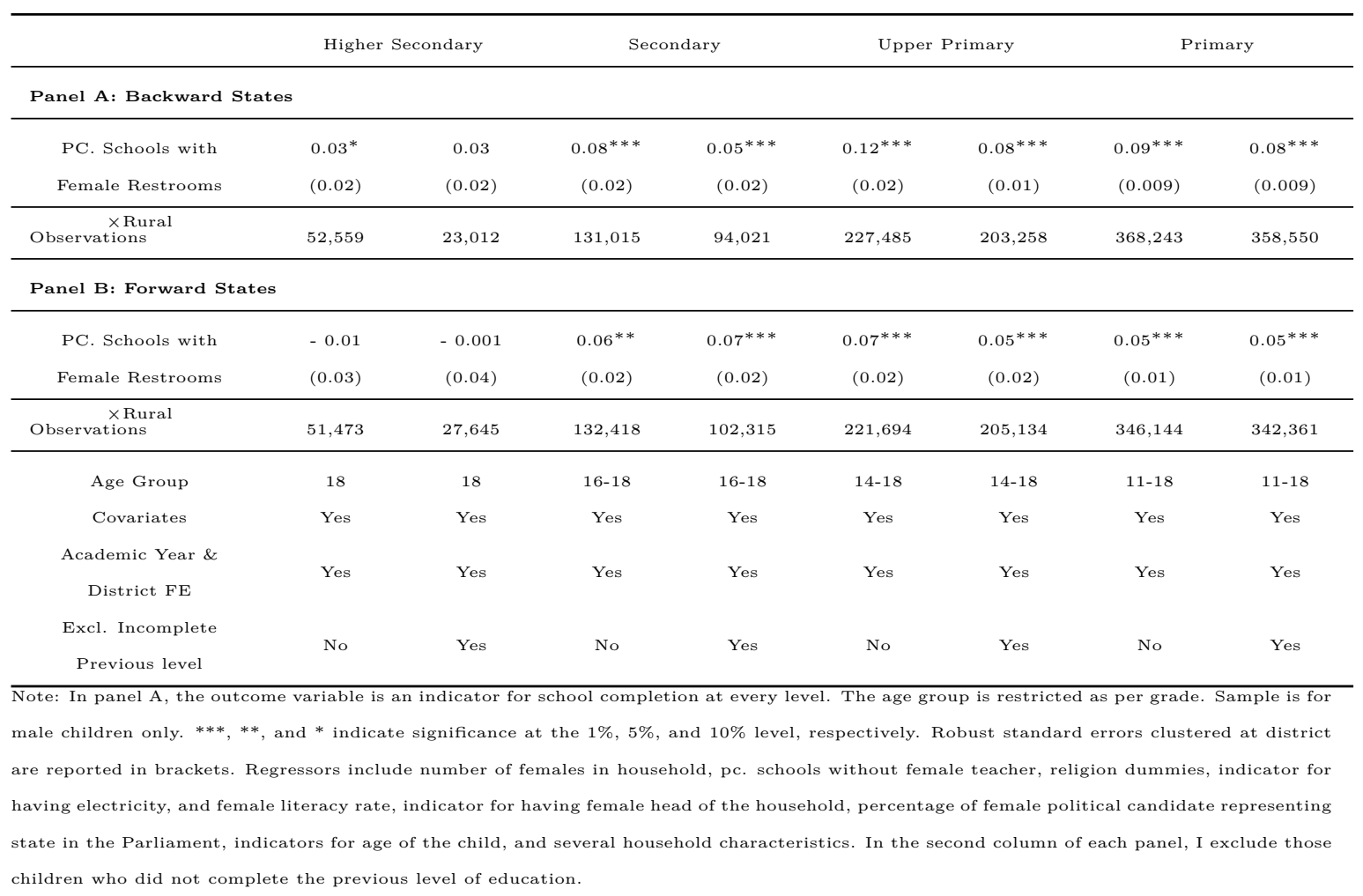


Table 2.14: Effect of Percent of Schools with Restrooms School on Years of Education

\begin{tabular}{|c|c|c|c|c|c|c|c|c|}
\hline & \multicolumn{2}{|c|}{ Higher Secondary } & \multicolumn{2}{|c|}{ Secondary } & \multicolumn{2}{|c|}{ Upper Primary } & \multicolumn{2}{|c|}{ Primary } \\
\hline PC. Schools with & $0.58^{* * *}$ & -0.005 & $0.57^{* * *}$ & 0.01 & $0.68^{* * *}$ & $0.27^{* * *}$ & $0.56^{* * *}$ & $0.26^{* * *}$ \\
\hline Female Restrooms & $(0.15)$ & $(0.05)$ & $(0.12)$ & $(0.05)$ & $(0.10)$ & $(0.06)$ & $(0.07)$ & $(0.07)$ \\
\hline$\underset{\substack{\times \text { Rural } \\
\text { Observations }}}{ }$ & 52,559 & 23,012 & 131,015 & 94,021 & 227,485 & 203,258 & 368,243 & 358,550 \\
\hline \multicolumn{9}{|c|}{ Panel B: Forward States } \\
\hline PC. Schools with & $0.30^{*}$ & 0.05 & $0.47^{* *}$ & $0.15^{* *}$ & $0.37^{* * *}$ & $0.20^{* * *}$ & $0.24^{* * *}$ & $0.26 * * *$ \\
\hline Female Restrooms & $(0.18)$ & $(0.07)$ & $(0.14)$ & $(0.06)$ & $(0.10)$ & $(0.08)$ & $(0.07)$ & $(0.07)$ \\
\hline$\underset{\substack{\times \text { Rural } \\
\text { Observations }}}{\text { Ond }}$ & 51,473 & 27,645 & 132,418 & 102,315 & 221,694 & 205,134 & 346,144 & 342,361 \\
\hline Age Group & 18 & 18 & $16-18$ & $16-18$ & $14-18$ & $14-18$ & $11-18$ & $11-18$ \\
\hline Covariates & Yes & Yes & Yes & Yes & Yes & Yes & Yes & Yes \\
\hline $\begin{array}{c}\text { Academic Year \& } \\
\text { District FE }\end{array}$ & Yes & Yes & Yes & Yes & Yes & Yes & Yes & Yes \\
\hline $\begin{array}{c}\text { Excl. Incomplete } \\
\text { Previous level }\end{array}$ & No & Yes & No & Yes & No & Yes & No & Yes \\
\hline \multicolumn{9}{|c|}{$\begin{array}{l}\text { Note: In panel } \mathrm{A} \text {, the outcome variable is years of education completed. The age group is restricted as per the age for grade. Sample is for male } \\
\text { children only. } * * *, * * \text {, and } * \text { indicate significance at the } 1 \%, 5 \% \text {, and } 10 \% \text { level, respectively. Robust standard errors clustered at district are } \\
\text { reported in brackets. Regressors include number of females in household, pc. schools without female teacher, religion dummies, indicator for } \\
\text { having electricity, and female literacy rate, indicator for having female head of the household, percentage of female political candidate representing }\end{array}$} \\
\hline
\end{tabular}




\title{
Chapter 3
}

\author{
Terrorism and Early Childhood Health Outcomes: \\ Evidence from Pakistan (Co-authored with Umair Khalil \& Daniel \\ Grossman)
}

\subsection{Introduction}

Early childhood, including the in-utero period, is an important developmental period (see e.g. Heckman 2006; Barker 1990). Violence and other stressors can have negative effects on the health of both mothers and their children. Thus, violent incidents suffered in-utero and in early childhood can have critical impacts on childhood and later life health and human capital outcomes (see e.g., Barker, 1990; Almond and Currie, 2011). Terrorism and violent attacks on civilian populations are examples of events that may lead to increased stress and negative health outcomes for children, and they have increased precipitously across the globe in recent decades (Backer et al., 2016). These events lead to fatalities, destroy infrastructure, and create an environment of fear, which can have both short- and long-term consequences on health and affect health through numerous potential mechanisms.

A drastic and sudden rise in terrorist and violent incidents in Pakistan has occurred since the mid 2000s after more than a decade of relative peace, as depicted in Figure A.3. According to the Global Terrorism Database, around $13 \%$ of attacks worldwide occurred in Pakistan from 2006-2011, our study period (GTDNational Consortium for the Study of Terrorism and Responses to Terrorism (START), 2018). Further- 
more, Pakistan already fares poorly in basic health indicators: it ranks 8th highest in the world in proportion of children under 5 being stunted (WHOUnited Nations Children's Fund, World Health Organization, The World Bank, 2018); it has the 6th lowest health expenditure to GDP ratio; and it has only 0.6 hospital beds per 1000 people (WHO World Health Organization, 2018).

In this paper, we explore whether exposure to terrorist incidents contributes to worse health outcomes among young children in Pakistan, specifically those aged between 0 and 5 years. We exploit spatial and temporal variation in the occurrence of terrorist incidents across tehsils (sub-districts) in the Pakistani province of Punjab. We focus on exposure to terrorist attacks, both in-utero and post-birth, and study its effect on a variety of health outcomes. Our main outcome variables are binary indicators for the child being stunted or wasted (classified low weight) based on z-scores for age and gender. Measures based on height are considered particularly crucial variables to study in early childhood development in developing countries (Currie and Vogl, 2013). Long term effects of stunting are important given the documented relationships between stature and cognitive ability and eventual labor market outcomes (Case and Paxson, 2008). On the other hand, weight outcomes might be more likely to capture fluctuations in nutrition and other needs of the child in the short run. Vaccination take-up represents a potential mechanism through which exposure to violence may affect health and is a potential marker of health care access.

It is crucial to note that for our analysis to estimate plausibly causal impacts of exposure to terrorism, the employed research design first must handle the potential endogeneity of the incidence of terrorism. For instance, one can expect terrorist attacks not to be randomly 'assigned' across space and time, which can then manifest itself in correlations between tehsil level characteristics and likelihood of terrorist incidents. While we do not observe an exhaustive list of tehsil level measures, we can check the existence of such correlations using individual and household level measures from our survey data. Isolating variation in terrorism within tehsils by employing 
fixed effects is likely to allay such potential selection issues as detailed in section 3.2. Furthermore, one might still be concerned that the actual number of attacks instead can be correlated with some unobservable characteristics of the target population even after controlling for time invariant spatial fixed effects. Therefore, in addition to tehsil fixed effect we also employ tehsil specific linear trend specifications as well as a maternal fixed effect based strategy, comparing children born to the same mother but with different exposure to violent incidents due to the timing of their birth. While this may not completely address these concerns, the robustness of our estimates to these various specifications provides compelling evidence that our results represent causal impacts.

Our paper contributes to the growing empirical literature that has documented the negative impacts of exposure to violence on health outcomes at various points in the life cycle. These studies have explored this question using data from numerous countries, consistently estimating a robust negative effect of exposure to violence on health outcomes, primarily using difference-in-differences techniques or maternal fixed effects for identification (See for example: Palestine (Mansour and Rees, 2012); Eritrea and Ethiopia (Akresh et al., 2012b); Nigeria (Akresh et al., 2012a) Korea (Lee, 2014); Germany during World War II (Akbulut-Yuksel, 2017); and Mexico (Brown, 2018) among others.) Similarly, using quasi-experimental variation from landmine explosions in Colombia, Camacho (2008) documents a significant impact on birth weight, while Koppensteiner and Manacorda (2016) find a negative effect of homicide prevalence on infant health in Brazil. Terrorism also effects fertility (Berrebi and Ostwald, 2014), diet (Dabalen and Paul, 2014), educational attainment (Leon, 2012), human capital development (Duque, 2017) and women's health (Grimard and Laszlo, 2014). These are potential mechanisms through which the documented impacts on child health may operate. Our study underscores receipt of vaccines and access to medical care as additional important mechanisms through which early life violence may affect health. 
The two closest papers to ours are Mansour and Rees (2012) and Akresh et al. (2012b). Mansour and Rees (2012), using variation in non-combatant deaths to Palestinians during the second Intifada fighting between Israel and Palestine, find that an increase in deaths in-utero causes worse infant health at birth. Akresh et al. (2012b) focuses on pre- and post-birth violence, controlling for migration patterns and maternal fixed effects during the Eritrean-Ethiopian conflict. Their results are specific to a war context and they measure intensity of the conflict by the number of internally displaced persons per capita. They report decreased height for age for children born both before and during the war, highlighting the importance of focusing on violence after birth as well as in-utero.

Our paper differs from the previous literature in two related aspects. First, most of the literature cited above focuses on prolonged conflicts and wars that are more likely to induce internal migration and displacement. This migration complicates inference on the parameter of interest. Akresh et al. (2012b) do a particularly good job of dealing with this concern by using data on the exact location of a child during the war. Our focus on Punjab, which did not have an ongoing insurgency or active conflict, alleviates this concern. We discuss this in greater detail in the next section. Second, studies focusing on sustained violence but not full-blown wars, such that they are less likely to induce internal migration, generally have relatively lower intensity of violence which can make subsequent effects harder to detect (Ioannidis et al., 2017). In our sample period, $45 \%$ of attacks in Punjab had more than 10 recorded fatalities.

\subsection{Background}

\subsubsection{Terrorism in Pakistan}

Following the September 11 attacks, Pakistan became a front line state involved in the so-called War on Terror. Before its involvement in the Afghan war in 2001, Pakistan was mostly a peaceful country despite some previous sporadic violent incidents 
depicted in Figure A.3. Pakistan did not contribute any active military personnel to the coalition, but it provided access to its airspace and transport network for facilitating military operations in Afghanistan. Pakistan shares a 2,430 kilometer long, largely porous, border with Afghanistan and ethnically similar populations inhabit both sides. The Pashtun tribes on the Pakistani side of the border, referred to as the Federally Administered Tribal Areas (FATA), provided refuge to the Afghan Taliban and Al-Qaeda fighters fleeing from Afghanistan following the US-led invasion and actively participated in fighting what they saw as an occupying force in Afghanistan (Rubin and Rashid, 2008; Shah, 2012). Consequently, the Pakistani military launched an offensive in FATA in 2004 to curb the involvement of Pakistani citizens in aiding and abetting militants in Afghanistan fighting against the US led coalition (Abbas, 2004). Militant organizations based in FATA, responded to this offensive by targeting civilian non-combatants in Pakistani urban centers.

An additional trigger of terrorist activity in Pakistan occurred in July 2007 in the Pakistani capital of Islamabad (Hussain, 2010). The Pakistani military launched Operation Sunrise, referred to as the Siege of Lal Masjid (Red Mosque), to clear the mosque of suspected militants. While officials reported approximately 100 casualties of militants with links to Al-Qaeda, others claimed that the casualty figure was much higher and included unarmed women and children. The Tehreek-e-Taliban Pakistan, the main terrorist organization in Pakistan, formed in the aftermath of the Siege and vowed to take revenge for the deaths, leading to an increase in violence and intensity of terrorist attacks in Pakistan. While the history and impact of the incident is nuanced and complex (see e.g. Hussain, 2010, 2017), a key aspect of this raid and its aftermath for our identification strategy is that it was completely unanticipated.

This drastic rise in violent incidents has greatly affected Pakistan both in terms of economic and human losses. Terrorist activity caused $\$ 118$ billion in economic losses between 2002 and 2016 in Pakistan (Pakistan Economic Survey 2016). In addition, more than 60,000 Pakistanis have died in terror-related activities since 2002, a third 
of whom were civilian non-combatants (Crawford, 2017). However, we note that the majority of these deaths were in the active insurgency areas in FATA. These aggregate level statistics imply that the consequences of terrorist attacks in Pakistan are multifaceted: individuals suffer economic hardship, stress, and fear of losing one's life as a result of the increased incidence of violence.

The survey data used in our analysis, and outlined in detail in the next section, was conducted in 2011. We focus on children aged between 0 and 5 years. Terrorist activity between 2006 and 2011 provides us with variation in our 'treatment of interest'. Our data is from Punjab, the most populous province in Pakistan. Figure A.1 shows trends in attacks and fatalities in Punjab that closely mirror the overall trend for the entire country. Approximately 1,000 individuals were killed in Punjab over our study period.

Although terrorist activity in Punjab is only a fraction of that experienced by Pakistan as a whole in the sample period, our focus on Punjab stems from two concerns that are likely to help us with the causal identification of the parameter of interest. First, Khyber-Pakhtunkhwa, the other province in which violent incidents increased drastically, was virtually an active war zone due to a home-grown insurgency in the border area of FATA. Proximity to a conflict zone is likely associated with potential confounding from internal migration and displacement of refugees fleeing the conflict between the Pakistan army and militants. For instance, a 2009 operation conducted in the province resulted in over 1.2 million refugees migrating to southern cities to escape the war. Punjab is less likely to suffer from this concern and there is no documented wide scale internal migrations from or within the province. Second, Punjab is administratively divided into 150 tehsils or sub-districts and we observe this geographic marker in our MICS data, which provides spatial and temporal variation in attacks at a relatively finer level. In addition, among the health survey based data sets, Punjab has the largest sample size which is particularly helpful in implementing a maternal fixed effect based estimation methodology. We exclude Pakistan's two 
other provinces, Balochistan and Sindh, because MICS data for both provinces lack a tehsil identifier and provide information only at the much larger district level. This provides a much coarser measure of treatment exposure given that Balochistan has only 32 districts, while Sindh has only 29 districts.

Figure A.2 plots heat maps of the number of fatalities per attack by tehsils for each year between 2006 and 2011. Punjab was relatively peaceful in 2006 but starting in 2007 terrorist activity increased, varying by time and space the exposure to violence across pregnancies and tehsils in Punjab.

\subsubsection{Mechanisms}

Violence is an important correlate of preterm birth, low birth weight, and other measures of infant and early childhood health. It may affect health through numerous mechanisms including increased psychological stress for the child and/or family; reduced parental investment in a child's human capital; malnutrition due to disruptions of market activities; infrastructure destruction which may crowd out resources for economic development or health services; and reduced access to medical care. We discuss each of these pathways in turn below.

First, psychological stress on both the mother and child in response to terrorist activity can directly affect health. Maternal cortisol levels are correlated with fetal cortisol levels (Talge et al., 2007). Aizer et al. (2016) use a maternal fixed effect model and find little evidence of negative birth outcomes from elevated cortisol, but large effects on educational attainment and verbal IQ at age 7. Haushofer and Fehr (2014) provide a review of the interrelationship between poverty and stress: stress leads to risk-averse decision making and less direct investment in offspring, leading to worse long-term outcomes. Experiencing an additional disruptive occurrence such as a terrorist attack may exacerbate this risk aversion further for low income individuals. Stress affects infants and children directly, not just through a maternal stress channel (Saridjan et al., 2010; Haushofer and Fehr, 2014). For instance, sleep patterns 
and early morning cortisol levels are adversely impacted for adolescents exposed to neighborhood-level violent crime incidents (Heissel et al., 2017). Importantly, children's response to attacks may be modulated by adolescent emotional characteristics like hopefulness (Fletcher, 2018).

Second, attacks on public areas may disrupt local markets directly or through fear, dissuading individuals from traveling to nearby economic centers. Understanding the effect of terrorism on local and city market activities is an understudied topic (Desai, 2017). This can potentially reduce overall familial resources which can affect health in myriad ways. For instance, it can lead to a less healthy diet because mutually beneficial trade cannot occur or because one's budget constraint binds, limiting the amount or quality of food, increasing rates of malnutrition and stunting (Bozzoli and Quintana-Domeque, 2014; Lindo, 2011; Onis et al., 2013). Shah et al. (2003) provide descriptive evidence that stunting in Pakistan among children under age 3 is associated with low socioeconomic status, while terrorist activities decreased economic development substantially in Pakistan (Pakistan Economic Survey, 2016). Attacks that target civilian populations likely exacerbate stunting and malnutrition among the most vulnerable populations.

Third, terrorist attacks lead to greater investment in defense against attacks (Eckstein and Tsiddon, 2004). Together with decreased economic development, this likely crowds out potential investments in healthcare as well as private investment (Filmer et al., 2000; Jain et al., 2015; Eckstein and Tsiddon, 2004; Llussa and Tavares, 2011). In developing economies, individuals living in smaller areas may have to travel further for health care (Filmer et al., 2000), while wealthy and urban women are more likely to give birth in an institutional setting (Jain et al., 2015). Because higher stress exposure is associated with risk aversion (Haushofer and Fehr, 2014), parents may be unwilling to take children to receive basic medical services after violent attacks. To minimize exposure to terrorism, individuals may receive health care at smaller clinics tended by less experienced healthcare professionals closer to their home and 
may forego followup care out of fear. Finally, individuals may be less likely to receive basic health care including inoculations against preventable diseases, suggesting restrictions on both quality and quantity of care received.

The pathways delineated above provide support for a negative health effect of violent attacks in one's local area. While the results of these previous studies are not necessarily specific to children under age 5, they provide evidence of both short- and long-term effects of stress on health. Addtionally, effects of violence and stress at later ages such as during adolescence are not evidence against the existence of these associations at younger ages. Determining through which of these channels this effect occurs is difficult. We contribute to this literature by attempting to tease out the effects of terrorism attacks on health, focusing on vaccination receipt as a proxy for receipt of health care.

\subsection{Data and Methods}

\subsubsection{Descriptive Statistics}

We use data from two sources: the 2011 Multiple Indicator Cluster Survey (MICS) provides data on children's health outcomes while the Global Terrorism Database (GTD) provides terrorism data.

MICS is an international household survey program for children and women conducted by the United Nations International Children's Emergency Fund in collaboration with the Government of Punjab and UN Development Program. Its primary objective is to monitor the progress of children towards Millennium Development goals. MICS covers 102,545 households in 36 districts of Punjab which are further divided into 150 tehsils. For children under age 5, interviewers collect detailed information on individuals' source of nutrition. They also measure children's heights and weights. For children under age 3, MICS collects immunization histories from immunization cards, if available, or asks respondents about children's vaccinations. Additionally, it 
collects basic household demographic characteristics as well as prenatal care history, and newborn health.

GTD collects information on terrorist attacks around the world from 1970 through 2015 and has detailed data on date, place, fatalities, and nature of attack. For each child, we merge the number of attacks and fatalities that occurred during gestation period and post birth using their tehsil of residence. We use ArcGIS to geocode all attacks that occurred within Pakistan over our study period to the tehsil in which they occurred. The mean number of attacks during gestation per children is 0.11 and the average after birth is 0.52 .

We present descriptive statistics of the sample in Table A.1. The first column contains the sample of children born to a woman who gave birth at least twice during the sample period, our mother fixed effect sample. Here we report statistics on our estimation sample, which consists of families where multiple siblings are observed for comparability between our tehsil and mother fixed effect specifications. Estimated effects from the full sample are very similar to the results presented in the paper. Column (2) contains demographic characteristics of the children and households in tehsils in which an attack occurred at some point during the sample period, while column (3) limits the sample to areas in which an attack did not occur. Column (4) takes the difference of columns (2) and (3) and tests for statistical differences between the two. Tehsils with an attack had mothers and heads of households with lower socioeconomic status in terms of educational attainment and wealth score. For the outcome variables, approximately 33 percent of the sample children were stunted and 14 percent were severely stunted. 30 percent were low weight and 10 percent were very low weight. Rates of stunting and low weight were higher in areas that received an attack during our study period. While significant differences exist between the columns it is important to note that these differences exist on the extensive margin of whether an area ever had an attack, whereas our study exploits variation in the timing of attacks as well as within mother variation. 
Missing data on covariates is minimal, less than 1.5\%, conditional on non-missing outcome data. However, data on health and weight of the child is missing for around $11 \%$ of the observations. We do not employ imputation techniques as they are generally not recommended for outcome variables (Perales and Todd, 2018; Allison, 2001) as impuation models can potentially introduce bias.

\subsubsection{Methodology}

Our measures of exposure to terrorism is the ratio of fatalities per terrorist attack, which we term as the 'intensity of attack.' Any correlation between the choice of location by potential perpetrators and unobserved individual characteristics of the local population is likely to persist only at the extensive margin of the attack itself. The actual number of fatalities per attack is more likely to be a function of quasi-random elements specific to the day and exact location of the attack in a given city. For instance, whether the suicide attacker was able to by-pass multiple security barriers owing to security lapses, and whether he was able to detonate at the optimal time for maximum impact, which are hard to predict ex-ante. Additionally, how individuals and governments react is likely to be a function of both fatalities and attacks. Government investment in security increases in response to attacks (Eckstein and Tsiddon, 2004), while private investment decreases more due to fatalities than injuries (Llussa and Tavares, 2011). Individuals tend to value reductions in fatalities caused by terrorist attacks more than natural disaster fatalities (Viscusi, 2009), suggesting terrorism-related fatalities have more salience to the population at large. Furthermore, high intensity attacks are likely to have more economic consequences and cause more stress and fear as well.

Appendix table A.5 presents results from a regression of the incidence of our measures of terrorism on observable individual and household characteristics of respondents in our sample. Importantly, this test is on the intensive margin and we find little evidence of an empirical relationship between either the intensity or the fa- 
tality measure and observable characteristics of individuals living in terror affected regions. Columns (1) and (3) show that, even without controlling for tehsil fixed effects, the intensity of attacks is uncorrelated with maternal and household characteristics. Columns (2) and (4) then add tehsil fixed effects and find similar results. Columns (5) to (8) provide similar estimates for the number of fatalities measure of terrorist activity. However, some covariates for maternal education outcomes are marginally significant at the $10 \%$ level even in the fully controlled specification. The maternal fixed effect analysis, detailed below, is motivated by the potential existence of such correlations.

With the above discussion in mind, we estimate the following baseline regression,

$$
\begin{aligned}
H_{i j t}=\phi+\alpha_{j}+\lambda_{t}+\beta_{1}(\text { Intensity PreBirth } & \\
& \\
& +\beta_{2}\left(\text { Intensity PostBirth } \text { Int }_{i j t}\right)+\gamma X_{i j t}+\varepsilon_{i j t}
\end{aligned}
$$

where $H_{i j t}$ represents a health outcome for child $i$ living in tehsil $j$ in year $t, \alpha_{j}$ represents a tehsil fixed effect, which accounts for time invariant characteristics of the area, and $\lambda_{t}$ represents calendar birth month and separately birth year fixed effects, which control for seasonal variation in health and general trends in health over this time period. $X_{i j t}$ represents various maternal and household level controls, including age of mother at birth of child, a dummy for first child, whether child was breastfed, age of mother at marriage, parental education, and a household wealth index. $\varepsilon_{i j t}$ represents a random idiosyncratic error term, clustered at the tehsil level to allow for serial correlation. Our main parameters of interest, $\beta_{1}$ and $\beta_{2}$, capture the effect of exposure to terrorism in utero and post-birth. We present results from specifications using the total number of fatalities in a tehsil to measure exposure to terrorism instead of an intensity of attack measure as a robustness test in Appendix Table A.7 and find similar results. We observe the month and year of birth for each child, and exact date of birth for most children, but not their gestational length, hence we define in utero exposure as 9 months prior to the observed date of birth. We also augment equation 
(1) by including a tehsil specific time trend in some of the specifications below.

Our main heath outcomes are measures of stunting and low weight. For height we consider whether the child is classified as stunted or severely stunted defined as height-for-age-and-sex z-score below -2 and -3 , respectively. We define low weight and very low weight analogously. Our choice of these binary indicators as the main variable of interests is partially driven by the context of child health in Pakistan. Over $80 \%$ of children under 5 are classified as being below 'median' for their age and gender and this number is even higher for weight. In such a setting, using a continuous z-score, which estimates average effects, might mask crucial details at the lower end of the respective distributions. Nevertheless, for completeness we present results for continuous z-scores for both height and weight below as well. We also analyze the likelihood of the child being vaccinated for two different inoculations: the tuberculosis vaccine and the pentavalent vaccine.

Although tehsil fixed effects are likely to account for time invariant unobservable differences between regions that are and are not exposed to terrorism we estimate an even more saturated model by adding maternal fixed effects to equation (1):

$$
\begin{aligned}
H_{i j t m}=\phi+\alpha_{m}+\lambda_{t}+\beta_{1}(\text { Intensity PreBirth } \\
\text { ijt }) \\
+ \\
+\beta_{2}\left(\text { Intensity PostBirth } \text { Ijt }_{i}\right)+\gamma X_{i j t m}+\varepsilon_{i j t m}
\end{aligned}
$$

where all variables are defined as before except we include an additional index, $m$, denoting the same mother. The mother fixed effect, $\alpha_{m}$, allows us to compare children born to the same mother but with varying levels of terrorism exposure. This specification likely accounts for any remaining unobservable differences between mothers or households not captured by equation (1). Rates of divorce are extremely low in Pakistan hence it is safe to assume that mother and household unobservables will closely track each other. The inclusion of $\alpha_{m}$ subsumes the tehsil fixed effect, $\alpha_{j}$, from equation (1). $X_{i j t m}$ includes only maternal characteristics that vary between births like whether the child was ever breastfed and the age of mother at birth. To 
make estimates from equation (1) and (2) comparable, we limit all analyses for height and weight to mothers who report information on two or more children during sample period.

\subsection{Results}

\subsubsection{Height and Weight}

Table A.2 presents results from our baseline specifications given in equations (1) and (2) using our intensity of attack measure of exposure to terrorism. For ease of interpretation, we transform all estimated effects of exposure to terrorism into changes per 1000 children. Columns (1) and (5) include tehsil, month and year of birth fixed effects. Conditional on terrorism exposure being uncorrelated with predetermined individual level characteristics this specification captures the effect of exposure to terrorism on health outcomes. In Panel A, a 1 SD increase in the intensity of attack, which amounts to 2.4 fatalities per attack in our data, in utero leads to approximately 4 to 5 more children per 1000 being classified as stunted and as severely stunted in regions experiencing terrorism. This effect is substantially larger for post-birth attacks and leads to 13 more children per 1000 with stunted height. Results for severely stunted height are qualitatively similar, but lack statistical significance. In columns (2) and (6) we add maternal and household level controls. Our estimated coefficients change only marginally, as one would expect if terrorist activity is exogenous to the characteristics of the local population. This corroborates our section 3 discussion based on appendix table A.5 and presents indirect evidence that spurious correlations between exposure to terrorism and individual level characteristics are unlikely to bias our results.

Two recent papers, Kahn-Lang and Lang (2018) and Mora and Reggio (2017), have underscored the importance of flexibly incorporating potential time trends at the spatial unit level in a difference-in-differences analysis. Following their recommen- 
dations, in columns (3) and (7), as an alternative way of controlling for potentially spurious trends, we add tehsil-specific linear time trends. Our estimates are robust to this flexible specification.

We can only test the exogeneity of observable covariates in our data. If terrorist activity is correlated with unobservable individual level characteristics then our equation (1) estimates would not provide the causal effect of interest. We therefore estimate equation (2) which includes a maternal fixed effect and present results in columns (4) and (8). Mother fixed effects should conceivably remove confounding from unobservable mother characteristics as long as these unobservables do not vary over time within mothers. Our estimated effects change slightly in magnitude but, given that we have less variation to exploit as a result of comparing children born to the same mother, our standard errors increase substantially. A 1 SD increase in attack intensity pre-birth is associated with 4 more children per 1000 being classified as stunted. We estimate a slightly larger magnitude of 5 more births per 1000 for pre-birth attacks on severely stunted children and the effect is precisely estimated as well. Our estimate for post birth attacks is larger with a 1 SD increase in the attack intensity, around 2.6 deaths per attack, leads to around 18 more children per 1000 $(p<0.05)$ being classified as stunted. Akresh et al. (2012a) find reduced stature of individuals exposed during adolescense to the Nigerian Civil War. This suggests a potentially important role of concurrent nutrition and adequate health care in children's height and weight.

Table A.2 presents a similar analysis for being classified as low weight (weightfor-age-and-sex z-score $<-2$ ) and very low weight (weight-for-age-and-sex z-score $<-3)$. For low weight, we estimate a statistically significant effect only for postbirth exposure to terrorism with a $1 \mathrm{SD}$ increase in intensity leading to 8 to 12 more children per 1000 being classified as low weight depending on the specification used. However, for very low weight the estimated effect is concentrated in pre-birth attacks and is robustly and precisely estimated in all specifications. We highlight 
two important aspects of these results. First, our point estimates for post-birth are still fairly large but are much more imprecisely estimated than pre-birth attacks. Second, this potentially hints at the existence of heterogeneous treatment effects especially at the lower end of the weight distribution. This would be particularly true if children exposed to terrorism in-utero are more likely to be born premature and are in turn then also more likely to be severely underweight. Unfortunately, we do not observe the exact gestation of children in our data and hence cannot empirically isolate whether pre-birth terrorism is reducing child weight due to an increased incidence of prematurity. We discuss this concern in more detail in Section 4.3. Finally, once again our estimated effects are robust to the inclusion of tehsil-specific linear time trends in columns (3) and (7) and mother fixed effects in columns (4) and (8).

In Panel B of Table A.2 and A.3 we present results for the actual z-scores for both health measures. Although the point estimates are negative, they are generally small and only statistically significant for pre-birth from columns (1) to (3). This is not necessarily surprising if children at the lower end of the height and weight distributions are more likely to be impacted by exposure to terrorism, which is captured by our binary indicators above. In a recent study on the Nigerian Civil War, Akresh et al. (2017) find analogous results with impacts concentrated at the lower end of the distribution.

Finally, as a test of whether limiting our analysis sample to mothers who report multiple births in the past five years biases our findings, we report results for the full sample including mothers reporting a single birth in Appendix Table A.6. The results are remarkably similar across outcomes and specifications, except for likelihood for low weight where we find a much stronger effect of exposure to terrorism in-utero compared to our baseline specification in Table A.3.

\subsubsection{Vaccination Take-up}

Table A.4 explores whether exposure to terrorism, while pregnant, dissuades new 
mothers from taking their newborns to receive critical vaccination regimes. We do not include maternal fixed effects in these models because we only have data on children under age 3, greatly reducing our overall sample size and specifically our sample of mothers with multiple children. This is an interesting outcome in its own right, but also may be a mechanism to explain later childhood adverse outcomes presented above. The tuberculosis (TB) vaccine, recommended by the WHO to be administered as soon as possible after birth, is particularly important in Pakistan due to its high TB prevalence rate (Khan et al., 2017). Given the recommended timing of the administration of the vaccine, we construct windows of 30,60, and 90 days prior to the exact date of birth of the child and measure the exposure to terrorism that the mother experienced in these relevant windows. Our outcome variable captures the extreme event of mothers completely avoiding vaccination take-up, and takes the value 1 if the child is ever vaccinated and zero otherwise. The likely mechanism is stress and fear related, with a deteriorating security situation making it much more costly for mothers to risk taking their young children to local health facilities. Pakistan has a sparse coverage of health facilities and in some instances mothers may need to travel substantial distances to get to the nearest medical facility.

In Table A.4, Panel A Columns (1) to (3) estimate that a 1 SD increase in attack intensity before birth leads to between 2 and 7 fewer children per 1000 being administered the tuberculosis vaccine. Panel B present results for the pentavalent vaccine which provides children with immunity against: Haemophilus Influenza type B (a bacteria that causes meningitis, pneumonia and otitis), whooping cough, tetanus, hepatitis B, and diphtheria. A 1 SD increase in the attack intensity in the last 2 or 3 months of pregnancy leads to between 7 and 8 fewer children per 1000 receiving the vaccine.

The consistently negative findings for both vaccines provide evidence that a deteriorating security situation may reduce access to health services, which is a potential mechanism for explaining our earlier reported findings on height and weight based 
health outcomes. If violent attacks cause mothers to avoid taking their children for crucial vaccines right after birth then one can reasonably extrapolate that bouts of illnesses and childhood diseases are also likely to go untreated or under-treated due to the external increased cost of traveling to health facilities following violent incidents. Additionally, health workers may be direct targets of terrorism which further decreases health care availability (Pedersen, 2002). This dilatory effect likely compounds over the life cycle of a young child, manifesting itself in worse health outcomes.

\subsubsection{Limitations and Robustness Checks}

We recognize several limitations and potential sources of bias in our estimates, including migration, gestational age, and endogenous fertility. We perform several sensitivity analyses which we include in an online appendix and outline below. First, we cannot determine from our data whether a mother moves during our sample period. Based on reports from non-governmental organizations, internal migration in Pakistan during our study period was limited to Khyber-Pakhtunkhwa and to a lesser extent Balochistan provinces. We could find no evidence of internal migration within Punjab. To the extent that conflict-induced migration did occur but we fail to capture it due to data constraints, one would expect women to move from areas of higher violence to areas of lower violence. Given we classify all women geographically based on their location during their 2011 survey, we would expect our results to be a lower bound on the true effect of violence on health due to concerns akin to contamination.

Second, we do not observe gestational age and cannot control for potential selection and scarring in who gives birth (Bozzoli et al., 2009). If violence in utero affects gestational age, this could have long term effects on health as measured by height or weight. While this effect will be captured by our estimates, the policy response to decreased height and weight due to a reduction in gestational age may differ from that of a decrease in heigh and weight separate from a change in gestational age. Previous work focusing on terrorist activity in Spain, with a very large sample size, 
finds no effect on gestational age (Quintana-Domeque and Ródenas-Serrano, 2017). In online appendix table A.9, we estimate our equations separately by trimester. Because we do not observe gestational age, we proxy for gestational age using 270 days before date of birth. Consistent with previous literature, we find effects concentrated in the early trimesters of pregnancy especially for stunting (see e.g. Camacho, 2008; Koppensteiner and Manacorda, 2016). Following previous literature that finds worse maternal nutrition immediately before pregnancy is associated with worse birth outcomes (King, 2016; Grieger et al., 2014), we estimate the impact of violence 9 months before conception on child health outcomes in online appendix table A.10. We find no effect of pre-pregnancy attacks on height, but find fairly large effects on very low weight.

Another potential concern is differential selection into fertility, which may manifest as either women choosing not to become pregnant through behavioral changes such as increased contraceptive use or decreased sexual activity, or through biological mechanisms such that fetuses that actually come to term may be healthier as higher rates of stress related to violence may increase the rate of miscarriages, especially among fetuses with the lowest health endowments (Bozzoli et al., 2009; Almond, 2006). To address potential endogenous fertility concerns, we investigate birth spacing and rates of contraceptive use and find no evidence of differential time between births or rates of contraceptive use based on intensity of exposure to terrorist attacks.

As a final robustness check, we explore spillovers in attacks from neighboring tehsils in Appendix Table A.11. If terrorist activity in a broad region disrupts transportation infrastructure and supply routes of goods, like perishable food items, then one might expect significant impacts of violence in even neighboring areas that are different from the area of residence of the child. On the other hand, if the effects are primarily driven by stress related channels then one is more likely to find impacts concentrated only in the tehsil of residence of the mother and the child. These results are never statistically significant, implying a very localized effect of violent attacks. Overall, these findings 
suggest a larger role for stress and fear based channels explaining the adverse effects documented in our study, since these are particularly likely to be salient as a function of proximity to the attack.

\subsection{Conclusion}

In this paper, we study the effect of terrorism on health outcomes of children in Pakistan. We document higher rates of low height and low weight incidence among children under age 5 that are exposed to terrorist activity. Our analysis also explores the timings of these attacks and finds substantial impacts for post-natal exposure to violence on child health as well. While our in utero results reinforce the importance of maternal health while pregnant, post pregnancy results highlight the incomplete picture provided by focusing only on the in-utero time period. Given the long-term effects of in utero health shocks and early childhood health, these results are likely lower bounds (Almond and Currie, 2011; Heckman et al., 2013).

Our results support the idea that these health effects likely operate through reduced access to and receipt of medical care. While we can only investigate vaccination take up, we consider this a proxy for general health care receipt, especially for preventive care. We find reduced vaccination take up, which may suggest that following an attack, incidence of preventable diseases may increase. From a psychological perspective, women may be more afraid to travel to a physician and the stress of the attack may have a direct negative effect on the health on the child. From an infrastructure perspective, attacks may damage medical facilities and/or transportation infrastructure, decreasing the supply of either medical care or transportation to a doctor. Given the adverse effects of early childhood shocks on adult outcomes, adequate health and human capital interventions should be a major policy goal in regions suffering from sustained terrorist and violent activities. 


\section{A.1 Further Robustness Check}

In this section, we implement a number of robustness checks on the baseline estimates presented in the main text. We first investigate our findings by the trimester of attack of the mother's pregnancy and explore heterogeneity in this dimension. Next we explore whether attacks suffered prior to pregnancy have any impacts on the health of the child. Finally, section 7.3 explores whether attacks in neighbouring tehsils also impact child health as opposed to terrorism having a fairly localized effect.

\section{A.1.1 Alternative Specifications}

\section{A.1.1.1 Attacks By Trimesters}

The medical and biological literature has argued for the importance of earlier stages of pregnancy in determining eventual birth outcomes particularly the observed gestational age of the fetus (McLean et al., 1995). Because of these biological mechanisms, much of the literature exploring incidence of violence on child health has focused on negative shocks particularly during the first trimester of pregnancy. Camacho (2008) and Koppensteiner and Manacorda (2016) among others find robust evidence of increased violent activity during the first trimester of gestation adversely impacting health outcomes at birth.

Although we do not observe the exact gestational age of children in our sample, we nevertheless attempt such an analysis by splitting the 270 days before the date of birth, our window of pre-birth attacks in the above analysis, into three individual trimesters. Table A.9 presents results from such an analysis for our height and weight outcomes. Our estimates corroborate the findings in the literature with the prebirth effects from our baseline specifications being concentrated in the earlier phases of pregnancy for stunting. For instance, in our fully controlled, tehsil fixed effect specification in column (3) of Panel A, a 1 SD increase in attack intensity in the first

trimester of pregnancy leads to 5 and 4 more children per 1000 being classified as stunted and severely stunted, respectively. In column (4), we add mother fixed effect 
and still find a precisely estimated effect of 7 more children per 1000 being classified as stunted as a result of increased violence in the first trimester of pregnancy.

The estimated effects for weight, in Panel B of Table A.9, however, seem to be stronger for exposure during the second and third trimester, with likelihood of low birth being impacted by terrorist activity thorughout the course of the pregnancy. We would, nevertheless, like to caution the reader that because we do not observe the exact gestational age of the child, we are likely measuring our trimester 'treatment' periods with error, and hence these results are at best suggestive in nature.

\section{A.1.1.2 Attacks Immediately Prior to Child's Conception}

Recent research in the medical literature has identified pathways linking maternal nutrition at and before conception with child outcomes at birth. From a review of 45 studies, Ramakrishnan et al. (2012) conclude that worse maternal nutritional and vitamin intake even before pregnancy is related to increased likelihood of pre-term and low-birth weight births. Grieger et al. (2014) and King (2016) provide similar evidence regarding the importance of the 9 to 12 months period immediately prior to conception. In this subsection we try to augment our earlier analysis and explore the impact of violence 9 months before conception on child health outcomes.

Columns (3) and (7) in Table A.10 present results from our fully controlled tehsil fixed effect specification. Panel A shows that likelihood of being classified as stunted or severely stunted is not impacted by violence suffered by the mother in the preconception period. However, there is some evidence of violent activity 9 months prior to conception negatively influencing likelihood of very low weight. A 1 SD increase in intensity of attack in the pre-conception period leads to 4.4 more children per 1000 $(p<0.05)$ being classified as very low weight in our tehsil fixed effect specification. In our fully saturated specification that includes maternal fixed effects, we see an increase of 5 per 1000 children $(p<0.10)$ classified as very low weight as a result of pre-conception violence. Interestingly, we see very similar effect sizes for pre-birth 
measures of violence compared to our baseline estimates in Table A.3. The postbirth estimates though are slightly higher in magnitude especially for low weight classification compared to our baseline results. Overall the evidence presented in this section sheds light on the far-reaching effects of violence on child health outcomes, with negative shocks even before the mother is pregnant having an influence on child health measures.

\section{A.1.1.3 Spillovers from Neighboring Tehsils}

We next explore whether attacks in nearby regions impact health outcomes of children living in a given tehsil. If terrorist activity in a broad region disrupts transportation infrastructure and supply routes of goods, like perishable food items, then one might expect significant impacts of violence in even neighboring areas that are different from the area of residence of the child. On the other hand, if the effects are primarily driven by stress related channels then one is more likely to find impacts concentrated only in the tehsil of residence of the mother and the child. We present results from an exercise designed to uncover such potential mechanisms in Table A.11. We define neighboring regions as all tehsils (sub-districts) in the zila (district) of residence of the mother and the child. ${ }^{1}$ Therefore, the 'Intensity Pre-Birth Other Tehsils' variable in Table A.11 measures the pre-birth attack intensity in all neighboring tehsils in the zila of residence for a given child. We report results for our intensity variable only for our most saturated model - the mother fixed effects specification. ${ }^{2}$

Columns (1) and (4) reproduce results from our baseline specification and correspond to columns (4) and (8) in Tables A.2 and A.3. In columns (2) and (5) we investigate the effect of attacks only in neighboring regions on child health outcomes. None of the coefficients for any of the four outcomes we consider are statistically significant. In columns (3) and (6) we add both own tehsil and neighboring tehsil terrorist activity. The results for the former are almost identical to columns (1) and

\footnotetext{
${ }^{1}$ There are 150 tehsils and 36 zilas in Punjab with a mean of 4.2 and a median of 4 tehsils per zila.

${ }^{2}$ Results from the tehsil fixed effect specifications present identical patterns
} 
(4) and the estimates for the latter remain statistically indistinguishable from zero. Furthermore, given that the estimates on 'own' terror activity barely change after controlling for neighboring tehsils this implies negligible spatial correlation in terrorist activity. This provides further evidence, albeit indirect, that terrorists are unlikely to systematically choose particular areas as a function of its characteristics. Overall, these findings suggest a larger role for stress and fear based channels explaining the adverse effects documented in our study, since that these are particularly likely to be salient as function of proximity to the attack. 
Tables and Figures 
Figure A.1: Trends in Terrorism in Punjab - 1990 - 2016

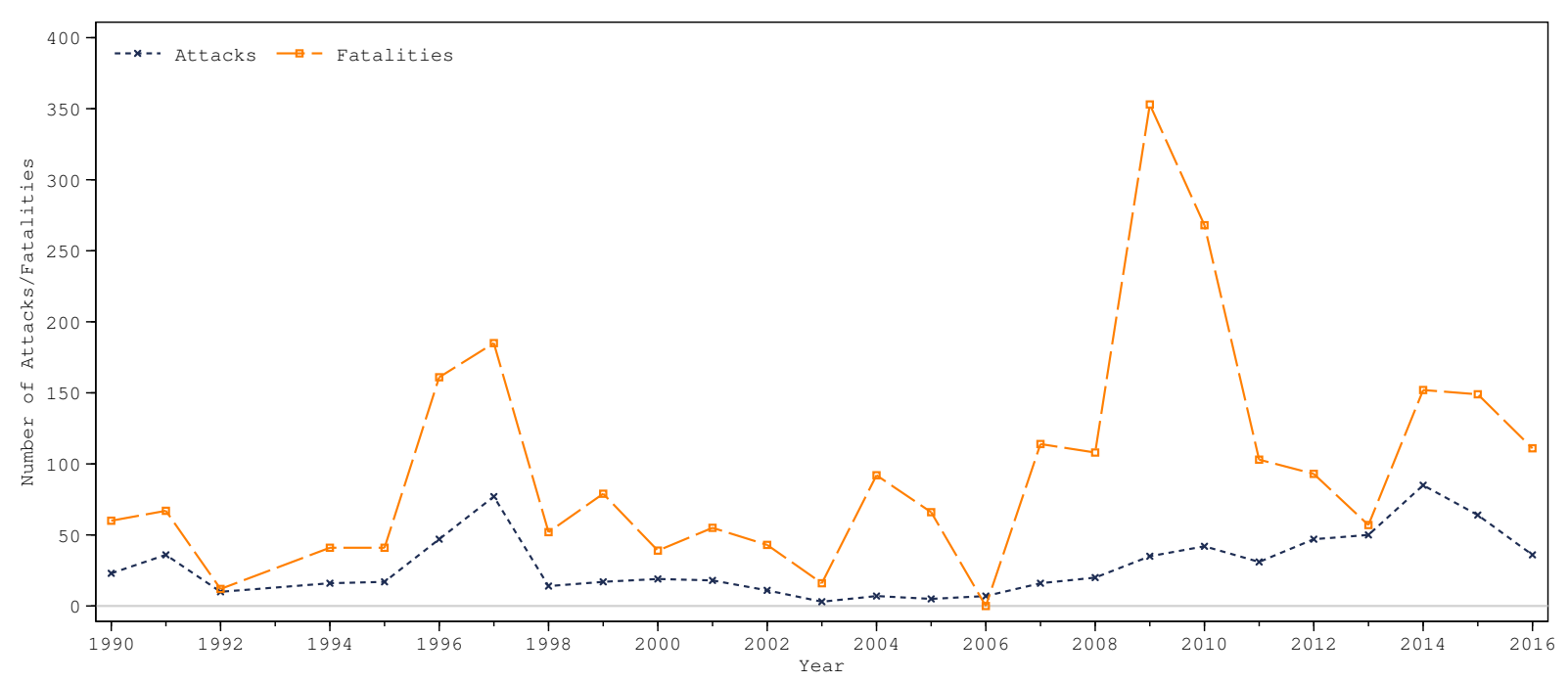

Note: Data based on the Global Terrorism Database (GTD) maintained by the University of Maryland.

Figure A.3: Trends in Terrorism in Pakistan - 1990 - 2016

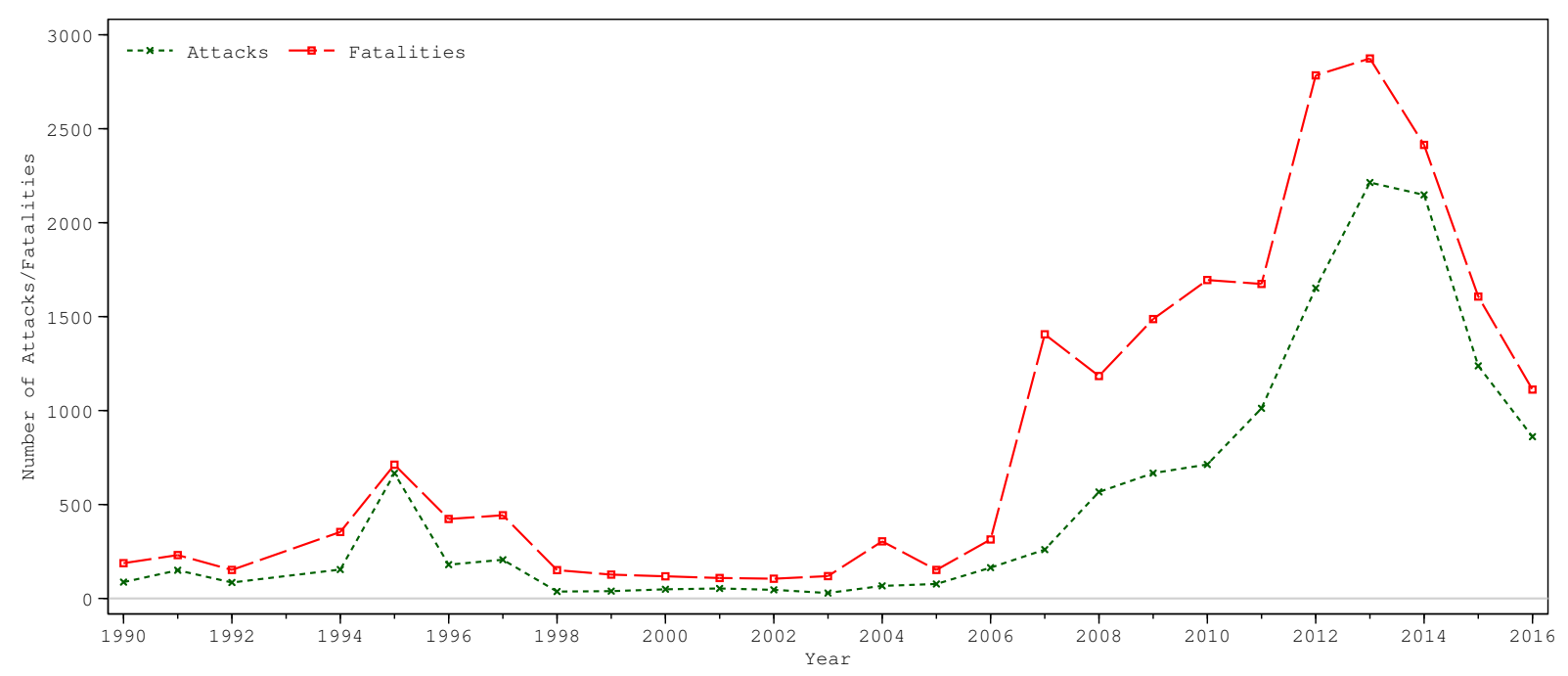

Note: Data based on the Global Terrorism Database (GTD) maintained by the University of Maryland. 
Table A.1: Descriptive Statistics by Terrorist Activity

\begin{tabular}{|c|c|c|c|c|}
\hline & Full Sample & Tehsil with Attacks & Tehsil without Attacks & Difference in Means \\
\hline & (1) & (2) & (3) & (4) \\
\hline Age at Marriage & 20.20 & 20.01 & 20.25 & $-0.247^{* * *}$ \\
\hline (in years) & $(4.231)$ & $(4.311)$ & $(4.206)$ & $(0.052)$ \\
\hline \multirow[t]{2}{*}{ No Education } & 0.489 & 0.506 & 0.485 & $0.021^{* * *}$ \\
\hline & $(0.499)$ & $(0.500)$ & $(0.499)$ & $(0.006)$ \\
\hline \multirow[t]{2}{*}{ Primary Education } & 0.192 & 0.177 & 0.196 & $-0.018^{* * *}$ \\
\hline & $(0.394)$ & $(0.383)$ & $(0.397)$ & $(0.005)$ \\
\hline Middle and Secondary & 0.224 & 0.221 & 0.225 & -0.005 \\
\hline Education & $(0.417)$ & $(0.415)$ & $(0.418)$ & $(0.005)$ \\
\hline \multirow[t]{2}{*}{ Higher Education } & 0.094 & 0.095 & 0.094 & 0.001 \\
\hline & $(0.292)$ & $(0.293)$ & $(0.291)$ & $(0.004)$ \\
\hline \multirow[t]{2}{*}{ Ever Breastfed } & 0.968 & 0.970 & 0.967 & 0.003 \\
\hline & $(0.176)$ & $(0.169)$ & $(0.178)$ & $(0.002)$ \\
\hline \multirow[t]{2}{*}{ Wealth Index } & -0.105 & -0.131 & -0.097 & $-0.034^{* *}$ \\
\hline & $(0.992)$ & $(1.039)$ & $(0.977)$ & $(0.012)$ \\
\hline \multirow[t]{2}{*}{ Head No Education } & 0.392 & 0.402 & 0.388 & 0.013 \\
\hline & $(0.488)$ & $(0.490)$ & $(0.487)$ & $(0.006)$ \\
\hline \multirow[t]{2}{*}{ Head Primary Education } & 0.184 & 0.172 & 0.187 & $-0.015^{* * *}$ \\
\hline & $(0.387)$ & $(0.378)$ & $(0.390)$ & $(0.005)$ \\
\hline Head Middle and & 0.322 & 0.321 & 0.322 & -0.001 \\
\hline Secondary Education & $(0.467)$ & $(0.467)$ & $(0.467)$ & $(0.006)$ \\
\hline \multirow[t]{2}{*}{ Head Higher Education } & 0.100 & 0.104 & 0.099 & 0.005 \\
\hline & $(0.301)$ & $(0.305)$ & $(0.299)$ & $(0.004)$ \\
\hline Number of Women $15-49$ & 1.652 & 1.641 & 1.655 & -0.013 \\
\hline years old & $(1.096)$ & $(1.122)$ & $(1.088)$ & $(0.013)$ \\
\hline \multirow[t]{2}{*}{ Stunted } & 0.327 & 0.334 & 0.325 & 0.010 \\
\hline & $(0.469)$ & $(0.472)$ & {$[(0.468)$} & $(0.006)$ \\
\hline \multirow[t]{2}{*}{ Severely Stunted } & 0.138 & 0.146 & 0.136 & 0.010 \\
\hline & $(0.345)$ & $(0.353)$ & $(0.343)$ & $(0.004)$ \\
\hline \multirow[t]{2}{*}{ Low Weight } & 0.295 & 0.304 & 0.293 & 0.011 \\
\hline & $(0.456)$ & $(0.459)$ & $(0.455)$ & $(0.006)$ \\
\hline \multirow[t]{2}{*}{ Very Low Weight } & 0.098 & 0.104 & 0.096 & 0.008 \\
\hline & $(0.297)$ & $(0.305)$ & $(0.294)$ & $(0.004)$ \\
\hline Number of Observations & 40,169 & 8,993 & 31,236 & 40,169 \\
\hline
\end{tabular}


Figure A.2: Intensity of Attacks by Tehsil 2007-2011

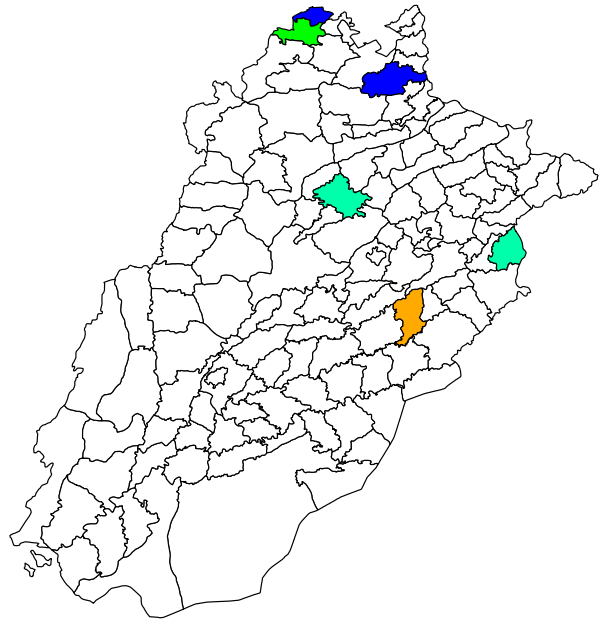

(a) 2007

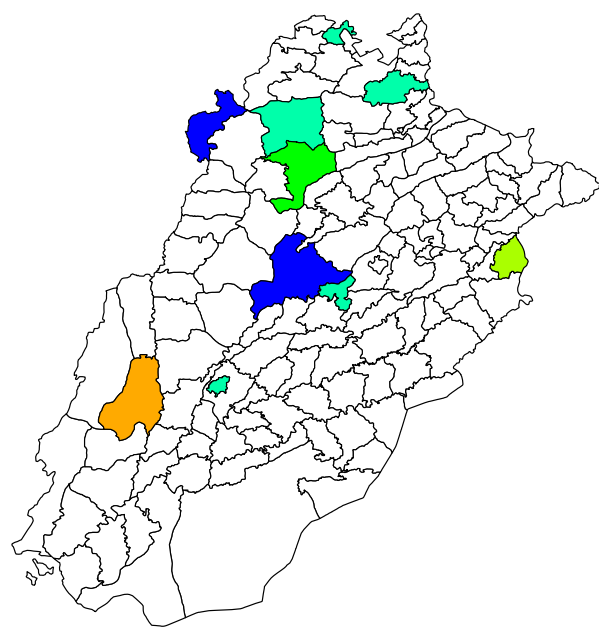

(c) 2009

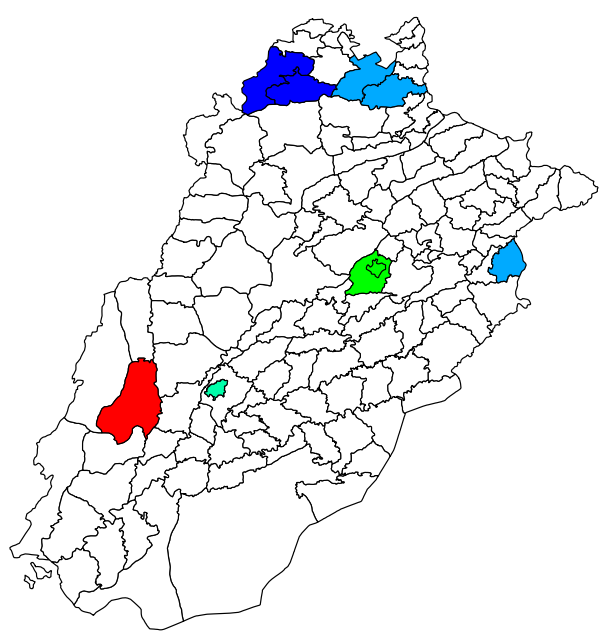

(e) 2011

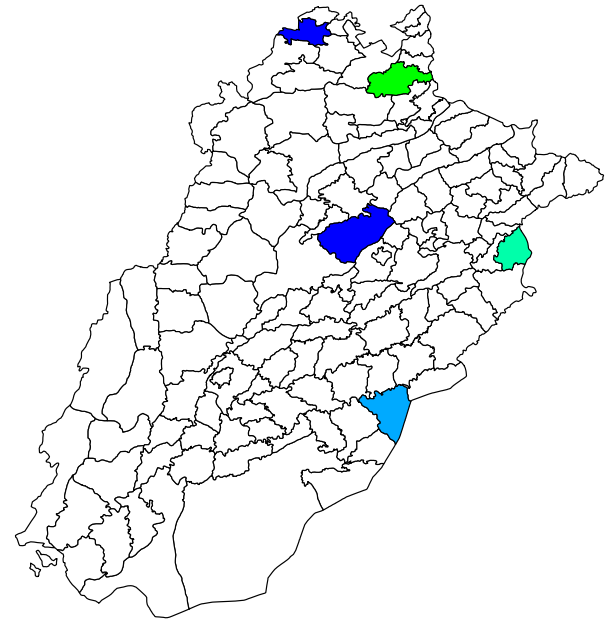

(b) 2008

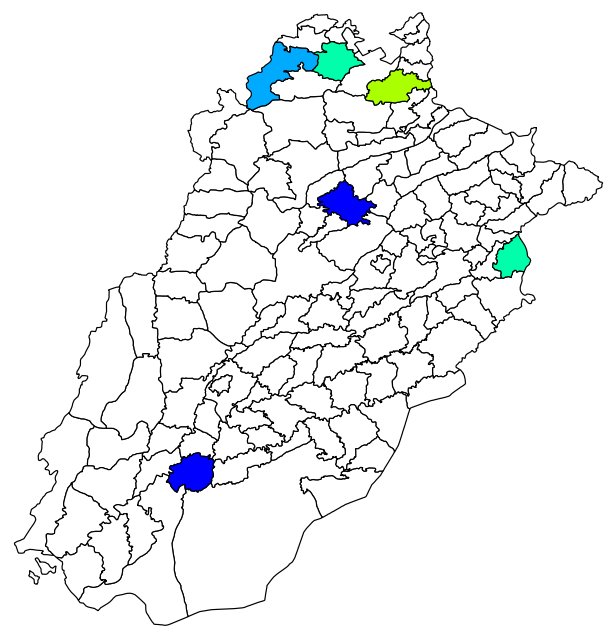

(d) 2010

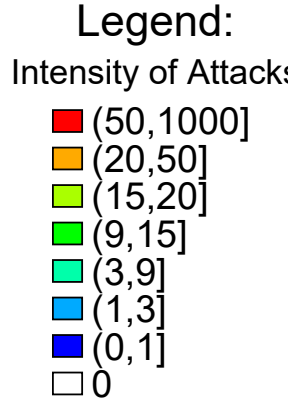




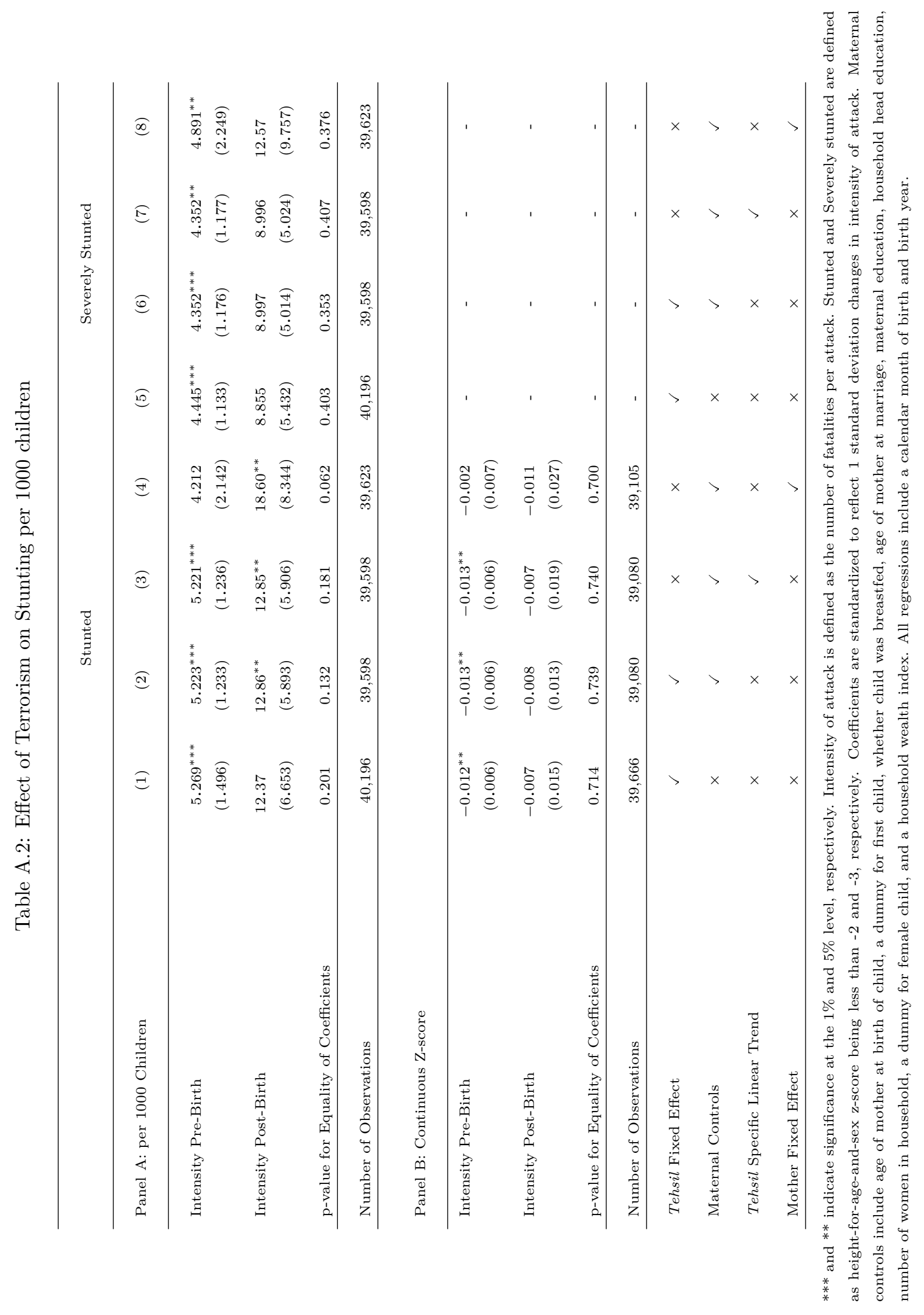




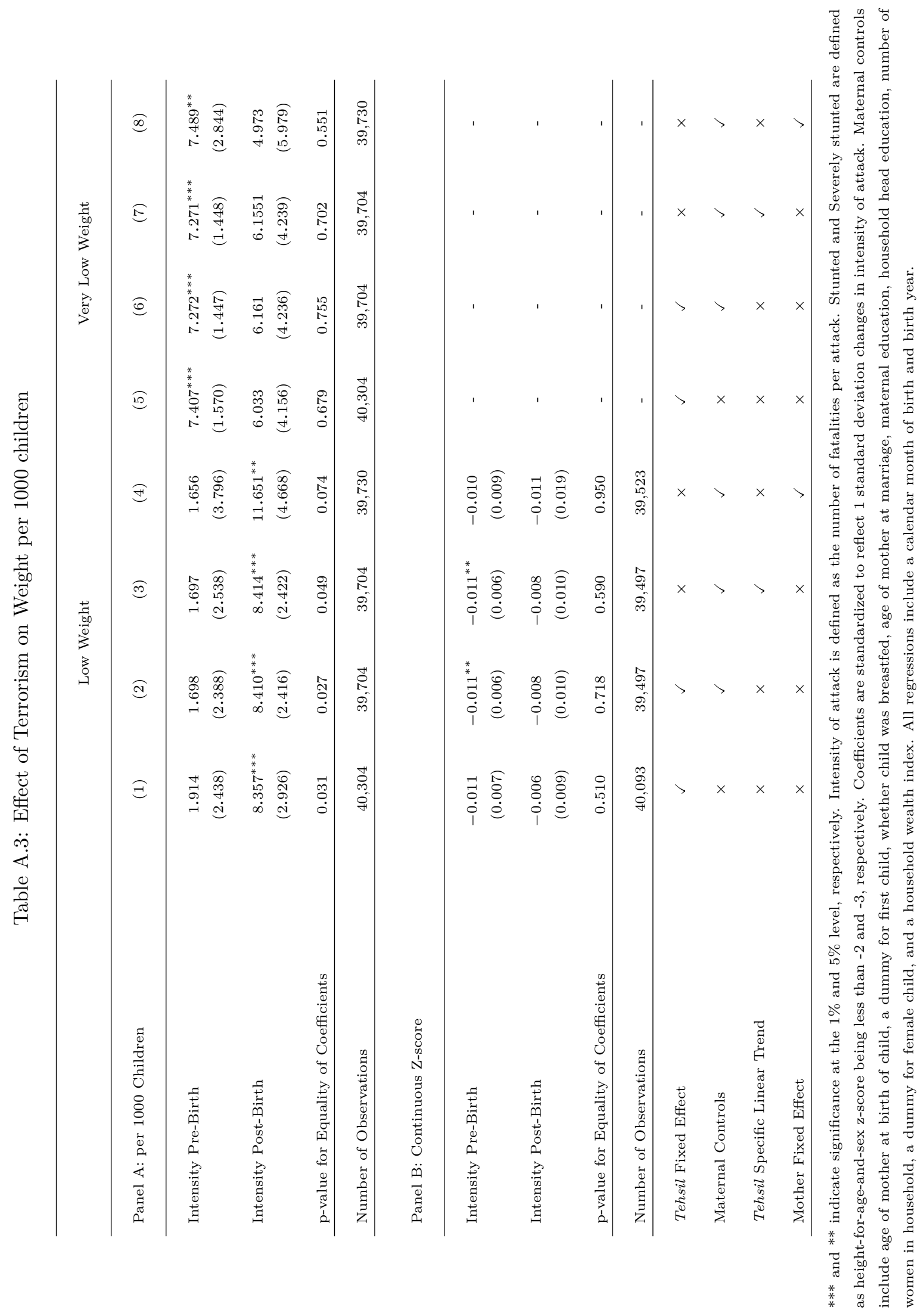


Table A.4: Effect of Terrorism on Vaccination Take-up at Birth (per 1000 children)

\begin{tabular}{lccc}
\hline & $(1)$ & $(2)$ & $(3)$ \\
\hline & & & \\
Panel A: Tuberculosis & 30 days & 60 days & 90 days \\
\hline Intensity in Relevant Window before Birth & $-2.283^{* *}$ & $-7.031^{* * *}$ & $-5.238^{* * *}$ \\
& $(1.111)$ & $(2.062)$ & $(1.718)$ \\
Number of Observations & 17,021 & 17,021 & 17,021 \\
\hline $\begin{array}{l}\text { Panel B: Pentavalent } \\
\text { Intensity in Relevant Window before Birth }\end{array}$ & -2.205 & $-8.404^{* * *}$ & $-6.864^{* * *}$ \\
& $(1.651)$ & $(2.884)$ & $(3.231)$ \\
& 14,375 & 14,375 & 14,375 \\
\hline
\end{tabular}


Table A.5: Incidence of Terrorism and Maternal and Household Characteristics

\begin{tabular}{|c|c|c|c|c|c|c|c|c|}
\hline & \multicolumn{4}{|c|}{ Intensity of Attack } & \multicolumn{4}{|c|}{ Number of Fatalities } \\
\hline & \multicolumn{2}{|c|}{ Pre-Birth } & \multicolumn{2}{|c|}{ Post-Birth } & \multicolumn{2}{|c|}{ Pre-Birth } & \multicolumn{2}{|c|}{ Post-Birth } \\
\hline & (1) & $(2)$ & (3) & $(4)$ & (5) & (6) & (7) & (8) \\
\hline \multicolumn{9}{|l|}{ Maternal Vars. } \\
\hline Age at Childbirth & $\begin{array}{c}0.003 \\
(0.005)\end{array}$ & $\begin{array}{c}0.001 \\
(0.001)\end{array}$ & $\begin{array}{c}0.005 \\
(0.008)\end{array}$ & $\begin{array}{r}-0.001 \\
(0.001)\end{array}$ & $\begin{array}{c}-0.0016 \\
(0.078)\end{array}$ & $\begin{array}{c}0.002 \\
(0.002)\end{array}$ & $\begin{array}{c}-0.021 \\
(0.046)\end{array}$ & $\begin{array}{r}-0.012 \\
(0.007)\end{array}$ \\
\hline Age at Marriage & $\begin{array}{r}-0.019 \\
(0.016)\end{array}$ & $\begin{array}{r}-0.004 \\
(0.003)\end{array}$ & $\begin{array}{r}-0.019 \\
(0.031)\end{array}$ & $\begin{array}{c}0.003 \\
(0.003)\end{array}$ & $\begin{array}{r}-0.021 \\
(0.018)\end{array}$ & $\begin{array}{c}0.001 \\
(0.007)\end{array}$ & $\begin{array}{r}-0.114 \\
(0.109)\end{array}$ & $\begin{array}{c}0.010 \\
(0.010)\end{array}$ \\
\hline Child Breast Fed & $\begin{array}{c}-0.002 \\
(0.095)\end{array}$ & $\begin{array}{r}-0.026 \\
(0.035)\end{array}$ & $\begin{array}{c}0.040 \\
(0.164)\end{array}$ & $\begin{array}{c}-0.036 \\
(0.042)\end{array}$ & $\begin{array}{r}-0.085 \\
(0.172)\end{array}$ & $\begin{array}{l}-0.016 \\
(0.045)\end{array}$ & $\begin{array}{r}-0.237 \\
(0.869)\end{array}$ & $\begin{array}{c}0.026 \\
(0.161)\end{array}$ \\
\hline Primary Educ & $\begin{array}{c}-0.076 \\
(0.100)\end{array}$ & $\begin{array}{r}-0.033 \\
(0.025)\end{array}$ & $\begin{array}{r}-0.181 \\
(0.182)\end{array}$ & $\begin{array}{c}-0.013 \\
(0.017)\end{array}$ & $\begin{array}{c}0.067 \\
(0.211)\end{array}$ & $\begin{array}{c}-0.023 \\
(0.047)\end{array}$ & $\begin{array}{c}0.111 \\
(0.710)\end{array}$ & $\begin{array}{r}-0.109 \\
(0.082)\end{array}$ \\
\hline Secondary Educ & $\begin{array}{r}-0.006 \\
(0.117)\end{array}$ & $\begin{array}{r}-0.055 \\
(0.056)\end{array}$ & $\begin{array}{r}-0.110 \\
(0.146)\end{array}$ & $\begin{array}{c}0.001 \\
(0.021)\end{array}$ & $\begin{array}{c}0.515 \\
(0.576)\end{array}$ & $\begin{array}{c}0.086 \\
(0.195)\end{array}$ & $\begin{array}{c}1.864 \\
(2.018)\end{array}$ & $\begin{array}{r}-0.044 \\
(0.108)\end{array}$ \\
\hline Middle Educ & $\begin{array}{r}-0.029 \\
(0.093)\end{array}$ & $\begin{array}{r}-0.029 \\
(0.045)\end{array}$ & $\begin{array}{r}-0.182 \\
(0.144)\end{array}$ & $\begin{array}{c}-0.041 \\
(0.043)\end{array}$ & $\begin{array}{c}0.268 \\
(0.322)\end{array}$ & $\begin{array}{c}0.011 \\
(0.085)\end{array}$ & $\begin{array}{c}0.984 \\
(1.410)\end{array}$ & $\begin{array}{r}-0.199 \\
(0.117)\end{array}$ \\
\hline Higher Educ & $\begin{array}{c}0.062 \\
(0.077) \\
\end{array}$ & $\begin{array}{c}0.055 \\
(0.045) \\
\end{array}$ & $\begin{array}{r}-0.311 \\
(0.243) \\
\end{array}$ & $\begin{array}{r}-0.060 \\
(0.033) \\
\end{array}$ & $\begin{array}{c}0.255 \\
(0.202) \\
\end{array}$ & $\begin{array}{c}0.253 \\
(0.153) \\
\end{array}$ & $\begin{array}{r}-0.757 \\
(0.557) \\
\end{array}$ & $\begin{array}{r}-0.147 \\
(0.175) \\
\end{array}$ \\
\hline \multicolumn{9}{|l|}{$\underline{\text { Household Head }}$} \\
\hline Primary Educ & $\begin{array}{c}-0.052 \\
(0.055)\end{array}$ & $\begin{array}{r}-0.036 \\
(0.034)\end{array}$ & $\begin{array}{r}-0.094 \\
(0.103)\end{array}$ & $\begin{array}{c}-0.015 \\
(0.024)\end{array}$ & $\begin{array}{c}0.023 \\
(0.127)\end{array}$ & $\begin{array}{c}0.019 \\
(0.080)\end{array}$ & $\begin{array}{c}0.096 \\
(0.399)\end{array}$ & $\begin{array}{c}0.131 \\
(0.131)\end{array}$ \\
\hline Secondary Educ & $\begin{array}{c}0.017 \\
(0.028)\end{array}$ & $\begin{array}{r}-0.006 \\
(0.037)\end{array}$ & $\begin{array}{r}-0.014 \\
(0.113)\end{array}$ & $\begin{array}{c}-0.004 \\
(0.015)\end{array}$ & $\begin{array}{c}0.059 \\
(0.076)\end{array}$ & $\begin{array}{c}0.017 \\
(0.099)\end{array}$ & $\begin{array}{c}0.235 \\
(0.429)\end{array}$ & $\begin{array}{c}0.158 \\
(0.116)\end{array}$ \\
\hline Middle Educ & $\begin{array}{c}0.055 \\
(0.074)\end{array}$ & $\begin{array}{r}-0.021 \\
(0.043)\end{array}$ & $\begin{array}{c}0.021 \\
(0.069)\end{array}$ & $\begin{array}{r}-0.017 \\
(0.019)\end{array}$ & $\begin{array}{c}0.388 \\
(0.309)\end{array}$ & $\begin{array}{c}0.039 \\
(0.093)\end{array}$ & $\begin{array}{c}1.615 \\
(1.214)\end{array}$ & $\begin{array}{c}0.147 \\
(0.226)\end{array}$ \\
\hline Higher Educ & $\begin{array}{c}0.055 \\
(0.074)\end{array}$ & $\begin{array}{r}-0.021 \\
(0.043)\end{array}$ & $\begin{array}{c}0.124 \\
(0.184)\end{array}$ & $\begin{array}{c}-0.023 \\
(0.022)\end{array}$ & $\begin{array}{r}-0.051 \\
(0.083)\end{array}$ & $\begin{array}{c}-0.248 \\
(0.151)\end{array}$ & $\begin{array}{c}1.324 \\
(0.829)\end{array}$ & $\begin{array}{c}0.392 \\
(0.323)\end{array}$ \\
\hline Wealth Index & $\begin{array}{c}0.013 \\
(0.106) \\
\end{array}$ & $\begin{array}{c}0.030 \\
(0.019) \\
\end{array}$ & $\begin{array}{c}0.121 \\
(0.235) \\
\end{array}$ & $\begin{array}{c}0.018 \\
(0.020) \\
\end{array}$ & $\begin{array}{c}0.189 \\
(0.228) \\
\end{array}$ & $\begin{array}{r}-0.029 \\
(0.079) \\
\end{array}$ & $\begin{array}{c}1.297 \\
(1.453) \\
\end{array}$ & $\begin{array}{r}-0.013 \\
(0.053) \\
\end{array}$ \\
\hline Tehsil F.E & $x$ & $\checkmark$ & $x$ & $\checkmark$ & $x$ & $\checkmark$ & $x$ & $\checkmark$ \\
\hline $\begin{array}{l}\text { Birth Year } \\
\text { \& Month F.E }\end{array}$ & $x$ & $\checkmark$ & $x$ & $\checkmark$ & $x$ & $\checkmark$ & $x$ & $\checkmark$ \\
\hline
\end{tabular}

$* * *$, and $* *$ indicate significance at the $1 \%$, and $5 \%$ level, respectively. Intensity of attack is defined as the number of fatalities per attack. The number of observations across columns is 41,025 . 


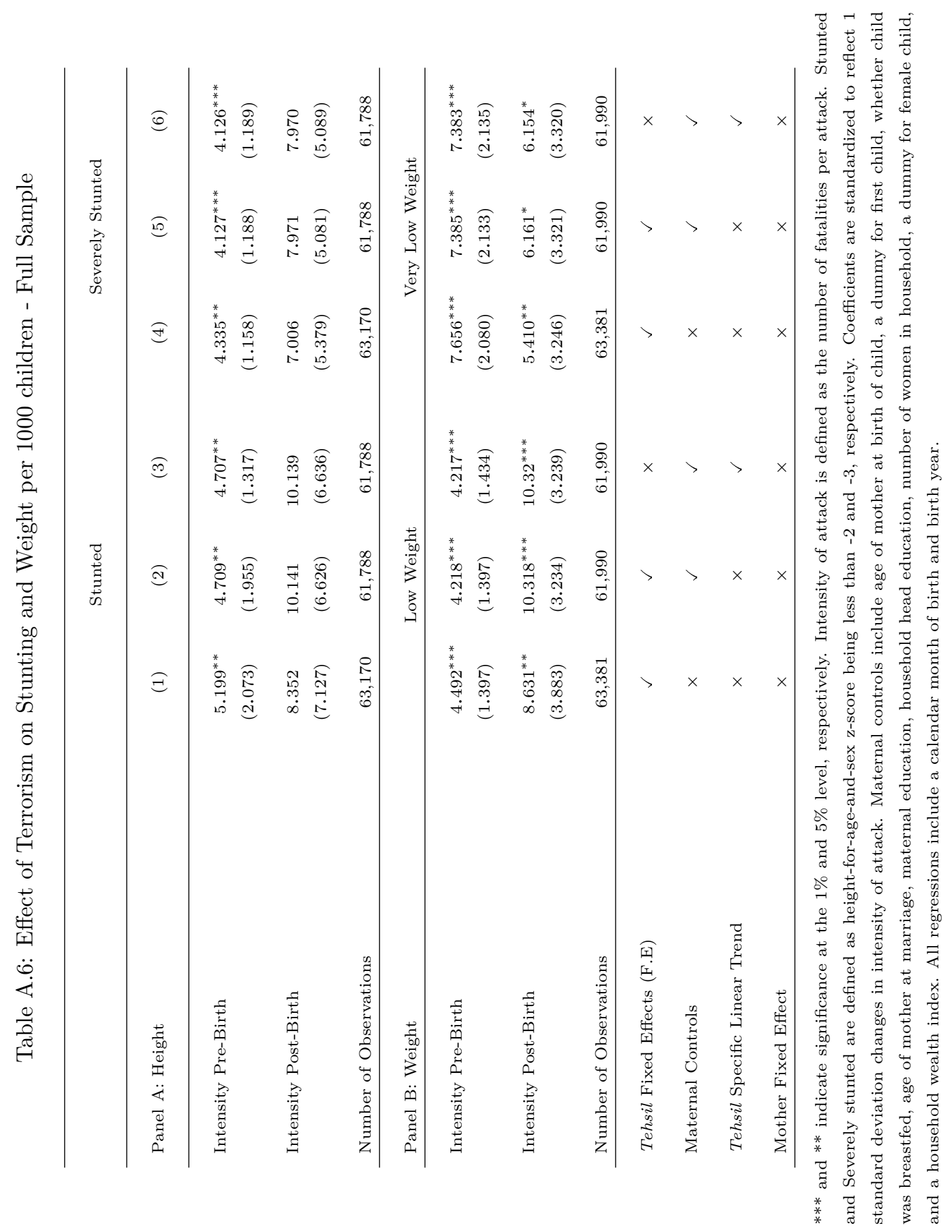




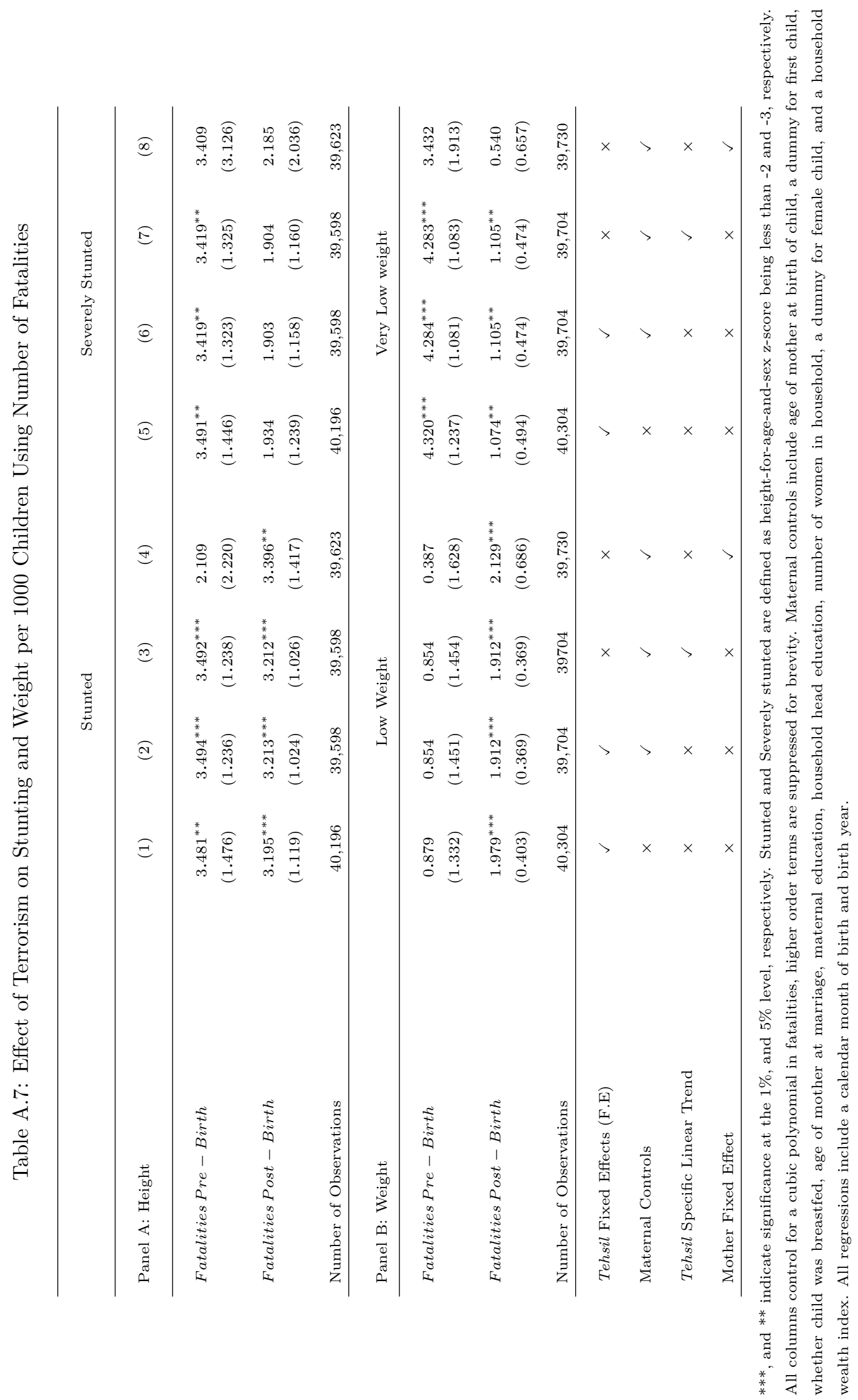




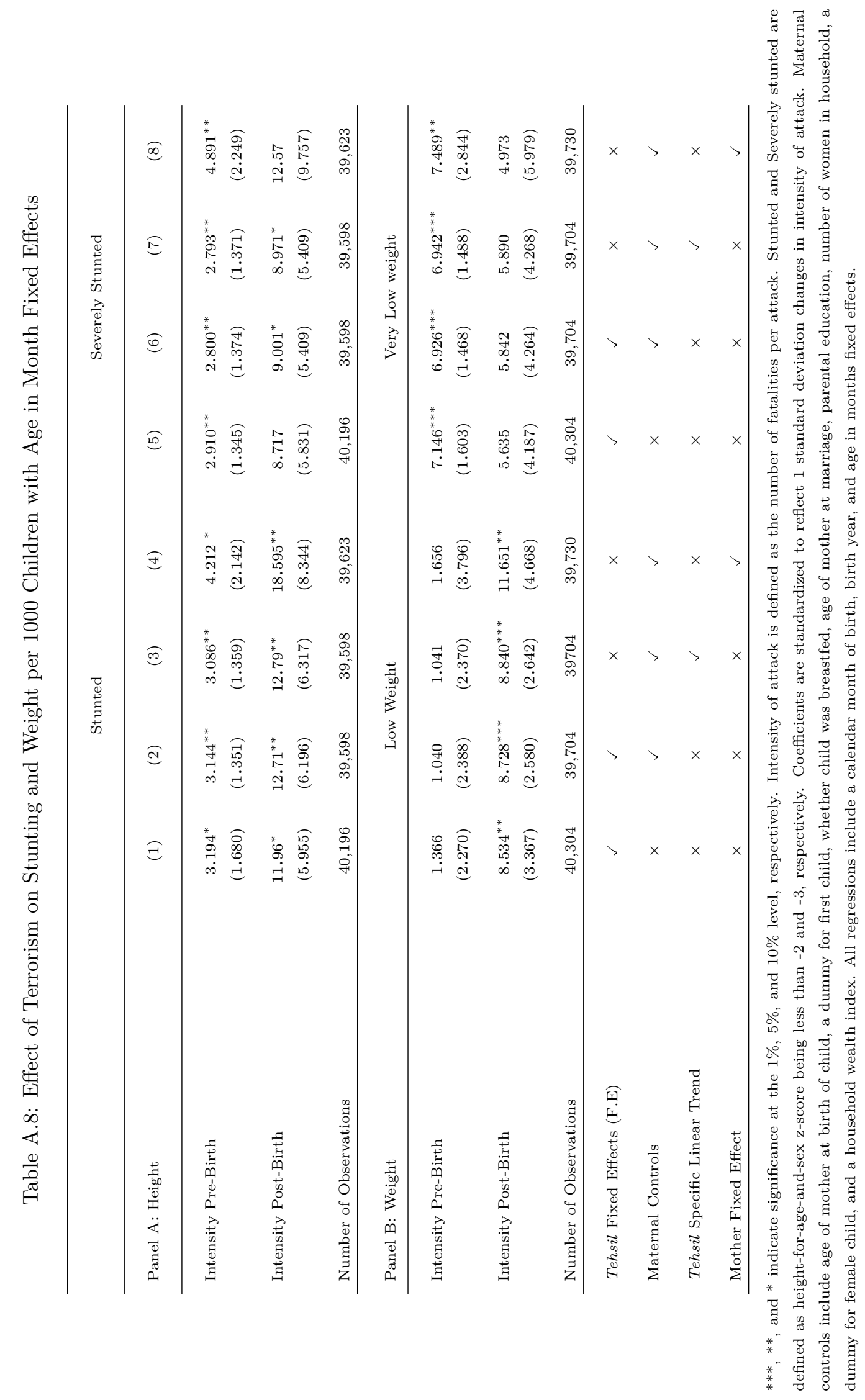


चี

跑

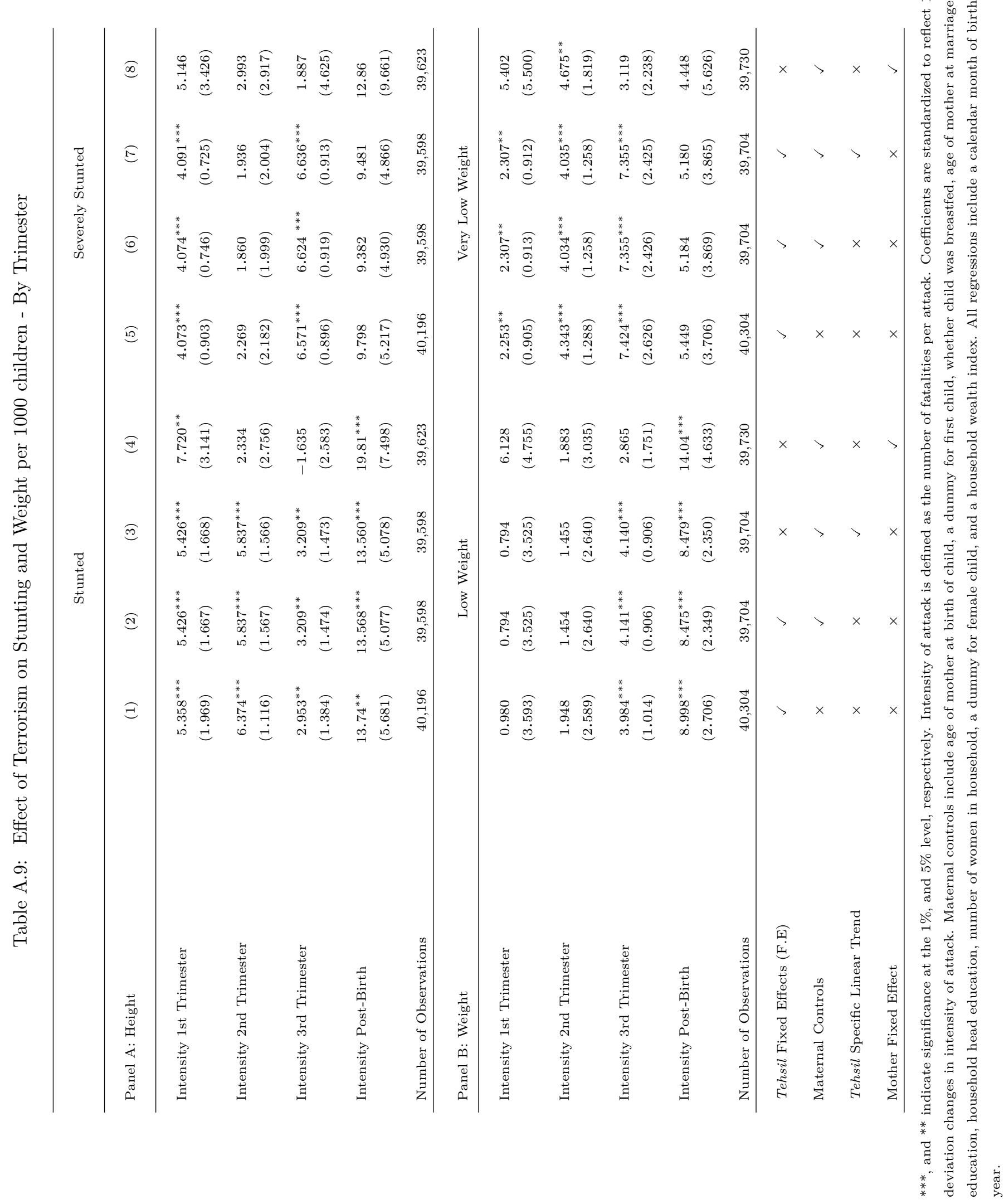




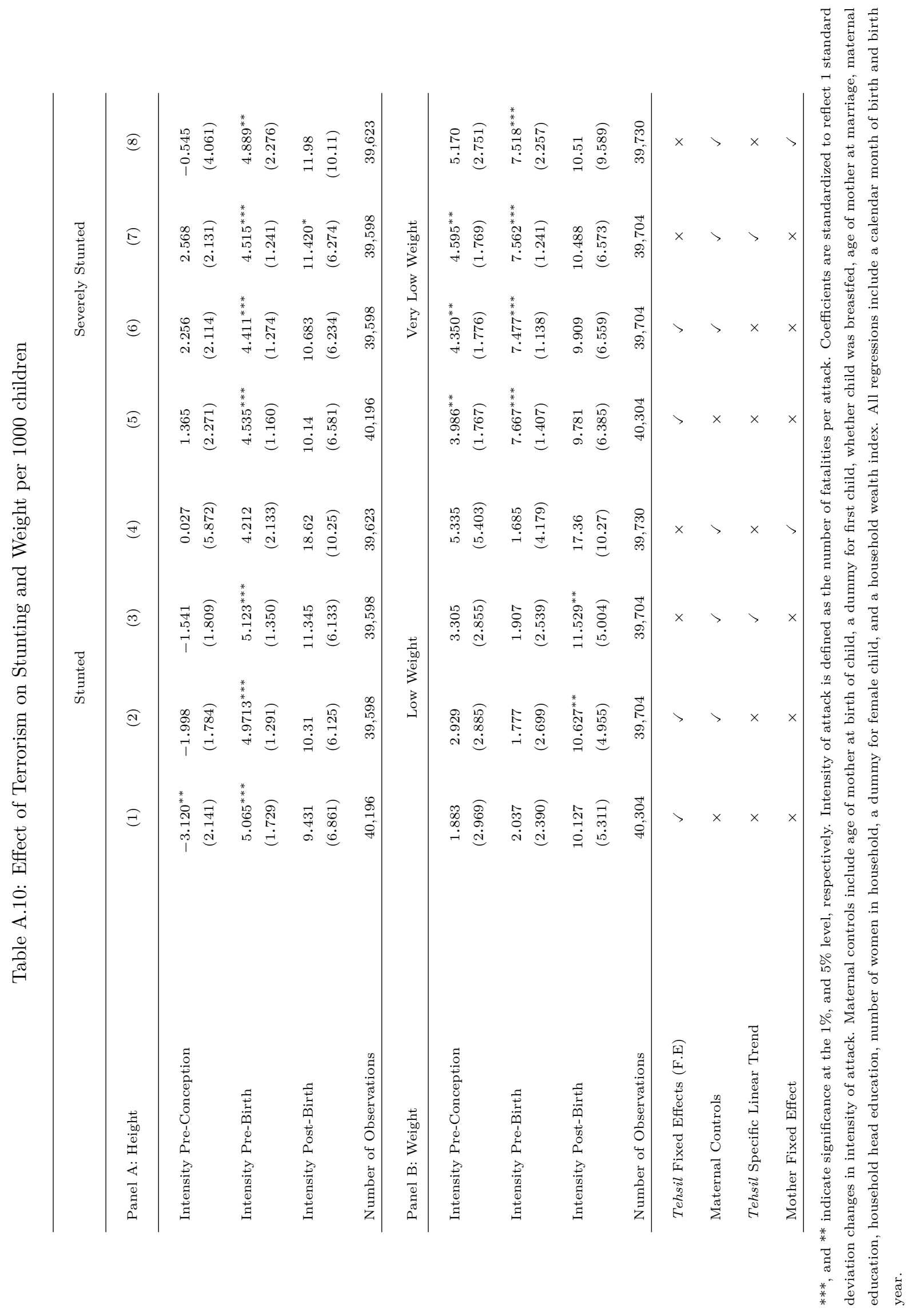


Table A.11: Spillovers from Neighboring Tehsils - Stunting and Weight - Mother Fixed Effects

\begin{tabular}{|c|c|c|c|c|c|c|}
\hline \multirow[b]{2}{*}{ Panel A: Height } & \multicolumn{3}{|c|}{ Stunted } & \multicolumn{3}{|c|}{ Severely Stunted } \\
\hline & (1) & $(2)$ & (3) & $(4)$ & $(5)$ & (6) \\
\hline Intensity Pre-Birth & 4.212 & - & 4.239 & $4.891^{* *}$ & - & $4.794^{* *}$ \\
\hline Own Tehsil & $(2.142)$ & & $(2.147)$ & $(2.249)$ & & $(2.272)$ \\
\hline Intensity Post-Birth & $18.595^{* *}$ & - & $18.55^{* *}$ & 12.57 & - & 12.61 \\
\hline Own Tehsil & $(8.344)$ & & $(8.297)$ & $(9.757)$ & & $(10.02)$ \\
\hline Intensity Pre-Birth & - & 2.284 & 1.827 & - & -2.301 & -2.606 \\
\hline Other Tehsils & & $(5.504)$ & $(5.483)$ & & $(4.974)$ & $(5.020)$ \\
\hline Intensity Post-Birth & - & -0.884 & -1.463 & - & 6.464 & 5.963 \\
\hline Other Tehsils & & $(10.53)$ & $(11.03)$ & & $(9.858)$ & $(10.20)$ \\
\hline Number of Observations & 39,623 & 39,623 & 39,623 & 39,623 & 39,623 & 39,623 \\
\hline Panel B: Weight & \multicolumn{3}{|c|}{ Low Weight } & \multicolumn{3}{|c|}{ Very Low Weight } \\
\hline Intensity Pre-Birth & 1.656 & - & 1.415 & $7.489^{* *}$ & - & $7.341^{* *}$ \\
\hline Own Tehsil & $(3.796)$ & & $(3.405)$ & $(2.844)$ & & $(2.945)$ \\
\hline Intensity Post-Birth & $11.65^{* *}$ & - & $11.32^{* *}$ & 4.973 & - & 4.928 \\
\hline Own Tehsil & $(4.668)$ & & $(5.185)$ & $(5.979)$ & & $(6.542)$ \\
\hline Intensity Pre-Birth & - & 5.926 & 5.650 & - & -0.661 & -0.763 \\
\hline Other Tehsils & & $(6.094)$ & $(6.018)$ & & $(4.728)$ & $(4.706)$ \\
\hline Intensity Post-Birth & - & $17.50^{*}$ & 17.24 & - & 10.42 & 9.936 \\
\hline Other Tehsils & & $(9.480)$ & $(9.338)$ & & $(7.189)$ & $(7.515)$ \\
\hline Mother Fixed Effects (F.E) & $\checkmark$ & $\checkmark$ & $\checkmark$ & $\checkmark$ & $\checkmark$ & $\checkmark$ \\
\hline Birth Year and Month F.E & $\checkmark$ & $\checkmark$ & $\checkmark$ & $\checkmark$ & $\checkmark$ & $\checkmark$ \\
\hline Time Varying Maternal Controls & $\checkmark$ & $\checkmark$ & $\checkmark$ & $\checkmark$ & $\checkmark$ & $\checkmark$ \\
\hline Number of Observations & 39,730 & 39,730 & 39,730 & 39,730 & 39,730 & 39,730 \\
\hline
\end{tabular}

***, and $* *$ indicate significance at the $1 \%$, and $5 \%$ level, respectively. Intensity of attack is defined as the number of fatalities per attack. Coefficients are standardized to reflect 1 standard deviation changes in intensity of attack. Maternal controls include age of mother at birth of child, a dummy for first child, whether child was breastfed, age of mother at marriage, maternal education, household head education, number of women in household, a dummy for female child, and a household wealth index. All regressions include a calendar month of birth and birth year. 


\section{Bibliography}

Abadian, S. (1996). Women's autonomy and its impact on fertility. World development, 24(12):17931809.

Abbas, Z. (2004). Pakistan's undeclared war. BBC News. [Online; accessed 19-November-2017].

Acharya, S. and Luitel, B. C. (2006). The functioning and effectiveness of scholarship and incentive schemes in Nepal. UNESCO, Kathmandu Office.

Adukia, A. (2017). Sanitation and education. American Economic Journal: Applied Economics, $9(2): 23-59$.

Aizer, A., Stroud, L., and Buka, S. (2016). Maternal stress and child outcomes: Evidence from siblings. Journal of Human Resources, 51(3):523-555.

Akbulut-Yuksel, M. (2017). War during childhood: The long run effects of warfare on health. Journal of Health Economics, 53:117-130.

Akresh, R., Bhalotra, S., Leone, M., and Osili, U. (2012a). War and stature: growing up during the nigerian civil war. The American Economic Review, 102(3):273-277.

Akresh, R., Bhalotra, S., Leone, M., and Osili, U. O. (2017). First and second generation impacts of the biafran war. Technical report, National Bureau of Economic Research.

Akresh, R., Lucchetti, L., and Thirumurthy, H. (2012b). Wars and child health: Evidence from the eritrean-ethiopian conflict. Journal of development economics, 99(2):330-340.

Alam, A., Baez, J. E., and Del Carpio, X. V. (2011). Does cash for school influence young women's behavior in the longer term? Evidence from Pakistan. The World Bank.

Alfano, M., Arulampalam, W., and Flores, A. (2014). Widening the gender gap: The unintended consequences of conditional cash transfers in India. Unpublished Draft. 
Allison, P. D. (2001). Missing data, volume 136. Sage publications.

Almond, D. (2006). Is the 1918 influenza pandemic over? long term effects of in utero influenza exposure in the post 1940 u.s. population. Journal of Political Economy, 114(4):672-712.

Almond, D. and Currie, J. (2011). Killing me softly: The fetal origins hypothesis. The Journal of Economic Perspectives, 25(3):153-172.

Angrist, J. (2002). How do sex ratios affect marriage and labor markets? Evidence from America's second generation. The Quarterly Journal of Economics, 117(3):997-1038.

Anukriti, S. (2018). Financial incentives and the fertility-sex ratio trade-off. American Economic Journal: Applied Economics, 10(2):27-57.

Anukriti, S., Kwon, S., and Prakash, N. (2018). Household savings and marriage payments: Evidence from dowry in India.

Anukriti, S and Bhalotra, Sonia R and Tam, Eddy Hiu Fung (2016). On the quantity and quality of girls: New evidence on abortion, fertility, and parental investments.

Backer, D., Bhavnani, R., and Huth, P. (2016). Peace and Conflict 2016. Routledge.

Balk, D. (1994). Individual and community aspects of women's status and fertility in rural Bangladesh. Population Studies, 48(1):21-45.

Bank, T. W. (2018). India states briefs.

Barker, D. (1990). The fetal and infant origins of adult disease. BMJ: British Medical Journal, $301(6761): 1111$.

Berrebi, C. and Ostwald, J. (2014). Terrorism and fertility: evidence for a causal influence of terrorism on fertility. Oxford Economic Papers, 67(1):63-82.

Bhalotra, S., Brulé, R., and Roy, S. (2018). Women's inheritance rights reform and the preference for sons in India. Journal of Development Economics.

Bhalotra, S. and Cochrane, T. (2010). Where have all the young girls gone? Identification of sex selection in India. IZA Discussion Paper No. 5381.

Bhalotra, S. and Van Soest, A. (2008). Birth-spacing, fertility and neonatal mortality in India: Dynamics, frailty, and fecundity. Journal of Econometrics, 143(2):274-290. 
Bozzoli, C., Deaton, A., and Quintana-Domeque, C. (2009). The weight of the crisis: evidence from newborns in argentina. Demography, 46(4):647-669.

Bozzoli, C. and Quintana-Domeque, C. (2014). The weight of the crisis: evidence from newborns in argentina. Review of Economics and Statistics, 96(3):550-562.

Brown, R. (2018). The mexican drug war and early-life health: the impact of violence crime on birth outcomes. Demography, 55:319-340.

Burgers, L. (2000). Background and rationale for school sanitation and hygiene education. New York.

Calderone, M. (2017). Are there different spillover effects from cash transfers to men and women? UNU-WIDER Working Paper.

Caldwell, B. K. (2006). Family size control by infanticide in the great agrarian societies of Asia. In Demographic Transition Theory, pages 131-153. Springer.

Camacho, A. (2008). Stress and birth weight: evidence from terrorist attacks. American Economic Review, 98(2):511-515.

Case, A. and Paxson, C. (2008). Stature and status: Height, ability, and labor market outcomes. Journal of political Economy, 116(3):499-532.

Castilla, C. (2018). Political role models and child marriage in India. Review of Development Economics, 22(4):1409-1431.

Chatterjee, S. (2008). Concept and evolution of dowry. International Journal of Humanities and Social Science Invention, 7(01):85-90.

Chaudhury, N. and Parajuli, D. (2007). Conditional cash transfers and female schooling: The impact of the female school stipend program on public school enrollments in Punjab, Pakistan. The World Bank.

Crawford, N. (2017). Update on the human costs of war for afganistan and pakistan, 2001 to mid2016. Cost of War project working paper, Watson Institute for International and Public Affairs, Brown University.

Csapo, M. (2017). The spillover effects of excludable cash transfers: Costs of the miracle cure for development woes. Unpublished Draft. 
Currie, J. and Vogl, T. (2013). Early-life health and adult circumstance in developing countries. Annu. Rev. Econ., 5(1):1-36.

Dabalen, A. and Paul, S. (2014). Effect of conflict on dietary diversity: Evidence from côte d'ivoire. World Development, 58:143-158.

Dang, G., Kulkarni, V. S., and Gaiha, R. (2018). Why dowry deaths have risen in India? ASARC Working Paper 2018/03.

Das Gupta, M., Zhenghua, J., Bohua, L., Zhenming, X., Chung, W., and Hwa-Ok, B. (2003). Why is son preference so persistent in East and South Asia? A cross-country study of China, India and the Republic of Korea. The Journal of Development Studies, 40(2):153-187.

Deininger, K., Goyal, A., and Nagarajan, H. (2013). Women's inheritance rights and intergenerational transmission of resources in India. Journal of Human Resources, 48(1):114-141.

Department of Drinking Water Ministry (2005). School sanitation and hygiene education in India investment in building children's future. Water, Sanitation, Hygiene Education for Schools Rountable Meeting.

Desai, S. (2017). Economic effects of terrorism: Local and city considerations, priorities for research and policy. Geography Compass, 11(11):e12332-n/a. e12332 GECO-1035.R1.

Duflo, E. (2012). Women empowerment and economic development. Journal of Economic literature, $50(4): 1051-79$.

Duque, V. (2017). Early-life conditions and child development: Evidence from a violent conflict. SSM - Population Health, 3:121 - 131.

Ebenstein, A. (2010). The missing girls of China and the unintended consequences of the one child policy. Journal of Human Resources, 45(1):87-115.

Eckstein, Z. and Tsiddon, D. (2004). Macroeconomic consequences of terror: theory and the case of israel. Journal of Monetary Economics, 51(5):971 - 1002.

Edlund, Lena and Li, Hongbin and Yi, Junjian and Zhang, Junsen (2007). Sex ratios and crime: evidence from China's one-child policy. Technical report, IZA Discussion Papers.

Edlund, Lena and Li, Hongbin and Yi, Junjian and Zhang, Junsen (2013). Sex ratios and crime: Evidence from china. Review of Economics and Statistics, 95(5):1520-1534. 
Fan, V. and Anand, S. (2016). The health workforce in India. Human Resources for Health Observer Series No. 16 .

Fentiman, A., Hall, A., and Bundy, D. (1999). School enrolment patterns in rural Ghana: a comparative study of the impact of location, gender, age and health on children's access to basic schooling. Comparative education, 35(3):331-349.

Filmer, D., Hammer, J., and Pritchett, L. (2000). Weak links in the chain: A diagnosis of health policy in poor countries. The World Bank Research Observer, 15(2):199-224.

Government of Pakistan, Ministry of FinanceGovernment of Pakistan, Ministry of Finance (2016). Pakistan economic survey 2015-16.

GTDNational Consortium for the Study of Terrorism and Responses to Terrorism (START) (2018). Global terrorism database [data file]. Accessed: December 30, 2018.

WHO World Health Organization (2018). Global health expenditure database. Geneva: World Health Organization.

WHOUnited Nations Children's Fund, World Health Organization, The World Bank (2018). Unicefwho-world bank joint child malnutrition estimates. UNICEF, New York; WHO, Geneva; The World Bank, Washington, DC.

Fiszbein, A. and Schady, N. R. (2009). Conditional cash transfers: Reducing present and future poverty. The World Bank.

Fletcher, J. (2018). Crushing hope: Short term responses to tragedy vary by hopefulness. Social Science $\&$ Medicine, 201:59-62.

Garg, S. and Anand, T. (2015). Menstruation related myths in India: strategies for combating it. Journal of Family Medicine and Primary Care, 4(2):184.

Gertler, P. (2004). Do conditional cash transfers improve child health? Evidence from PROGRESA's control randomized experiment. American economic review, 94(2):336-341.

Goodkind, D. (1996). On substituting sex preference strategies in East Asia: Does prenatal sex selection reduce postnatal discrimination? Population and Development Review, 22(1):111-126.

Grieger, J., Grzeskowiak, L., and Clifton, V. (2014). Preconception dietary patterns in human pregnancies are associated with preterm delivery. The Journal of nutrition, 144(7):1075-1080. 
Grimard, F. and Laszlo, S. (2014). Long-term effects of civil conflict on women's health outcomes in peru. World Development, 54:139-155.

Grossman, M. and Joyce, T. J. (1990). Unobservables, pregnancy resolutions, and birth weight production functions in New York City. Journal of Political Economy, 98(5, Part 1):983-1007.

Gruber, J., Levine, P., and Staiger, D. (1999). Abortion legalization and child living circumstances: Who is the "marginal child"? The Quarterly Journal of Economics, 114(1):263-291.

Guerrero, N., Molina, O., and Winkelried, D. (2018). Conditional cash transfers, spillovers, and informal health care: Evidence from Peru.

Gupta, M. D. (1987). Selective discrimination against female children in rural Punjab, India. Population and development review, 13(1):77-100.

Gupta, S. (2017). Perils of the paperwork: The impact of information and application assistance welfare program take-up in India. Unpublished Draft;. John F. Kennedy School of Government, Harvard University.

Haushofer, J. and Fehr, E. (2014). On the psychology of poverty. Science, 344(6186):862-867.

Hazarika, G. (2000). Gender differences in children's nutrition and access to health care in Pakistan. The Journal of Development Studies, 37(1):73-92.

Heckman, J., Pinto, R., and Savelyev, P. (2013). Understanding the mechanisms through which an influential early childhood program boosted adult outcomes. The American economic review, 103(6):2052-2086.

Heckman, J. J. (2006). Skill formation and the economics of investing in disadvantaged children. Science, 312(5782):1900-1902.

Heissel, J., Sharkey, P., Torrats-Espinosa, G., Grant, K., and Adam, E. (2017). Violence and vigilance: the acute effects of community violent crime on sleep and cortisol. Child development.

Henderson, J. V., Storeygard, A., and Weil, D. N. (2012). Measuring economic growth from outer space. American Economic Review, 102(2):994-1028.

Hussain, Z. (2010). The Scorpion's Tail: The Relentless Rise of Islamic Militants in Pakistan and how it Threatens America. Free Press.

Hussain, Z. (2017). The legacy of lal masjid. Dawn.com. [Online; accessed 7-January-2019]. 
Ioannidis, J., Stanley, T., and Doucouliagos, H. (2017). The power of bias in economics research. The Economic Journal, 127(605).

Jain, A., Sathar, Z., and Haque, M. (2015). The constraints of distance and poverty on institutional deliveries in pakistan: Evidence from georeference-linked data. Studies in Family Planning, $46(1): 21-39$.

Jayachandran, S. and Kuziemko, I. (2011). Why do mothers breastfeed girls less than boys? Evidence and implications for child health in India. The Quarterly journal of economics, 126(3):1485-1538.

Jayachandran, S. and Pande, R. (2015). Why are Indian children so short? National Bureau of Economic Research.

Kahn-Lang, A. and Lang, K. (2018). The promise and pitfalls of differences-in-differences: Reflections on '16 and pregnant' and other applications. Technical Report Working Paper, National Bureau of Economic Research.

Kalsi, P. (2015). Abortion legalization, sex selection, and female university enrollment in Taiwan. Economic Development and Cultural Change, 64(1):163-185.

Kalsi, P. (2017). Seeing is believing-can increasing the number of female leaders reduce sex selection in rural India? Journal of Development Economics, 126:1-18.

Kaur, R. (2013). Mapping the adverse consequences of sex selection and gender imbalance in India and China. Economic and Political Weekly, 48(35):37-44.

Khan, M., Mirza, S., and Qadeer, E. (2017). Tb control in pakistan. In Handbook of Global Tuberculosis Control, pages 15-25. Springer.

Khandker, S., Pitt, M., and Fuwa, N. (2003). Subsidy to promote girls' secondary education: the female stipend program in Bangladesh. World Bank, Washington DC.

Kim, Hyoungjong and Rhee, Dong-Eun (2019). Toilets for education: Evidence from Kenya's primary school-level data. International Journal of Educational Development, 70:102090.

King, J. (2016). A summary of pathways or mechanisms linking preconception maternal nutrition with birth outcomes. The Journal of nutrition, 146(7):1437S-1444S.

Kirk, J. and Sommer, M. (2006). Menstruation and body awareness: linking girls' health with girls' education. Royal Tropical Institute (KIT), Special on Gender and Health, pages 1-22. 
Koppensteiner, M. and Manacorda, M. (2016). Violence and birth outcomes: Evidence from homicides in brazil. Journal of Development Economics, 119:16-33.

Kremer, M., Chaudhury, N., Rogers, F. H., Muralidharan, K., and Hammer, J. (2005). Teacher absence in India: A snapshot. Journal of the European Economic Association, 3(2-3):658-667.

Kumar, A., Singh, U., Samuel, S., Kullappa, M., Raman, R., Prakash, M., Arokiam, K., Satyavada, A., and Mittal, P. (2010). A decade of the Total Sanitation Campaign. rapid assessment of processes and outcomes. volume 1 : Main report. Technical report, Water and Sanitation Program.

Kumar, S. and Sinha, N. (2018). Preventing more "missing girls": A review of policies to tackle son preference. The World Bank.

Lakshminarayanan, S. and Jayalakshmy, R. (2015). Diarrheal diseases among children in India: current scenario and future perspectives. Journal of Natural Science, Biology, and Medicine, $6(1): 24$.

Laxminarayan, R. and Ganguly, N. K. (2011). India's vaccine deficit: Why more than half of Indian children are not fully immunized, and what can and should be done. Health Affairs, 30(6):10961103.

Lee, C. (2014). In utero exposure to the korean war and its long-term effects on socioeconomic and health outcomes. Journal of health economics, 33:76-93.

Lee, Y. J. (2018). Gender, electoral competition, and sanitation in India. Comparative Politics, $50(4): 587-605$.

Leon, G. (2012). Civil conflict and human capital accumulation the long-term effects of political violence in perú. Journal of Human Resources, 47(4):991-1022.

Li, B. and Zhang, H. (2017). Does population control lead to better child quality? Evidence from China's one-child policy enforcement. Journal of Comparative Economics, 45(2):246-260.

Li, H. and Zhang, J. (2007). Do high birth rates hamper economic growth? The Review of Economics and Statistics, 89(1):110-117.

Lim, S. S., Dandona, L., Hoisington, J. A., James, S. L., Hogan, M. C., and Gakidou, E. (2010). India's Janani Suraksha Yojana, a conditional cash transfer programme to increase births in health facilities: an impact evaluation. The Lancet, 375(9730):2009-2023. 
Lindo, J. (2011). Parental job loss and infant health. Journal of Health Economics, 30(5):869 - 879.

Litman, J. (2018). Menstruation stigma must stop. period. Public Health Advocate.

Llussa, F. and Tavares, J. (2011). Which terror at which cost? on the economic consequences of terrorist attacks. Economics Letters, 110(1):52 - 55 .

Mansour, H. and Rees, D. (2012). Armed conflict and birth weight: Evidence from the al-aqsa intifada. Journal of Development Economics, 99(1):190-199.

McCleary-Sills, J., Hanmer, L., Parsons, J., and Klugman, J. (2015). Child marriage: A critical barrier to girls' schooling and gender equality in education. The Review of Faith 83 International Affairs, 13(3):69-80.

McLean, M., Bisits, A., Davies, J., Woods, R., Lowry, P., and Smith, R. (1995). A placental clock controlling the length of human pregnancy. Nature medicine, 1(5):460-463.

Ministry of Health and Family Welfare (2017). National immunization schedule (nis) for infants, children and pregnant women. Government of India.

Mora, R. and Reggio, I. (2017). Alternative diff-in-diffs estimators with several pretreatment periods. Econometric Reviews, pages 1-22.

Murhekar, M. (2017). Epidemiology of diphtheria in India, 1996-2016: Implications for prevention and control. The American Journal of Tropical Medicine and Hygiene, 97(2):313-318.

Nandi, A. and Deolalikar, A. B. (2013). Does a legal ban on sex-selective abortions improve child sex ratios? Evidence from a policy change in India. Journal of Development Economics, 103:216-228.

Onis, M., Dewey, K., Borghi, E., Onyango, A., Blössner, M., Daelmans, B., Piwoz, E., and Branca, F. (2013). The world health organization's global target for reducing childhood stunting by 2025: rationale and proposed actions. Maternal \& child nutrition, 9(S2):6-26.

Pande, R. P. and Yazbeck, A. S. (2003). What's in a country average? wealth, gender, and regional inequalities in immunization in india. Social Science \& Medicine, 57(11):2075-2088.

Parker, S. W. and Todd, P. E. (2017). Conditional cash transfers: The case of Progresa/Oportunidades. Journal of Economic Literature, 55(3):866-915.

Parker, S. W. and Vogl, T. (2018). Do conditional cash transfers improve economic outcomes in the next generation? Evidence from Mexico. National Bureau of Economic Research. 
Paxson, C. and Schady, N. R. (2002). The allocation and impact of social funds: spending on school infrastructure in Peru. The World Bank Economic Review, 16(2):297-319.

Pedersen, D. (2002). Political violence, ethnic conflict, and contemporary wars: broad implications for health and social well-being. Social science \& medicine, 55(2):175-190.

Perales, F. and Todd, A. (2018). Structural stigma and the health and wellbeing of australian lgb populations: Exploiting geographic variation in the results of the 2017 same-sex marriage plebiscite. Social Science \& Medicine.

Pitt, M. M. and Rosenzweig, M. R. (1990). Estimating the intrahousehold incidence of illness: Child health and gender-inequality in the allocation of time. International Economic Review, pages 969-989.

Pokhrel, S., Snow, R., Dong, H., Hidayat, B., Flessa, S., and Sauerborn, R. (2005). Gender role and child health care utilization in nepal. Health policy, 74(1):100-109.

Pörtner, C. C. (2015). Sex-selective abortions, fertility, and birth spacing. The World Bank.

Prabhu, K. S., Sahay, R., et al. (2009). Conditional cash transfer schemes for alleviating human poverty: Relevance for india. Discussion Paper, UNDP India.

Pruss-Ustun, Annette and World Health Organization and others (2008). Safer water, better health: costs, benefits and sustainability of interventions to protect and promote health. World Health Organization, Geneva.

Quintana-Domeque, C. and Ródenas-Serrano, P. (2017). The hidden costs of terrorism: The effects on health at birth. Journal of Health Economics.

Ramakrishnan, U., Grant, F., Goldenberg, T., Zongrone, A., and Martorell, R. (2012). Effect of women's nutrition before and during early pregnancy on maternal and infant outcomes: a systematic review. Paediatric and perinatal epidemiology, 26(s1):285-301.

Ray, R. and Datta, R. (2017). Do separate female toilets in primary and upper primary schools improve female enrollment? a case study from India. Children and Youth Services Review, 79:263273.

Roy, S. (2015). Empowering women? Inheritance rights, female education and dowry payments in India. Journal of Development Economics, 114:233-251. 
Rubin, B. and Rashid, A. (2008). From great game to grand bargain ending chaos in afghanistan and pakistan. Foreign Affairs, 87:30-44.

Sado, L., Spaho, A., and Hotchkiss, D. R. (2014). The influence of women's empowerment on maternal health care utilization: Evidence from Albania. Social Science \& Medicine, 114:169177.

Saridjan, N., Huizink, A., Koetsier, J., Jaddoe, V., Mackenbach, J., Hofman, A., Kirschbaum, C., Verhulst, F., and Tiemeier, H. (2010). Do social disadvantage and early family adversity affect the diurnal cortisol rhythm in infants? The Generation R Study. Hormones and Behavior , $57(2): 247-254$.

Sawyer, C. C. (2012). Child mortality estimation: estimating sex differences in childhood mortality since the 1970s. PLoS Medicine, 9(8):e1001287.

Schenker, J. G. (2002). Gender selection: cultural and religious perspectives. Journal of assisted reproduction and genetics, 19(9):400-410.

Schultz, T. P. (2004). School subsidies for the poor: evaluating the Mexican Progresa poverty program. Journal of development Economics, 74(1):199-250.

Sekhar, T. (2010). Special financial incentive schemes for the girl child in India: A review of select schemes. The Planning Commission, Government of India and United Nations Population Fund.

Shah, S. (2012). Political reforms in the federally administered tribal areas (fata): Will it end the militancy. Paper no. 64, Heidelberg Papers in South Asian and Comparative Politics.

Shah, S., Selwyn, B., Luby, S., Merchant, A., and Bano, R. (2003). Prevalence and correlates of stunting among children in rural pakistan. Pediatrics international, 45(1):49-53.

Sineath, S. A. (2004). Son preference and sex selection among hindus in India. http://purl.flvc.org/fsu/fd/FSU_migr_etd-1709.

Singh, P. K., Singh, L., Kumar, C., and Rai, R. K. (2013). Correlates of maternal healthcare service utilisation among adolescent women in Mali: Analysis of a nationally representative cross-sectional survey, 2006. Journal of Public Health, 21(1):15-27.

Sinha, N. and Yoong, J. (2009). Long-term financial incentives and investment in daughters: Evidence from conditional cash transfers in North India. The World Bank. 
Snel, M., Ganguly, S., and Shordt, K. (2002). School Sanitation and Hygiene Education - India. Resource Book. Delft, the Netherlands, IRC International Water and Sanitation Centre (Technical Paper Series), (39):21.

Soares, S., Guerreiro Osorio, R., Veras Soares, F., Medeiros, M., and Zepeda, E. (2009). Conditional cash transfers in Brazil, Chile and Mexico: Impacts upon inequality. Estudios económicos.

Sreenivas, M. (2008). Wives, widows, and concubines: The conjugal family ideal in colonial India. Indiana University Press.

Srinivasan, S. and Bedi, A. S. (2011). Ensuring daughter survival in Tamil Nadu, India. Oxford Development Studies, 39(3):253-283.

Sudha, S. and Rajan, S. I. (1999). Female demographic disadvantage in India 1981-1991: Sex selective abortions and female infanticide. Development and change, 30(3):585-618.

Talge, N., Neal, C., Glover, V., the Early Stress, T. R., Fetal, P. S. N., on Child, N. E., and Health, A. M. (2007). Antenatal maternal stress and long-term effects on child neurodevelopment: how and why? Journal of Child Psychology and Psychiatry, 48(3-4):245-261.

Thapa, D. K. and Niehof, A. (2013). Women's autonomy and husbands' involvement in maternal health care in Nepal. Social Science \& Medicine, 93:1-10.

The World Bank (2018). India states briefs.

United Nations (2010). The millennium development goals report. Washington: United Nations.

Vaidya, S. R. (2015). Commitment of measles elimination by 2020: Challenges in India. Indian Pediatrics, 52(2):103-106.

Vanneman, R., Desai, S. B., and Vikram, K. (2012). Son preference in India. Annual Meeting of the Population Association of America, San Francisco, CA.

Viscusi, W. K. (2009). Valuing risks of death from terrorism and natural disasters. Journal of Risk and Uncertainty, 38(3):191-213. 